\title{
Supplementary information for
}

\section{Microbiological versus chemical reductive sulfidation: an experimental and theoretical study}

Oriane Della-Negra ${ }^{\dagger}$, Brieuc Le Cacher de Bonneville ${ }^{\dagger \ddagger}$, Sébastien Chaussonnerie ${ }^{\dagger}$, Denis Le Paslier $^{* \dagger}$, Gilles Frison ${ }^{*}{ }^{* \neq}$, Pierre-Loïc Saaidi ${ }^{* \dagger}$

†Génomique Métabolique, Genoscope, Institut François Jacob, CEA, CNRS, Univ Evry, Université Paris-Saclay, 91057 Evry, France

Laboratoire de Chimie Moléculaire, Ecole Polytechnique, CNRS, IP Paris, Palaiseau, France

${ }^{\text {\#} S o r b o n n e ~ U n i v e r s i t e ́, ~ C N R S, ~ L a b o r a t o i r e ~ d e ~ C h i m i e ~ T h e ́ o r i q u e, ~ P a r i s, ~ F r a n c e ~}$ 


\section{Supplementary methods}

\section{General procedure used for the identification of the compounds detected by GC-MS}

(i) Thiol derivatives and other products were identified by matching the recorded mass spectra with those of authentic samples, mass spectra of library (NIST), and/or data available in literature.

(ii) If the target thiols were not found, alcohol derivatives were searched according to the same procedure and in-source mass fragmentation patterns were compared taking into account the $\mathrm{m} / \mathrm{z}+16$ shift.

(iii) In the case of thiols we checked that we observed a loss of $\mathrm{m} / \mathrm{z} 32$ or 33 from the molecular ion profile corresponding to the loss of $\mathrm{S}^{\bullet}$ or $\mathrm{HS}^{\bullet}$.

(iv) The Sulfur element is mainly present under two forms: the major stable isotope ${ }^{32} \mathrm{~S}(95.0 \%)$ and the minor stable isotope $34 \mathrm{~S}$ (4.3\%). So, for each suspected thiol, we checked that the molecular ion profile contained the radical ions $[\mathrm{M}]^{+\bullet}$ and $[\mathrm{M}+2]^{+\bullet}$ with a ratio similar to the isotopic ${ }^{34} \mathrm{~S} /{ }^{32} \mathrm{~S}$ ratio.

\section{Assessment of the computational levels Comparison between DFT and $\operatorname{CCSD}(T)$ results}

It is well known that self-interaction error in DFT functionals can lead to inaccurate results for radicals ${ }^{1-}$ ${ }^{5}$. To check whether this problem can occur to describe single-electronic reduction of thiones, test calculations of $\Delta \mathrm{E}_{3}$ have been performed for five small thione at the CCSD(T) level and compared with the results obtained with PBEO and M06 functionals. Figure S1 shows that results obtained by both functionals nicely correlate with $\operatorname{CCSD}(T)$ values, even if absolute DFT values overestimate the electron affinity of thione computed at the $a b$ initio level.
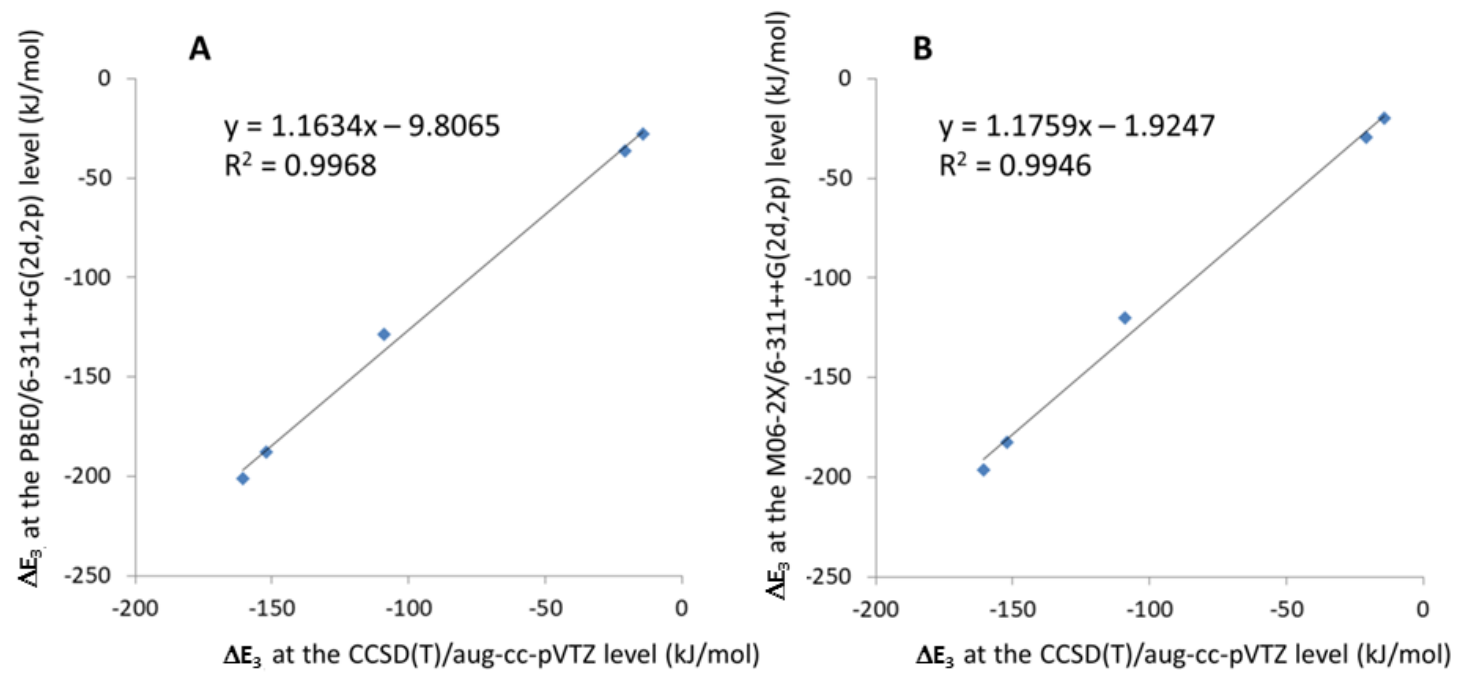

Figure S1. Comparison of $\Delta \mathrm{E}_{3}$ computed at various levels of calculation for 1a-3a, 14a and 16a. Optimized geometry at the PBE0/6-31+G(d,p) level for PBEO and CCSD $(T)$ final energies and the M06-2X/6-31+G(d,p) level for M06-2X final energies.

Comparison between PBEO and M06- $2 X$ results 
Reactions displayed in Schemes 1-3 (main text) were studied for all molecules 1a-29a with the PBE0 and M06-2X functionals. Figure S2 shows the comparison between PBEO and M06-2X results obtained for gas phase reaction energies (A1-A3) and Gibbs free energy of reaction including solvation effect (B1-B3). The influence of solvation during geometry optimization for the PBEO functional is shown in Figure S2 (C1-C3). In all cases, a good to excellent correlation is obtained. The hydrogenation reaction (A2-C2) shows the lowest discrepancies. PBEO and M06-2X give similar gas phase reaction energy for the monoelectronic reduction process ( $A 1)$, but small deviations appear after inclusion of solvation effect (B1-C1). In particular, inclusion of solvation during the geometry optimization process induces noticeable deviation for $\mathbf{1 a}$ and $\mathbf{2} \mathbf{a}$. Detailed examination of the optimized geometries for these systems allows explaining this result. The attachment of the added electron does not take place on the $\mathrm{C}=\mathrm{S}$ double bond, but mainly on a $\mathrm{C}-\mathrm{Cl}$ bond, inducing its breaking. This behavior is accentuated by solvation, which stabilizes the formed $\mathrm{Cl}^{-}$anion. The most significant difference between PBEO and M06-2X is observed for the hydration reaction. In this case, however, solvation does not induce any deviation.

\section{Comparison with experimental data}

As indicated above, PBEO and M06-2X give similar results, showing that, a priori, the results of both functionals can be used interchangeably. Comparison with experimental data nevertheless indicates the slightly better accuracy of the M06-2X results. Indeed, for 7 of the 29 studied molecules (1a, 3a5a, 15a, 16a and 20a), the carbonyl hydration constant $K_{\text {hyd }}$ has been experimentally measured. Molecule 3a being the reference used to compute the relative hydration constants, a comparison of $\log K_{\text {hyd }}$ with the experimental data can be made for the 6 other calculated results. The best correlation $\left(R^{2}=0.9975\right)$ is obtained for M06-2X results (Figure S3). 

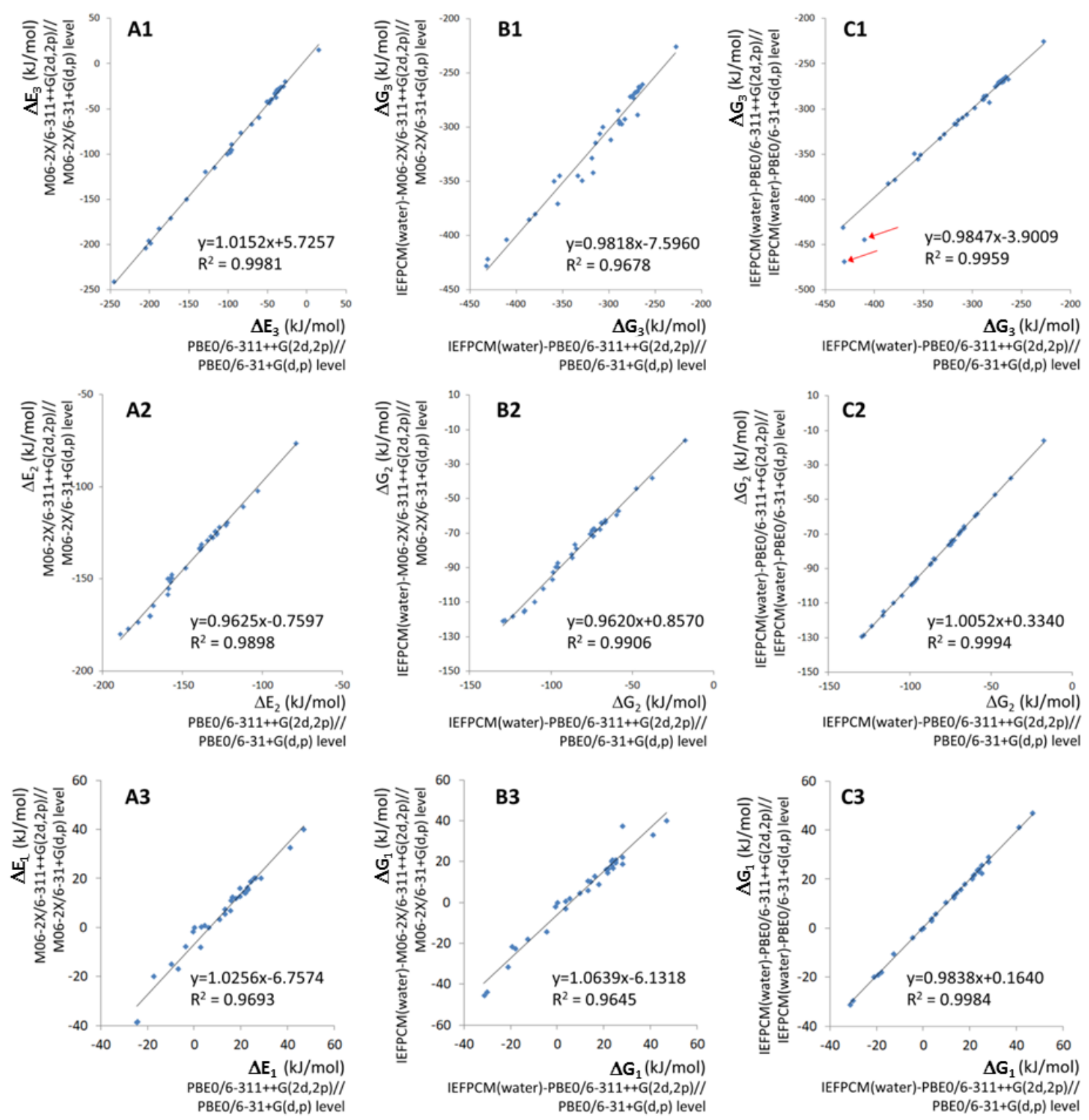

Figure S2. Comparison of energy of reactions displayed in schemes 1-3 (main text) computed at various DFT levels. All points are included in the trendlines, except the two outliers (molecules $\mathbf{1 a}$ and $\mathbf{2 a}$ ) indicated by a red arrow in $\mathrm{C} 1$.
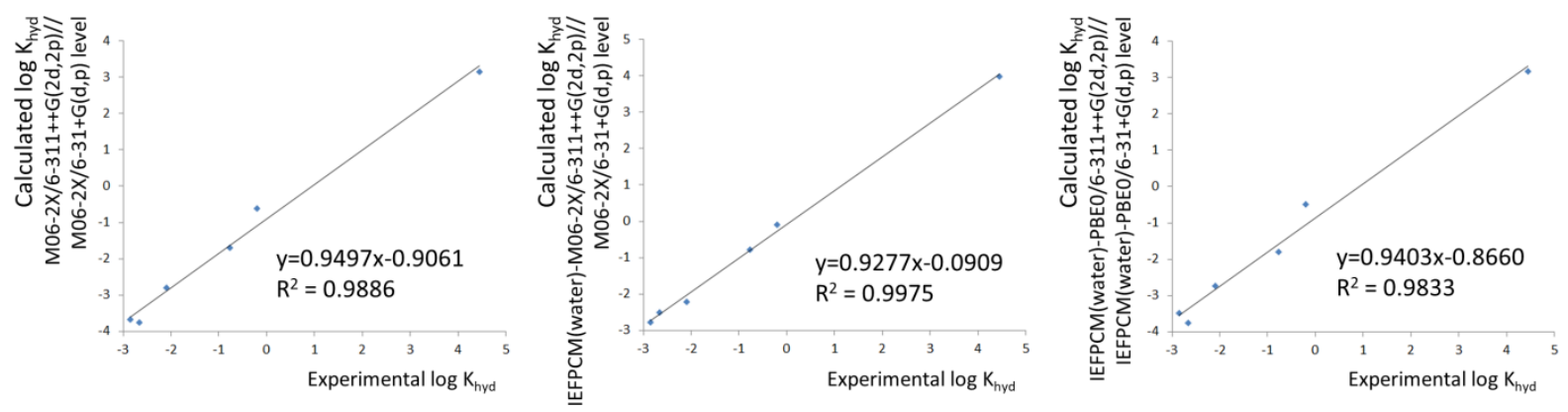

Figure S3. Comparison of calculated and experimental log Khyd. 


\section{Supplementary tables}

Table S1. Energies of the exchange reaction displayed in scheme 1 (main text) in $\mathrm{kJ} / \mathrm{mol}$.

\begin{tabular}{|c|c|c|c|c|c|}
\hline molecule & $\Delta \mathrm{E}_{1}$ & $\Delta \mathrm{G}_{1}$ & $\Delta \mathrm{E}_{1}$ & $\Delta \mathrm{G}_{1}$ & $\Delta \mathrm{G}_{1}$ \\
\hline $\begin{array}{l}\text { Optimized } \\
\text { geometry }\end{array}$ & \multicolumn{2}{|c|}{ PBE0/6-31+G(d,p) } & \multicolumn{2}{|c|}{$\mathrm{M} 06-2 \mathrm{X} / 6-31+\mathrm{G}(\mathrm{d}, \mathrm{p})$} & $\begin{array}{c}\text { IEFPCM(water)- } \\
\text { PBE0/ } \\
6-31+G(d, p)\end{array}$ \\
\hline Final energy & $\begin{array}{c}\text { PBE0/6- } \\
311++G(2 d, 2 p)\end{array}$ & $\begin{array}{c}\text { IEFPCM(water)- } \\
\text { PBE0/ } \\
6-311++G(2 d, 2 p)\end{array}$ & $\begin{array}{c}M 06-2 X / 6- \\
311++G(2 d, 2 p)\end{array}$ & $\begin{array}{l}\text { IEFPCM(water)- } \\
\text { M06-2X/ } \\
6-311++G(2 d, 2 p)\end{array}$ & $\begin{array}{c}\text { IEFPCM(water)- } \\
\text { PBE0/ } \\
6-311++G(2 d, 2 p)\end{array}$ \\
\hline $29 a$ & 59.631 & 61.140 & 49.499 & 53.031 & 60.959 \\
\hline $28 a$ & 46.854 & 47.010 & 39.983 & 39.958 & 47.065 \\
\hline $22 a$ & 28.690 & 28.174 & 20.237 & 37.464 & 29.002 \\
\hline $27 a$ & 41.219 & 41.229 & 32.606 & 32.952 & 41.100 \\
\hline $17 a$ & 23.000 & 28.061 & 15.309 & 22.058 & 27.063 \\
\hline $19 a$ & 19.759 & 23.782 & 12.666 & 20.879 & 23.110 \\
\hline $9 a$ & 24.183 & 25.119 & 18.877 & 20.813 & 22.269 \\
\hline $18 a$ & 22.758 & 23.305 & 16.299 & 20.159 & 23.760 \\
\hline $21 a$ & 26.352 & 25.126 & 20.161 & 19.585 & 25.635 \\
\hline $26 a$ & 21.863 & 28.164 & 14.079 & 18.791 & 27.034 \\
\hline $25 a$ & 21.431 & 23.892 & 14.299 & 16.662 & 24.051 \\
\hline $8 a$ & 24.219 & 21.826 & 18.853 & 16.582 & 21.789 \\
\hline $16 a$ & 15.710 & 21.061 & 10.943 & 15.972 & 20.024 \\
\hline $20 a$ & 17.883 & 21.601 & 11.810 & 14.430 & 21.604 \\
\hline $5 a$ & 19.713 & 16.137 & 16.035 & 12.839 & 15.733 \\
\hline $7 a$ & 16.322 & 13.133 & 12.389 & 10.391 & 12.347 \\
\hline $6 a$ & 13.364 & 14.457 & 5.387 & 10.009 & 14.275 \\
\hline $24 a$ & 15.659 & 17.806 & 6.866 & 8.905 & 18.027 \\
\hline $23 a$ & 10.913 & 13.316 & 3.268 & 5.854 & 13.114 \\
\hline $15 a$ & 13.252 & 9.802 & 7.405 & 4.598 & 10.438 \\
\hline $11 a$ & 4.529 & 5.351 & 0.662 & 1.876 & 5.733 \\
\hline $4 a$ & 3.052 & 3.682 & 0.145 & 0.708 & 2.974 \\
\hline $3 a$ & 0.000 & 0.000 & 0.000 & 0.000 & 0.000 \\
\hline $10 a$ & -0.381 & -0.703 & -1.758 & -2.165 & -0.546 \\
\hline $14 a$ & -3.491 & -12.571 & -7.717 & -18.152 & -10.577 \\
\hline $2 a$ & -17.267 & -19.300 & -19.830 & -21.589 & -19.109 \\
\hline $1 a$ & -9.629 & -17.836 & -14.950 & -22.523 & -17.918 \\
\hline $13 a$ & -24.376 & -30.026 & -38.500 & -43.722 & -29.562 \\
\hline $12 a$ & -24.582 & -31.378 & -38.631 & -45.653 & -31.157 \\
\hline
\end{tabular}


Table S2. Energies of reaction displayed in scheme 2 (main text) in kJ/mol.

\begin{tabular}{|c|c|c|c|c|c|}
\hline molecule & $\Delta \mathrm{E}_{2}$ & $\Delta G_{2}$ & $\Delta \mathrm{E}_{2}$ & $\Delta \mathrm{G}_{2}$ & $\Delta \mathrm{G}_{2}$ \\
\hline $\begin{array}{l}\text { Optimized } \\
\text { geometry }\end{array}$ & \multicolumn{2}{|c|}{$\mathrm{PBE} / 6-31+\mathrm{G}(\mathrm{d}, \mathrm{p})$} & \multicolumn{2}{|c|}{$M 06-2 X / 6-31+G(d, p)$} & $\begin{array}{c}\text { IEFPCM(water)- } \\
\text { PBEO/ } \\
6-31+G(d, p)\end{array}$ \\
\hline Final energy & $\begin{array}{c}\text { PBE0/6- } \\
311++G(2 d, 2 p)\end{array}$ & $\begin{array}{c}\text { IEFPCM(water)- } \\
\text { PBE0/ } \\
6-311++G(2 d, 2 p)\end{array}$ & $\begin{array}{c}M 06-2 X / 6- \\
311++G(2 d, 2 p)\end{array}$ & $\begin{array}{c}\text { IEFPCM(water)- } \\
\text { M06-2X/ } \\
6-311++G(2 d, 2 p)\end{array}$ & $\begin{array}{l}\text { IEFPCM(water)- } \\
\text { PBEO/ } \\
6-311++G(2 d, 2 p)\end{array}$ \\
\hline $1 a$ & -183.86 & -129.36 & -176.94 & -120.80 & -129.48 \\
\hline $2 a$ & -189.11 & -128.18 & -179.95 & -120.46 & -128.64 \\
\hline $12 a$ & -170.52 & -116.56 & -170.16 & -115.72 & -117.00 \\
\hline $13 a$ & -170.32 & -116.07 & -169.79 & -114.97 & -114.99 \\
\hline $10 a$ & -159.18 & -99.04 & -149.98 & -96.86 & -99.18 \\
\hline $6 a$ & -158.98 & -98.72 & -155.27 & -92.75 & -99.15 \\
\hline 11a & -156.75 & -95.90 & -149.59 & -89.81 & -95.31 \\
\hline $4 a$ & -157.84 & -97.01 & -149.77 & -89.65 & -97.63 \\
\hline $3 a$ & -156.72 & -95.68 & -147.57 & -87.39 & -96.11 \\
\hline $15 a$ & -157.71 & -87.12 & -151.76 & -82.42 & -87.83 \\
\hline $5 a$ & -138.44 & -84.32 & -132.73 & -78.78 & -84.58 \\
\hline $9 a$ & -138.31 & -85.07 & -133.13 & -76.65 & -84.12 \\
\hline $20 a$ & -138.33 & -74.27 & -133.13 & -71.75 & -74.08 \\
\hline $7 a$ & -128.63 & -75.90 & -125.73 & -70.50 & -76.35 \\
\hline $17 a$ & -138.00 & -74.76 & -131.31 & -68.46 & -76.20 \\
\hline $16 a$ & -139.36 & -72.55 & -133.25 & -68.31 & -73.61 \\
\hline $8 a$ & -128.49 & -69.84 & -125.13 & -67.86 & -70.19 \\
\hline $19 a$ & -139.10 & -74.08 & -134.03 & -67.69 & -75.16 \\
\hline $18 a$ & -134.41 & -73.36 & -128.92 & -67.65 & -73.91 \\
\hline $23 a$ & -132.12 & -68.56 & -127.09 & -64.57 & -68.16 \\
\hline $21 a$ & -129.55 & -68.91 & -123.93 & -64.19 & -68.84 \\
\hline $14 a$ & -129.34 & -66.43 & -124.42 & -63.50 & -66.54 \\
\hline $25 a$ & -129.34 & -66.43 & -124.42 & -63.50 & -66.54 \\
\hline $26 a$ & -126.76 & -66.33 & -122.00 & -62.56 & -65.48 \\
\hline $22 a$ & -122.74 & -59.54 & -120.68 & -59.34 & -59.47 \\
\hline $24 a$ & -121.87 & -58.48 & -119.37 & -57.32 & -58.42 \\
\hline $27 a$ & -111.91 & -47.50 & -110.65 & -44.05 & -47.39 \\
\hline $28 a$ & -102.99 & -37.87 & -102.14 & -38.20 & -37.82 \\
\hline $29 a$ & -78.82 & -17.40 & -76.25 & -16.28 & -15.80 \\
\hline
\end{tabular}


Table S3. Energies of reaction displayed in scheme 3 (main text) in kJ/mol.

\begin{tabular}{|c|c|c|c|c|c|}
\hline molecule & $\Delta \mathrm{E}_{3}$ & $\Delta G_{3}$ & $\Delta \mathrm{E}_{3}$ & $\Delta G_{3}$ & $\Delta G_{3}$ \\
\hline $\begin{array}{l}\text { Optimized } \\
\text { geometry }\end{array}$ & \multicolumn{2}{|c|}{$\mathrm{PBE} 0 / 6-31+\mathrm{G}(\mathrm{d}, \mathrm{p})$} & \multicolumn{2}{|c|}{ M06-2X/6-31+G(d,p) } & $\begin{array}{c}\text { IEFPCM(water)- } \\
\text { PBE0/ } \\
\text { 6-31+G(d,p) }\end{array}$ \\
\hline Final energy & $\begin{array}{c}\text { PBE0/6- } \\
311++G(2 d, 2 p)\end{array}$ & $\begin{array}{c}\text { IEFPCM(water)- } \\
\text { PBE0/ } \\
6-311++G(2 d, 2 p)\end{array}$ & $\begin{array}{c}\text { M06-2X/6- } \\
311++G(2 d, 2 p)\end{array}$ & $\begin{array}{c}\text { IEFPCM(water)- } \\
\text { M06-2X/ } \\
6-311++G(2 d, 2 p)\end{array}$ & $\begin{array}{c}\text { IEFPCM(water)- } \\
\text { PBE0/ } \\
\text { 6-311++G(2d,2p) }\end{array}$ \\
\hline $1 a$ & -200.86 & -430.83 & -196.03 & -422.06 & -468.74 \\
\hline $2 a$ & -187.94 & -410.28 & -182.49 & -403.94 & -444.42 \\
\hline $12 a$ & -204.55 & -386.12 & -204.09 & -385.18 & -382.68 \\
\hline $13 a$ & -198.73 & -379.29 & -198.51 & -380.03 & -378.39 \\
\hline $7 a$ & -152.75 & -355.29 & -150.08 & -370.68 & -355.41 \\
\hline $8 a$ & -101.05 & -328.57 & -100.16 & -349.40 & -327.92 \\
\hline $14 a$ & -128.71 & -353.00 & -119.74 & -344.74 & -351.04 \\
\hline $5 a$ & -117.24 & -333.43 & -114.74 & -344.61 & -332.85 \\
\hline $9 a$ & -95.67 & -317.97 & -89.35 & -328.56 & -316.70 \\
\hline $28 a$ & -70.33 & -297.52 & -67.30 & -311.94 & -299.09 \\
\hline $27 a$ & -97.44 & -309.95 & -96.30 & -306.06 & -309.58 \\
\hline $15 a$ & -84.28 & -306.16 & -76.81 & -300.04 & -306.56 \\
\hline $11 a$ & -47.26 & -286.16 & -43.54 & -296.94 & -285.15 \\
\hline $10 a$ & -44.49 & -288.74 & -39.82 & -296.35 & -286.44 \\
\hline $4 a$ & -46.02 & -288.50 & -39.94 & -294.51 & -289.23 \\
\hline $6 a$ & -60.46 & -282.90 & -59.61 & -292.66 & -293.11 \\
\hline $18 a$ & -50.61 & -268.83 & -42.18 & -288.70 & -269.90 \\
\hline $3 a$ & -36.09 & -289.66 & -29.45 & -284.63 & -289.17 \\
\hline $20 a$ & -38.14 & -276.48 & -29.72 & -272.02 & -275.61 \\
\hline $21 a$ & -32.81 & -274.11 & -26.23 & -270.85 & -272.56 \\
\hline $26 a$ & -35.75 & -271.66 & -29.48 & -268.08 & -269.32 \\
\hline $22 a$ & -37.29 & -270.77 & -31.10 & -268.03 & -270.32 \\
\hline $24 a$ & -40.38 & -269.55 & -33.19 & -267.37 & -268.34 \\
\hline $23 a$ & -33.71 & -268.98 & -26.41 & -266.52 & -267.49 \\
\hline $19 a$ & -40.00 & -266.71 & -31.76 & -264.07 & -266.32 \\
\hline $25 a$ & -29.51 & -266.32 & -25.34 & -263.54 & -264.29 \\
\hline $16 a$ & -27.54 & -267.26 & -19.74 & -262.83 & -266.89 \\
\hline $17 a$ & -35.67 & -263.77 & -28.28 & -260.58 & -267.10 \\
\hline 29a & 15.10 & -227.72 & 15.00 & -225.70 & -225.42 \\
\hline
\end{tabular}


Table S4. Bond lengths, orbital energies and spin densities corresponding to thioketones.

\begin{tabular}{|c|c|c|c|c|c|c|c|c|c|}
\hline Molecule & $\begin{array}{l}\text { Bond } \\
\text { length } \\
C=S(\AA ̊ \\
\text { M06- } \\
2 X)\end{array}$ & $\begin{array}{l}\text { Bond } \\
\text { length } \\
\mathrm{C}=\mathrm{S} \bullet \\
(\AA, \\
\text { M06- } \\
2 \mathrm{X}) \\
\end{array}$ & $\begin{array}{l}\text { Bond } \\
\text { length } \\
\mathrm{CH}-\mathrm{SH} \\
(\AA, \\
\mathrm{A} \text {, } \\
2 \mathrm{X}) \\
\end{array}$ & $\begin{array}{l}\text { Elongation } \\
\mathrm{C}=\mathrm{S}(\AA \AA \\
\mathrm{M} 06-2 \mathrm{X})\end{array}$ & $\begin{array}{l}\text { E(LUMO- } \\
C=S)(e V \\
\text { M06-2X) }\end{array}$ & $\begin{array}{l}\text { E(SOMO- } \\
C=S)(e V \\
M 06-2 X)\end{array}$ & $\begin{array}{l}\text { Spin } \\
\text { density } \\
\text { (C, } \\
\text { M06- } \\
2 \mathrm{X} \text { ) }\end{array}$ & $\begin{array}{l}\text { Spin } \\
\text { density } \\
\text { (S, } \\
\text { M06- } \\
2 \mathrm{X} \text { ) }\end{array}$ & $\begin{array}{l}\text { Spin } \\
\text { density } \\
\text { (C=S, } \\
\text { M06- } \\
2 \mathrm{X} \text { ) }\end{array}$ \\
\hline $3 a$ & 1.616 & 1.717 & 1.831 & 0.101 & -1.2735 & 0.4327 & 0.70 & 0.29 & 0.99 \\
\hline $4 a$ & 1.616 & 1.715 & 1.828 & 0.099 & -1.2136 & 0.2177 & 0.66 & 0.31 & 0.97 \\
\hline $6 a$ & 1.619 & 1.720 & 1.836 & 0.101 & -1.2082 & 0.0272 & 0.69 & 0.29 & 0.98 \\
\hline $10 a$ & 1.616 & 1.716 & 1.826 & 0.100 & -1.2354 & 0.2721 & 0.68 & 0.29 & 0.97 \\
\hline $11 a$ & 1.618 & 1.718 & 1.832 & 0.100 & -1.1483 & 0.2068 & 0.67 & 0.30 & 0.97 \\
\hline $5 a$ & 1.624 & 1.703 & 1.835 & 0.079 & -1.9402 & -0.4789 & 0.35 & 0.33 & 0.68 \\
\hline $7 a$ & 1.631 & 1.698 & 1.829 & 0.067 & -2.1851 & -0.9578 & 0.21 & 0.30 & 0.51 \\
\hline $8 a$ & 1.626 & 1.704 & 1.842 & 0.078 & -1.8640 & -0.2558 & 0.36 & 0.34 & 0.70 \\
\hline $9 a$ & 1.636 & 1.715 & 1.843 & 0.079 & -1.6354 & -0.3374 & 0.37 & 0.29 & 0.66 \\
\hline $1 a$ & 1.600 & 1.667 & 1.811 & 0.067 & -2.3402 & -3.0014 & -0.02 & 0.40 & 0.38 \\
\hline $2 a$ & 1.603 & 1.681 & 1.817 & 0.078 & -2.1307 & -2.7157 & 0.03 & 0.46 & 0.49 \\
\hline $16 a$ & 1.625 & 1.725 & 1.837 & 0.100 & -1.0640 & 0.2939 & 0.67 & 0.26 & 0.93 \\
\hline $17 a$ & 1.627 & 1.726 & 1.839 & 0.099 & -0.9578 & 0.0299 & 0.65 & 0.26 & 0.91 \\
\hline $18 a$ & 1.628 & 1.727 & 1.841 & 0.100 & -1.1429 & -0.0871 & 0.66 & 0.26 & 0.92 \\
\hline $19 a$ & 1.626 & 1.725 & 1.838 & 0.098 & -1.0177 & 0.0082 & 0.66 & 0.26 & 0.92 \\
\hline $20 a$ & 1.610 & 1.700 & 1.818 & 0.090 & -1.0993 & 0.2640 & 0.63 & 0.28 & 0.91 \\
\hline $21 a$ & 1.621 & 1.710 & 1.824 & 0.089 & -1.0585 & 0.4327 & 0.65 & 0.26 & 0.91 \\
\hline $22 a$ & 1.622 & 1.711 & 1.822 & 0.089 & -1.0504 & 0.2830 & 0.63 & 0.27 & 0.90 \\
\hline $23 a$ & 1.626 & 1.717 & 1.829 & 0.091 & -1.0095 & 0.2640 & 0.63 & 0.27 & 0.90 \\
\hline $24 a$ & 1.627 & 1.720 & 1.842 & 0.093 & -0.9932 & 0.0898 & 0.62 & 0.28 & 0.90 \\
\hline $25 a$ & 1.620 & 1.712 & 1.834 & 0.092 & -0.9578 & 0.2122 & 0.65 & 0.27 & 0.92 \\
\hline $26 a$ & 1.628 & 1.721 & 1.841 & 0.093 & -1.0204 & 0.2476 & 0.66 & 0.27 & 0.93 \\
\hline $32 a$ & 1.617 & 1.713 & 1.827 & 0.097 & -1.0095 & -0.1333 & 0.59 & 0.32 & 0.91 \\
\hline $12 a$ & 1.595 & 1.679 & 1.817 & 0.084 & -2.5824 & -1.8313 & 0.39 & 0.47 & 0.86 \\
\hline $13 a$ & 1.596 & 1.681 & 1.810 & 0.085 & -2.5198 & -1.7905 & 0.39 & 0.47 & 0.86 \\
\hline $27 a$ & 1.629 & 1.697 & 1.823 & 0.069 & -1.6572 & -0.3537 & 0.34 & 0.28 & 0.62 \\
\hline $28 a$ & 1.630 & 1.710 & 1.850 & 0.080 & -1.4623 & -0.0454 & 0.35 & 0.25 & 0.60 \\
\hline $14 a$ & 1.615 & 1.709 & 1.829 & 0.094 & -1.9892 & -0.9225 & 0.42 & 0.44 & 0.86 \\
\hline $15 a$ & 1.617 & 1.714 & 1.830 & 0.097 & -1.3252 & -0.2857 & 0.51 & 0.35 & 0.86 \\
\hline $29 a$ & 1.627 & 1.707 & 1.829 & 0.080 & -0.3456 & 0.1959 & 0.65 & 0.22 & 0.87 \\
\hline
\end{tabular}


Table S5. Bond length, orbital energy, angle and partial charges of the set of carbonyl compounds.

\begin{tabular}{|c|c|c|c|c|c|c|}
\hline Molecule & $\begin{array}{l}\text { E(LUMO- } \\
\mathrm{C}=\mathrm{O}) \\
(\mathrm{kJ} / \mathrm{mol}, \\
\mathrm{M} 06-2 \mathrm{X})\end{array}$ & $\begin{array}{l}\text { Bond length } \\
C=0(\AA \text {, } \\
M 06-2 X)\end{array}$ & $\begin{array}{l}\text { Angle } C-C(O)-C \\
\left({ }^{\circ}, M 06-2 X\right)\end{array}$ & $\begin{array}{l}q(C) \\
(M 06- \\
2 X)\end{array}$ & $\begin{array}{l}q(0) \\
(M 06-2 X)\end{array}$ & $\begin{array}{l}\text { polarisation } \\
\mathrm{C}=\mathrm{O}(\% \mathrm{C})\end{array}$ \\
\hline $3 a$ & 0.314 & 1.207 & 115.8 & 0.41 & -0.54 & 33.86 \\
\hline $4 a$ & 0.159 & 1.207 & 115.1 & 0.43 & -0.55 & 33.58 \\
\hline $6 a$ & 0.290 & 1.209 & 115.5 & 0.43 & -0.56 & 33.12 \\
\hline $10 a$ & 0.255 & 1.207 & 115.3 & 0.43 & -0.54 & 33.80 \\
\hline $11 a$ & 0.267 & 1.207 & 114.7 & 0.43 & -0.55 & 33.31 \\
\hline $5 a$ & -1.050 & 1.210 & 115.1 & 0.41 & -0.54 & 33.56 \\
\hline $7 a$ & -1.542 & 1.214 & 115.7 & 0.38 & -0.56 & 33.30 \\
\hline $8 a$ & -0.927 & 1.210 & 113.6 & 0.36 & -0.53 & 34.19 \\
\hline $9 a$ & -0.599 & 1.215 & 117.9 & 0.38 & -0.55 & 33.66 \\
\hline $16 a$ & 0.513 & 1.212 & 116.6 & 0.58 & -0.56 & 33.33 \\
\hline $17 a$ & 0.534 & 1.213 & 116.6 & 0.60 & -0.57 & 32.81 \\
\hline $18 a$ & 0.425 & 1.213 & 116.5 & 0.59 & -0.57 & 32.88 \\
\hline $19 a$ & 0.359 & 1.212 & 116.6 & 0.59 & -0.56 & 33.02 \\
\hline $20 a$ & 0.334 & 1.200 & 92.6 & 0.60 & -0.54 & 32.97 \\
\hline $21 a$ & 0.445 & 1.208 & 108.7 & 0.60 & -0.56 & 32.81 \\
\hline $22 a$ & 0.313 & 1.208 & 109.2 & 0.61 & -0.56 & 33.87 \\
\hline $23 a$ & 0.168 & 1.213 & 115.4 & 0.59 & -0.56 & 33.28 \\
\hline $24 a$ & 0.138 & 1.213 & 115.5 & 0.60 & -0.56 & 33.10 \\
\hline $25 a$ & 0.268 & 1.208 & 106.1 & 0.61 & -0.56 & 32.83 \\
\hline $26 a$ & 0.386 & 1.214 & 119.8 & 0.60 & -0.57 & 32.96 \\
\hline $1 a$ & -1.061 & 1.193 & 112.3 & 0.39 & -0.48 & 35.35 \\
\hline $2 a$ & -0.907 & 1.197 & 113.1 & 0.39 & -0.49 & 35.19 \\
\hline $12 a$ & -1.465 & 1.191 & 99.1 & & & \\
\hline $13 a$ & -1.425 & 1.191 & 99.1 & 0.60 & -0.45 & 35.66 \\
\hline $27 a$ & -0.782 & 1.211 & 107.5 & 0.59 & -0.56 & 32.62 \\
\hline $28 a$ & -0.435 & 1.211 & 107.4 & 0.55 & -0.56 & 32.71 \\
\hline $14 a$ & -0.488 & 1.207 & 116.4 & 0.51 & -0.53 & 34.17 \\
\hline $15 a$ & 0.231 & 1.210 & 117.8 & 0.55 & -0.56 & 33.03 \\
\hline $29 a$ & 0.254 & 1.199 & 109.2 & 0.85 & -0.59 & 30.67 \\
\hline
\end{tabular}


Table S6. Comparison between experimental and referenced GC-MS in-source fragmentation of thiols or products obtained with chemical or microbiological transformations of carbonyl compounds. WSS = Spectral data were obtained from Wiley Subscription Services, Inc. (US), AIST = Spectral Database for Organic Compounds, SDBS, NIST = Mass Spectrometry Data Center. ${ }^{*}$ deuterated product, \# alcohol derivative, $\S$ isomer.

\begin{tabular}{|c|c|c|c|}
\hline Molecule & $\begin{array}{l}\text { Experimental GC-MS in source } \\
\text { fragmentation: } \mathrm{m} / \mathrm{z} \text { (intensity) }\end{array}$ & $\begin{array}{l}\text { Referenced GC-MS in source } \\
\text { fragmentation: } \mathrm{m} / \mathrm{z} \text { (intensity) }\end{array}$ & Reference \\
\hline $1 b$ & $\begin{array}{l}\text { 164(17), 129(30), 93(64), 60(100), } \\
47(51)\end{array}$ & $\begin{array}{l}\text { 148(4), 113(55), 82(38), 77(100), } \\
60(12), 49(82) \#\end{array}$ & WSS \\
\hline $2 b$ & $130(98), 98(88), 82(100)$ & 114(99), 85(98), 79(100), 61(99)\# & WSS \\
\hline $3 b$ & $63(100), 48(48)^{*}$ & $62(100), 48(76), 28(21)$ & WSS \\
\hline $4 b$ & $90(100), 75(8), 56(70)$ & 90(100), 75(10), 56(94) & WSS \\
\hline $5 b$ & 124(31), 91(100), 65(15) & 124(32), 91(100), 65(10) & WSS \\
\hline $6 b$ & $\begin{array}{l}\text { 136(32), 121(31), 107(32), 93(50), } \\
\text { 79(100) }\end{array}$ & $\begin{array}{l}\text { 136(39), 121(31), 107(44), 93(48), } \\
\text { 79(100) }\end{array}$ & WSS \\
\hline $6 c$ & $\begin{array}{l}\text { 170(94), 155(44), 136(42), 123(67), } \\
\text { 113(38), 95(100), 81(79), 67(60), } \\
55(40)\end{array}$ & $\begin{array}{l}\text { 170(20), 155(7), 136(93), 121(100), } \\
\text { 107(96), 93(93), 79(91), 67(36), } \\
55(33) \S\end{array}$ & $\begin{array}{l}\text { Schoenauer \& } \\
\text { Schieberle, } 2016^{6}\end{array}$ \\
\hline $7 b$ & 150(20), 115(100), 91(16) & 150(14), 115(100), 91(68) & WSS \\
\hline $8 b$ & $114(32), 81(100), 53(64)$ & 114(12), 81(100), 53(32) & WSS \\
\hline $9 b$ & $\begin{array}{l}\text { 134(29), 119(100), 103(5), 91(36), } \\
77(5), 65(4)\end{array}$ & $\begin{array}{l}\text { 134(35), 119(100), 103(4), 91(19), } \\
77(5), 65(4)\end{array}$ & WSS \\
\hline $9 c$ & $\begin{array}{l}\text { 168(9), 153(7), 134(33), 121(96), } \\
\text { 107(35), 91(100), 85(18), 77(51), } \\
65(20)\end{array}$ & $\begin{array}{l}\text { 168(7), 153(3), 134(76), 125(53), } \\
\text { 119(89), 107(47), 91(100), 85(23), } \\
77(47), 65(33) \S\end{array}$ & $\begin{array}{l}\text { Schoenauer \& } \\
\text { Schieberle, } 2016^{6}\end{array}$ \\
\hline $10 \mathrm{~b}$ & $118(40), 84(10), 69(34), 56(100)$ & 118(23), 84(11), 69(22), 56(100) & WSS \\
\hline $11 b$ & $116(34), 82(24), 67(100)$ & 100(1), 82(16), 68(100), 57(12)\# & WSS \\
\hline $14 b$ & $\begin{array}{l}\text { 113(60), 93(88), 80(94), 64(50), } \\
60(100), 51(24)^{*}\end{array}$ & $96(1), 77(5), 63(100), 43(78) \#$ & WSS \\
\hline $15 b$ & $\begin{array}{l}95(62), 85(78), 83(100), 62(60), 60(26), \\
47(36) *\end{array}$ & 78(35), 59(100), 47(99)\# & WSS \\
\hline $16 \mathrm{~b}$ & $77(63), 62(24), 43(100)^{*}$ & 76(64), 61(35), 43(100), 27(38) & WSS \\
\hline $17 b$ & $\begin{array}{l}\text { 119(60), 90(18), 86(50), 76(38), 70(18), } \\
56(100), 47(38)^{*}\end{array}$ & $\begin{array}{l}\text { 118(68), 89(26), 85(55), 75(53), 69(23), } \\
55(100), 47(72)\end{array}$ & WSS \\
\hline $18 \mathrm{~b}$ & $\begin{array}{l}\text { 112(87), 111(100), 97(62), 77(32), } \\
59(40), 51(25)\end{array}$ & $\begin{array}{l}\text { 112(79), 111(100), 97(57), 77(12), } \\
59(22), 45(18)\end{array}$ & WSS \\
\hline $19 b$ & $\begin{array}{l}\text { 145(34), 130(100), 102(19), 96(43), } \\
87(13), 69(25), 59(38)^{*}\end{array}$ & $\begin{array}{l}\text { 128(20), 110(28), 95(100), 69(40), } \\
55(20) \#\end{array}$ & WSS \\
\hline $20 b$ & $88(48), 60(100)$ & $88(60), 60(100)$ & WSS \\
\hline $21 b$ & $\begin{array}{l}\text { 102(36), 69(100), 67(60), 60(18), } \\
41(50)\end{array}$ & $\begin{array}{l}\text { 102(45), 69(100), 67(31), 60(28), } \\
41(83)\end{array}$ & WSS \\
\hline $22 b$ & $\begin{array}{l}\text { 116(93), 83(100), 67(53), 59(55), } \\
55(76)\end{array}$ & $\begin{array}{l}\text { 116(27), 83(100), 67(47), 59(24), } \\
55(73) \S\end{array}$ & NIST \\
\hline $23 b$ & 116(65), 82(62), 67(90), 55(100) & $\begin{array}{l}\text { 116(43), 82(64), 67(66), 55(100), } \\
41(79)\end{array}$ & WSS \\
\hline $24 b$ & $\begin{array}{l}\text { 130(38), 97(87), 81(75), 67(45), } \\
55(100)\end{array}$ & $\begin{array}{l}\text { 130(20), 97(51), 81(33), 67(16), } \\
55(100)\end{array}$ & NIST \\
\hline $25 b$ & 128(45), 95(100), 79(95), 67(82) & $128(20), 95(100), 67,39$ & $\begin{array}{l}\text { Fabbri et al., } \\
1993^{7}\end{array}$ \\
\hline $26 b$ & $\begin{array}{l}\text { 131(25), 97(52), 82(63), 67(42), } \\
55(100)^{*}\end{array}$ & $\begin{array}{l}\text { 114(3), 96(22), 81(32), 68(37), } \\
57(100) \#\end{array}$ & WSS \\
\hline $27 b$ & 151(45), 122(18), 105(100), 77(41)* & $\begin{array}{l}\text { 132(59), 120(31), 105(21), 92(15), } \\
\text { 77(13)\# }\end{array}$ & AIST \\
\hline $28 \mathrm{~b}$ & $116(44), 83(31), 55(100)$ & $116(30), 83(23), 55(100)$ & Dia et al., $2010^{8}$ \\
\hline
\end{tabular}




\section{Supplementary figures}
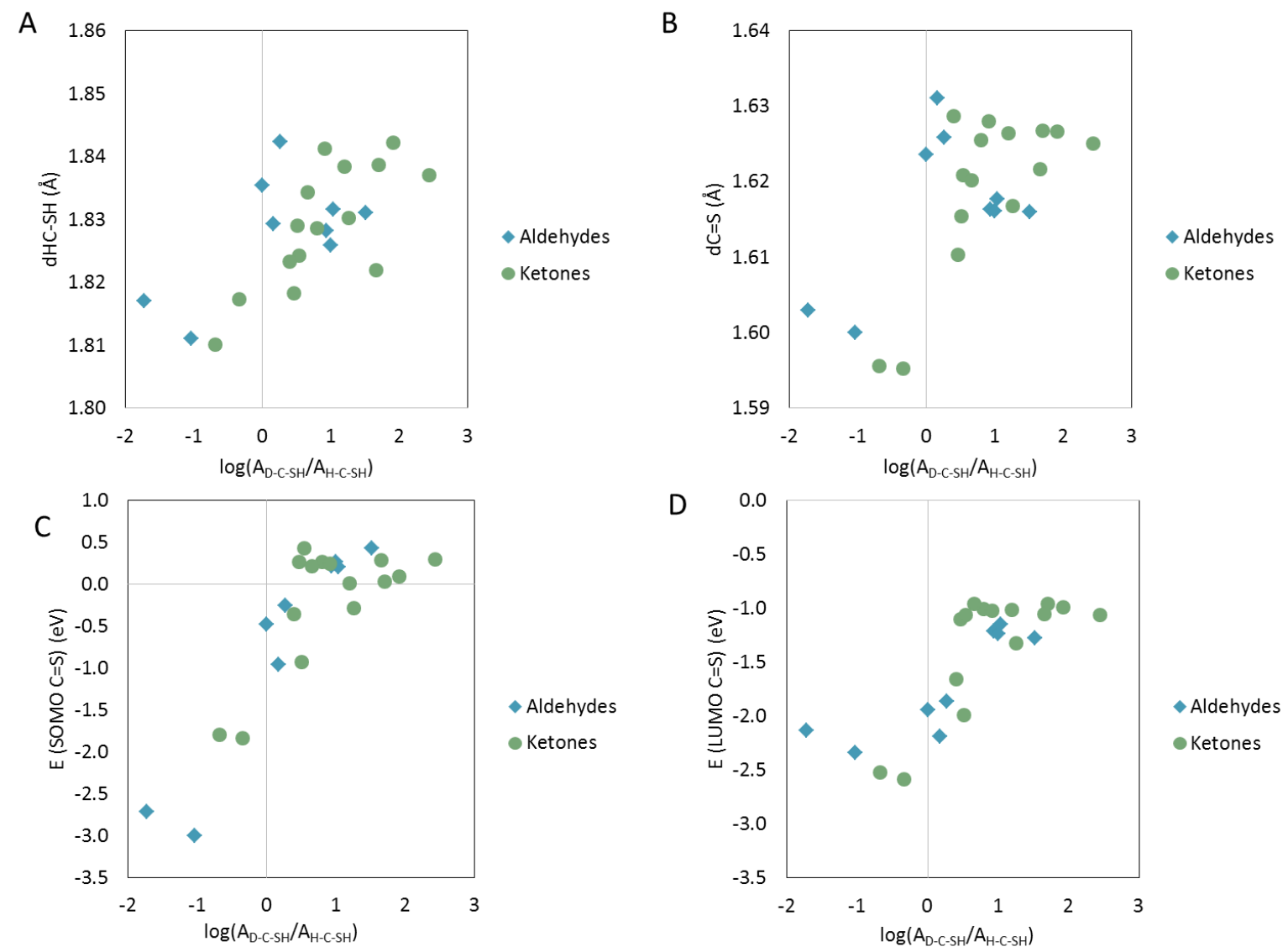

Figure S4. Correlations between the ability of carbonyl compounds to undergo direct reductive sulfidation using $\mathrm{P}_{4} \mathrm{~S}_{10}$ and selected theoretical parameters. A-Bond length of $\mathrm{HC}-\mathrm{SH}, \mathrm{B}$-bond length of $\mathrm{C}=\mathrm{S}, \mathrm{C}$-Energy of the single occupied molecular orbital of the $\mathrm{C}=\mathrm{S}$ bond (SOMO), D-Energy of the lowest unoccupied molecular orbital of the $\mathrm{C}=\mathrm{S}$ bond (LUMO). AD-C-SH$/ \mathrm{AH}_{\mathrm{H}-\mathrm{C}-\mathrm{SH}}$ represents the GC-MS peak area ratio of the deuterated thiol over the non-deuterated thiol. 


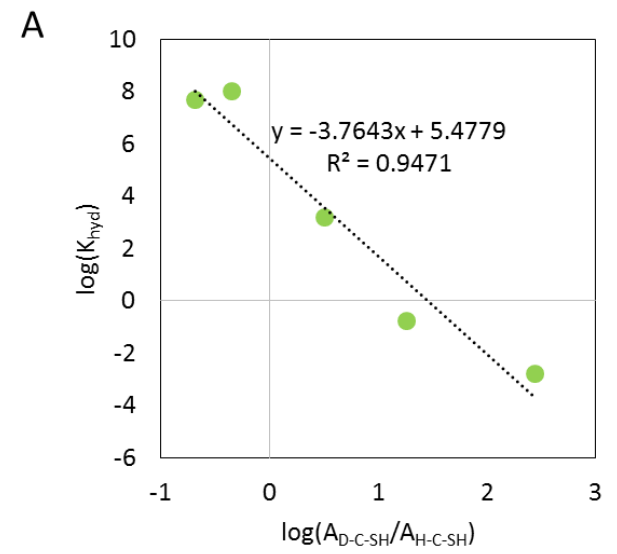

B
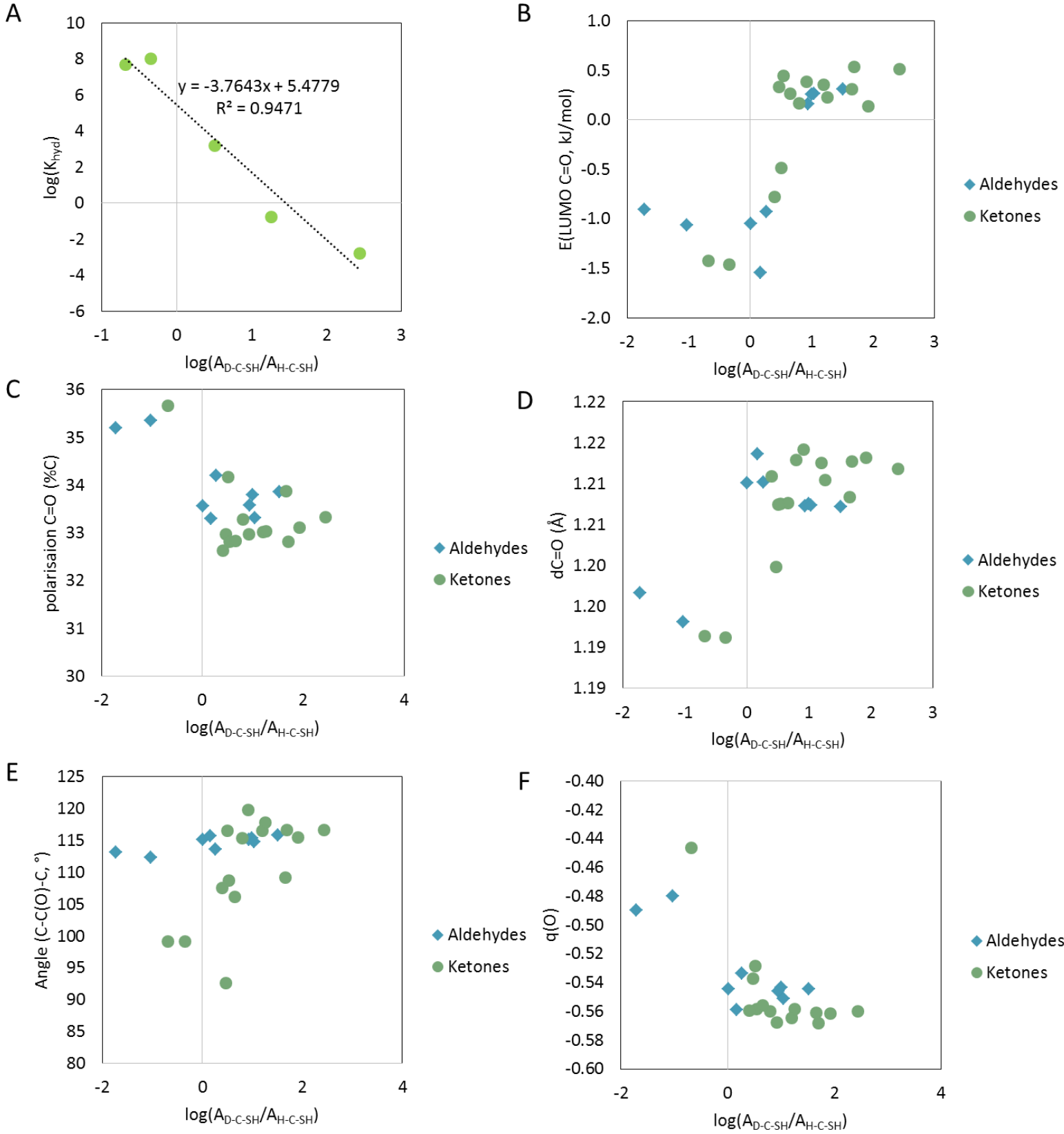

Figure S5. Correlations between the ability of carbonyl compounds to undergo direct reductive sulfidation using $\mathrm{P}_{4} \mathrm{~S}_{10}$ and selected theoretical parameters. $\mathrm{A}-\log (\mathrm{Khyd})$, the hydration constant of the $\mathrm{C}=\mathrm{O}$ bond of chlordecone, 10-monohydrochlordecone, 1-fluoropropan-2-one, 1,3-difluoropropan-2-one and acetone, B- Energy of the lowest unoccupied molecular orbital of the $\mathrm{C}=\mathrm{O}$ bond (LUMO), $\mathrm{C}$-polarisation of the $\mathrm{C}=\mathrm{O}$ bond, $\mathrm{D}$-bond length of $\mathrm{C}=\mathrm{O}$, E-Angle of the $\mathrm{C}-\mathrm{C}(\mathrm{O})-\mathrm{C}$, F-Partial charge of the oxygen atom on the $\mathrm{C}=\mathrm{O}$ bond. $\mathrm{A}_{\mathrm{D}-\mathrm{C}-\mathrm{SH}} / \mathrm{AH}_{\text {H-C-SH }}$ represents the GC-MS peak area ratio of the deuterated thiol over the non-deuterated thiol. 
A



C 37

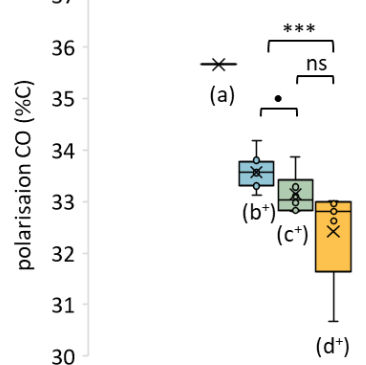

B
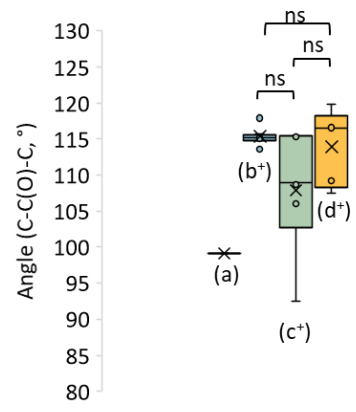

- Transformed in several weeks

$\square$ Transformed in a few days

Partially transformed after several weeks

$\square$ Not transformed

D

Transformed in several weeks

1.22

1.215

1.210

1.205

$\square$ Transformed in a few

days

¿ 1.200

I্

1.190

1.185

1.180

1.175 $\left(c^{+}\right)$

- Transformed in several weeks

$\square \quad$ Transformed in a few days

$\square$ Partially transformed after several weeks

$\square$ Not transformed

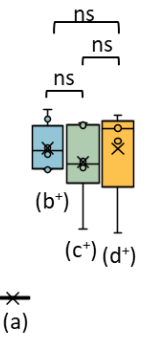

- Transformed in several weeks

$\square$ Transformed in a few days

$\square \quad$ Partially transformed after several weeks

$\square \quad$ Not transformed

Figure S6. Boxplots displaying the different transformation states of carbonyl compound after incubation with Desulfovibrio sp.86 as functions of selected calculated parameters. A- Energy of the lowest unoccupied molecular orbital of the $\mathrm{C}=\mathrm{O}$ bond (LUMO), B-Angle of the $\mathrm{C}-\mathrm{C}(\mathrm{O})-\mathrm{C}, \mathrm{C}$-polarisation of the $\mathrm{C}=\mathrm{O}$ bond, $\mathrm{D}$ - bond length of $\mathrm{C}=\mathrm{O}$. $\bullet=0.1<\mathrm{p}$-value $<0.05, *=0.05<\mathrm{p}$-value $<0.01,{ }^{*} * 0.01<\mathrm{p}$-value $<0.001, * * *=0.001<\mathrm{p}$-value $<0$, ns $=$ not significant. 


\section{Supplementary chromatograms and mass spectra}
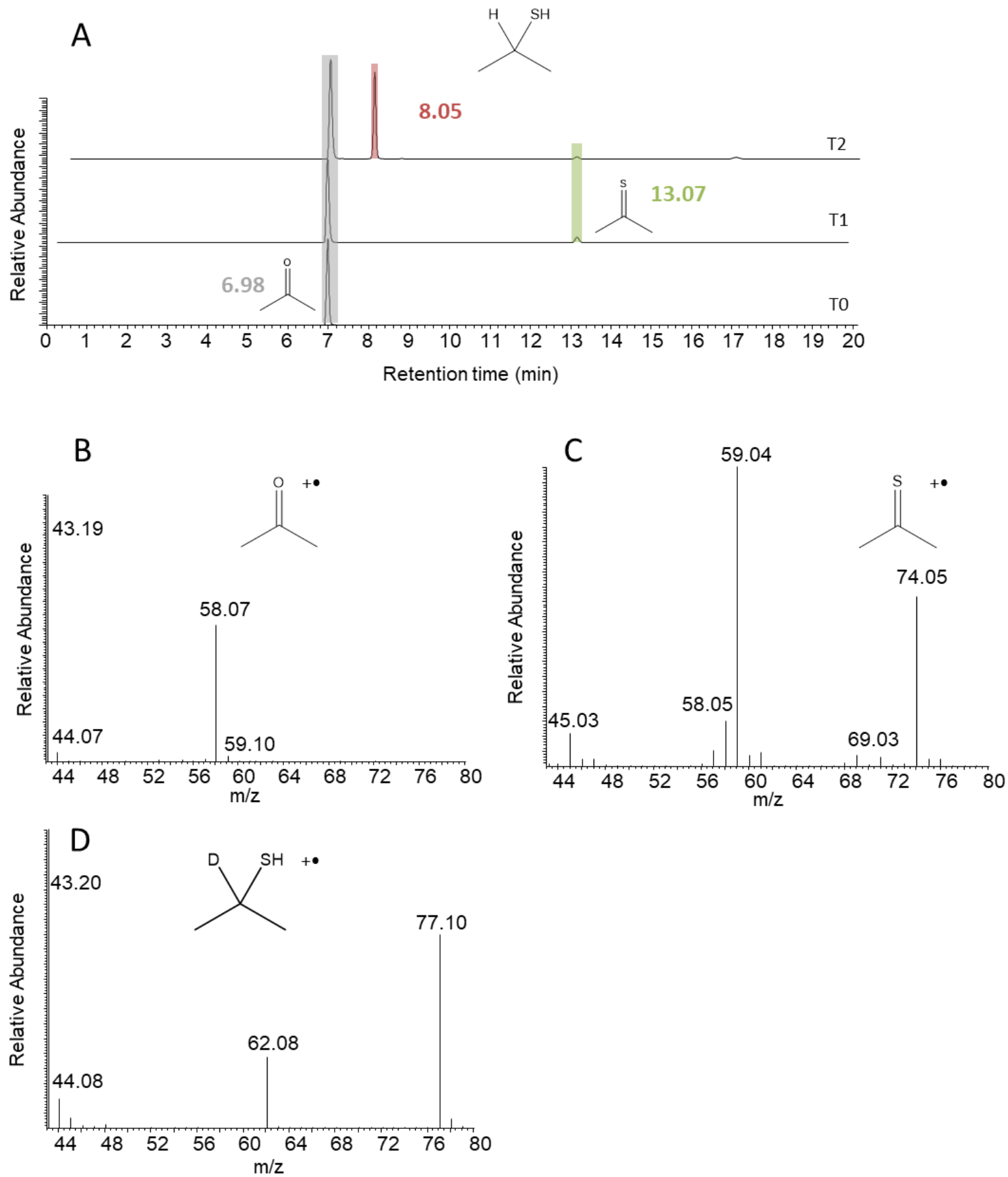

Figure S7. Chemical reductive sulfidation of acetone. A-HS-GC-MS-1 extracted ion chromatograms at the initial reaction time $(\mathrm{TO})$, after the sulfidation step using $\mathrm{P}_{4} \mathrm{~S}_{10}(\mathrm{~T} 1=12 \mathrm{~h})$, and after the reduction step using $\mathrm{NaBD}_{4}\left(\mathrm{~T}_{2}\right.$ $=12 \mathrm{~h}$ ). B-Mass spectrum of acetone. C-Mass spectrum of propane-2-thione. D-Mass spectrum of propan-2-thiol. Each mass spectrum came from GC-EI-MS analysis (positive mode). 
A

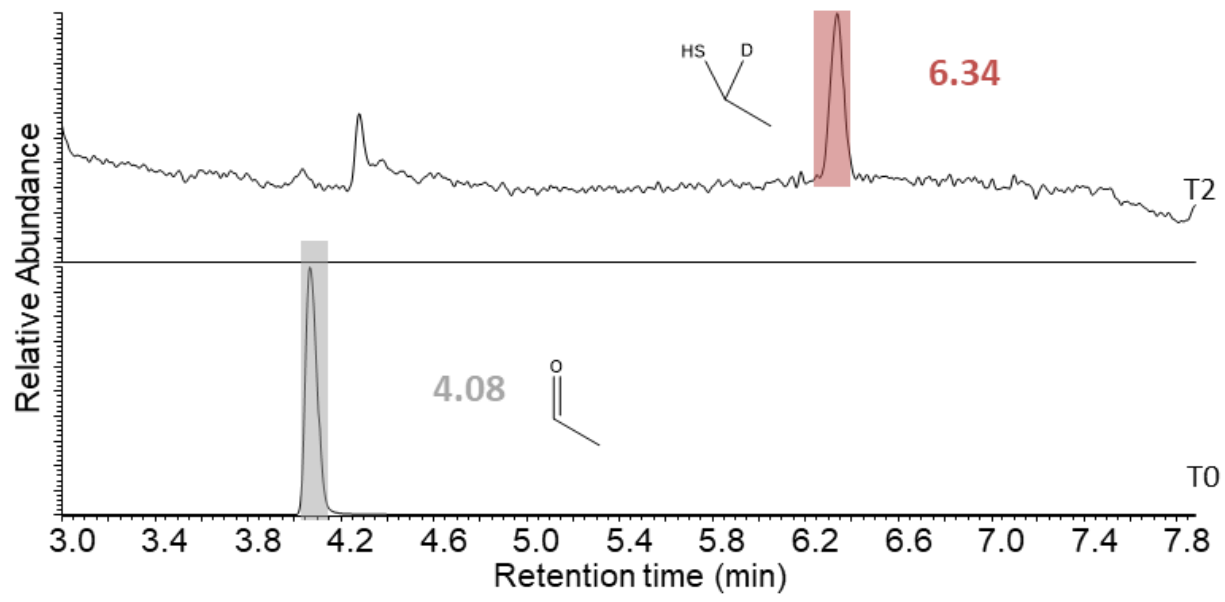

B

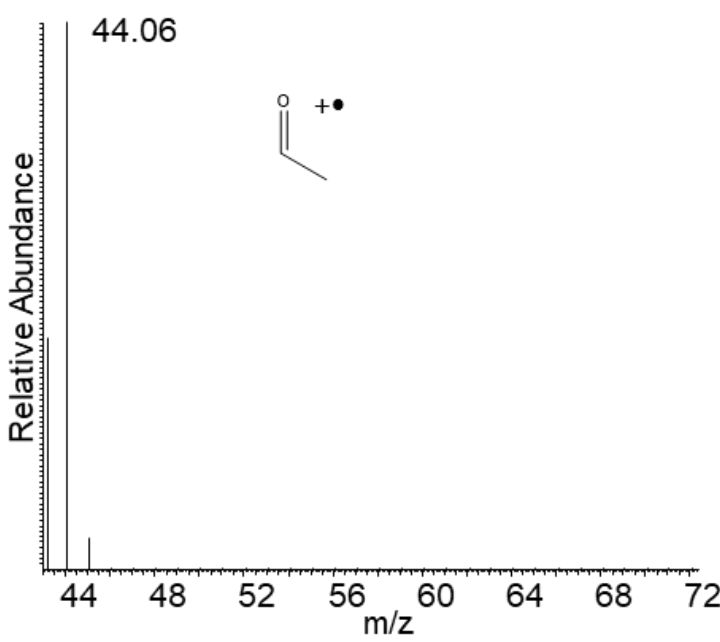

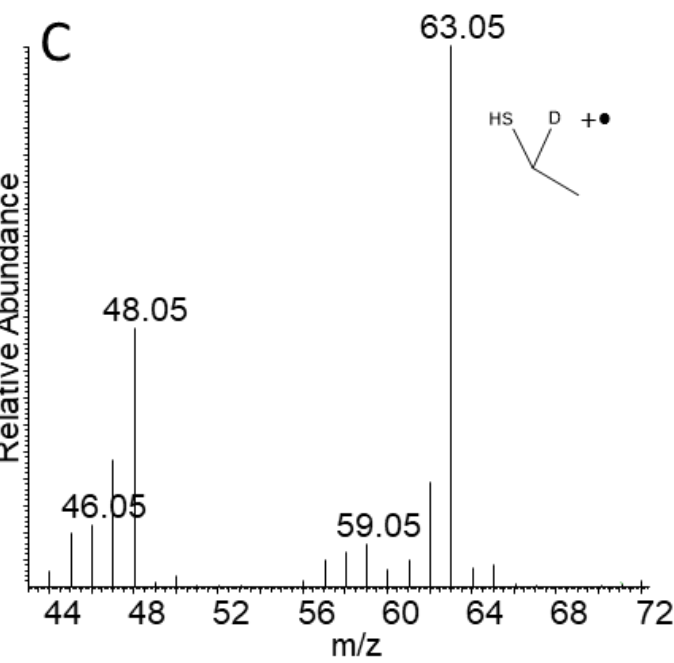

Figure S8. Chemical reductive sulfidation of ethanal. A-HS-GC-MS-1 extracted ion chromatograms at the initial reaction time (TO), after the sulfidation step using $\mathrm{P}_{4} \mathrm{~S}_{10}(\mathrm{~T} 1=12 \mathrm{~h})$, and after the reduction step using $\mathrm{NaBD}_{4}\left(\mathrm{~T}_{2}\right.$ $=12 \mathrm{~h}$ ). B-Mass spectrum of ethanethiol. C-Mass spectrum of ethanethiol. Each mass spectrum came from GC-EIMS analysis (positive mode). 

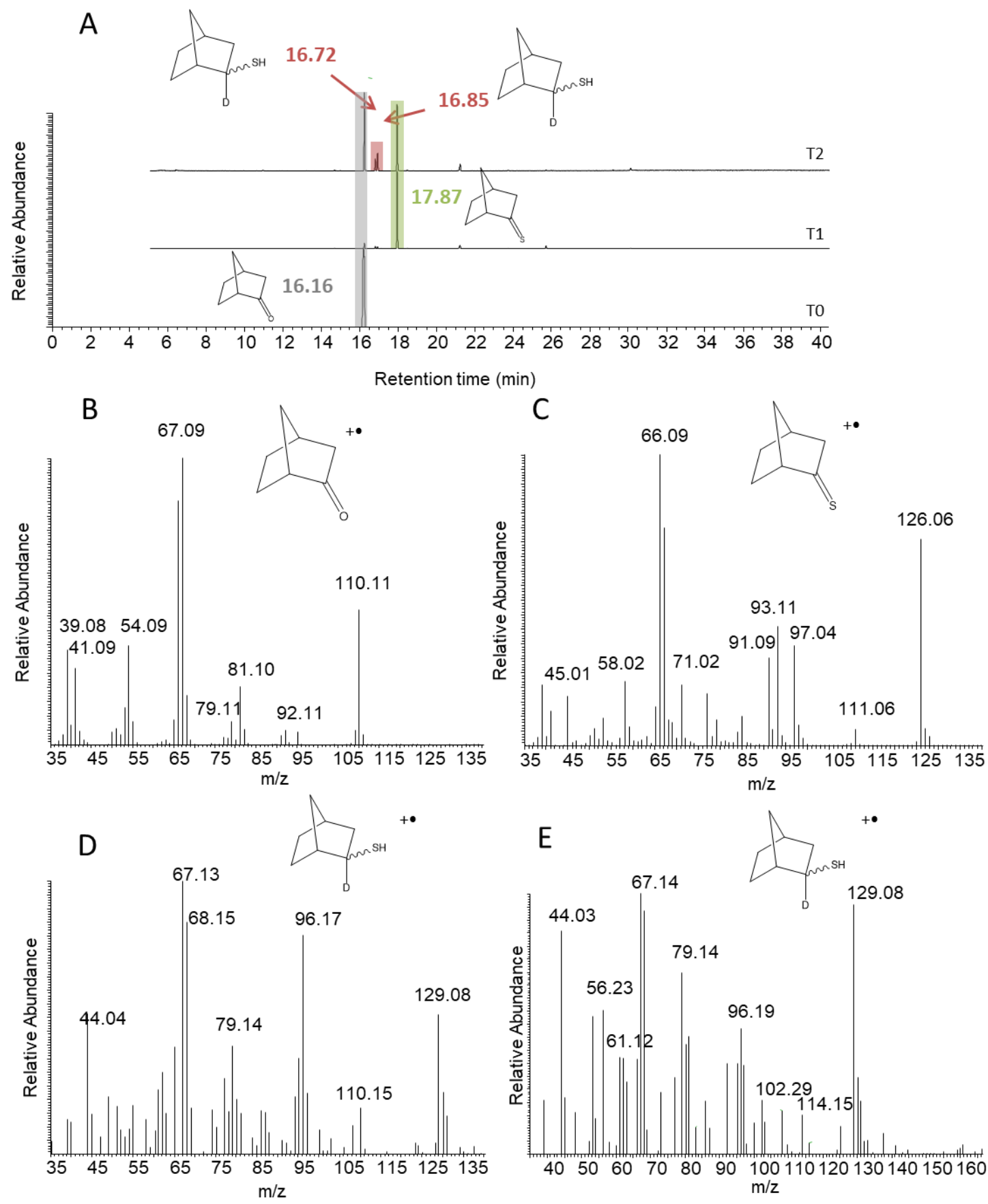

Figure S9. Chemical reductive sulfidation of norcamphor. A-HS-GC-MS-2 extracted ion chromatograms at the initial reaction time (T0), after the sulfidation step using $\mathrm{P}_{4} \mathrm{~S}_{10}(\mathrm{~T} 1=12 \mathrm{~h})$, and after the reduction step using $\mathrm{NaBD}_{4}$ ( $\mathrm{T} 2=12 \mathrm{~h}$ ). B-Mass spectrum of norcamphor. C- Mass spectrum of norcamphorthione. D-Mass spectrum of norcamphorthiol (16.72 min). E- Mass spectrum of norcamphorthiol (16.85 min). Each mass spectrum came from GC-EI-MS analysis (positive mode). 



D
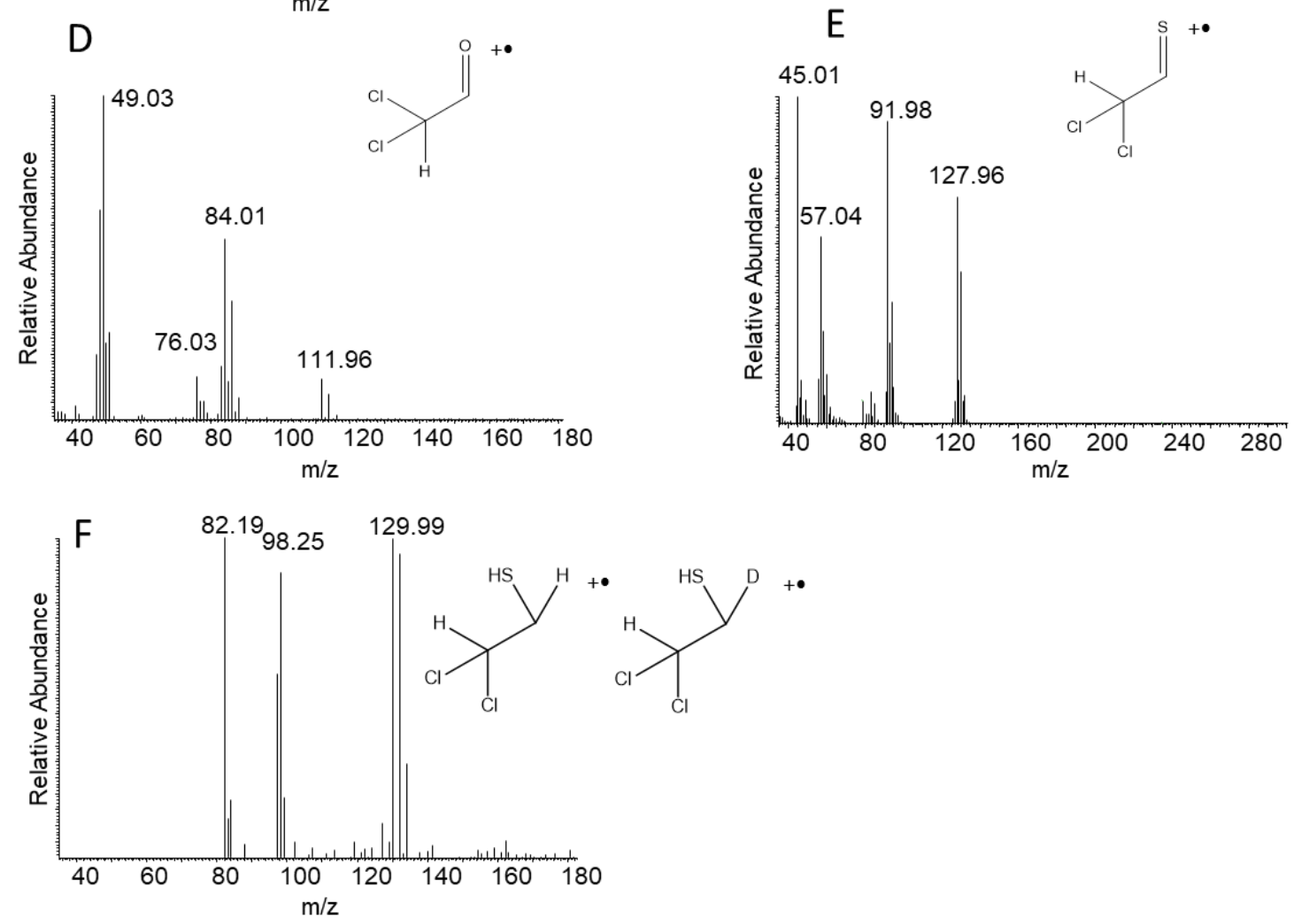

Figure S10. Chemical reductive sulfidation of chloral. A-HS-GC-MS-1 extracted ion chromatograms at the initial reaction time (TO), after the sulfidation step using $\mathrm{P}_{4} \mathrm{~S}_{10}(\mathrm{~T} 1=12 \mathrm{~h})$, and after the reduction step using $\mathrm{NaBD}_{4}\left(\mathrm{~T}_{2}\right.$ $=12 \mathrm{~h}$ ). B-Mass spectrum of chloral. C- Mass spectrum of 2,2,2-trichloroethane-1-thiol D-Mass spectrum of dichloroacetaldehyde E- Mass spectrum of 2,2-dichloroethane-1-thione. F-Mass spectrum of 2,2-dichloroethane1-thiol Each mass spectrum came from GC-EI-MS analysis (positive mode). 

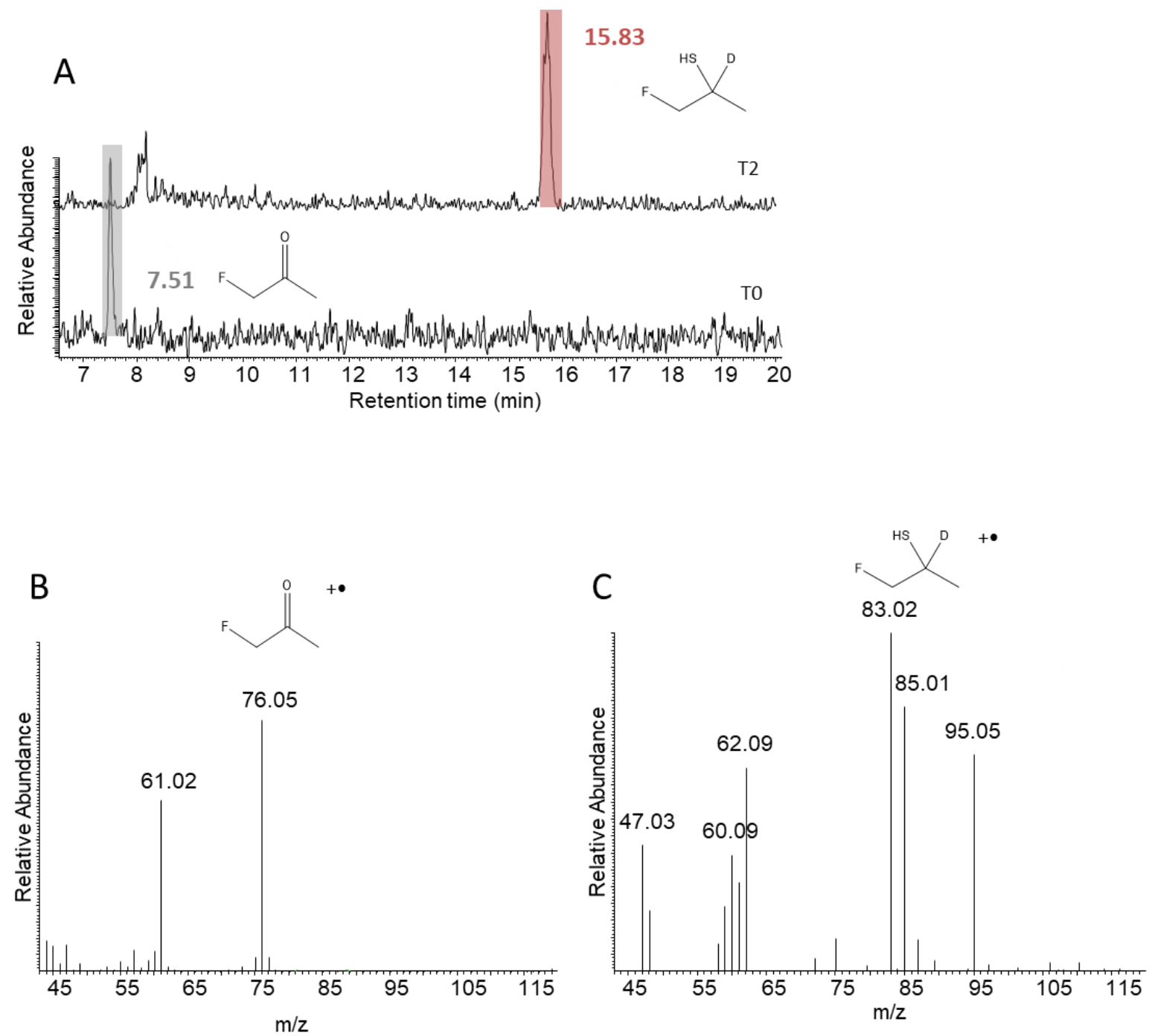

Figure S11. Chemical reductive sulfidation of 1-fluoropronane-2-one. A-HS-GC-MS-1 extracted ion chromatograms at the initial reaction time (T0), after the sulfidation step using $\mathrm{P}_{4} \mathrm{~S}_{10}(\mathrm{~T} 1=12 \mathrm{~h}$ ), and after the reduction step using $\mathrm{NaBD}_{4}(\mathrm{~T} 2=12 \mathrm{~h})$. B-Mass spectrum of 1-fluoropronane-2-one. C-Mass spectrum of 1fluoropronane-2-thiol. Each mass spectrum came from GC-EI-MS analysis (positive mode). 


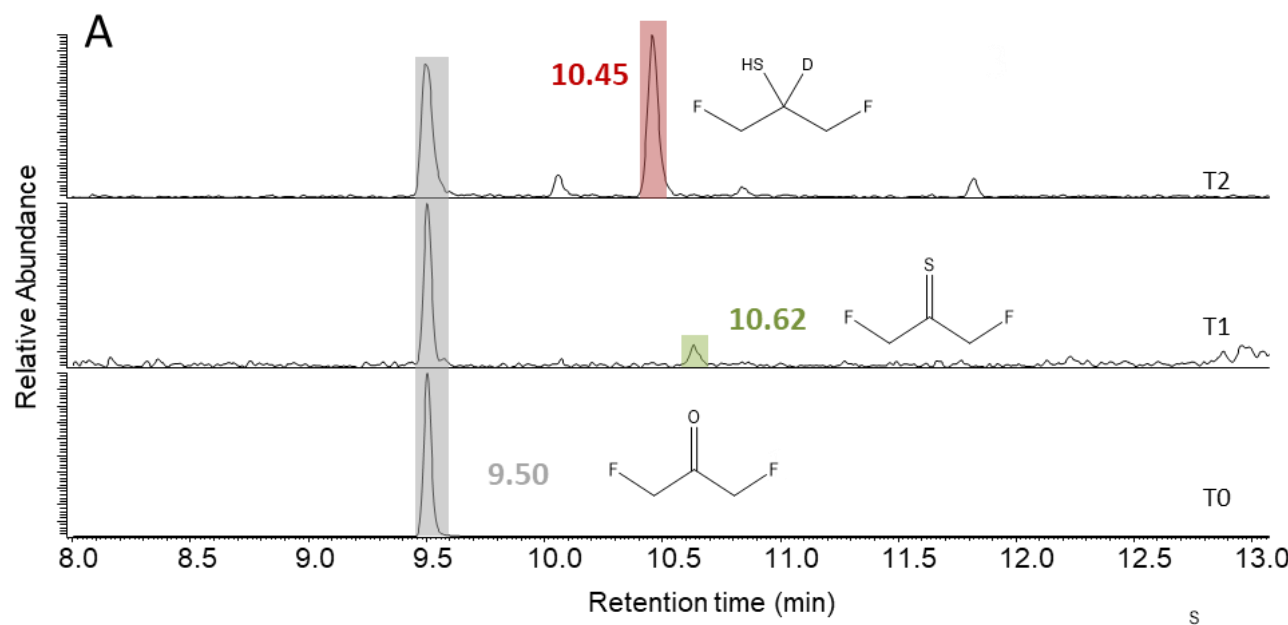

B

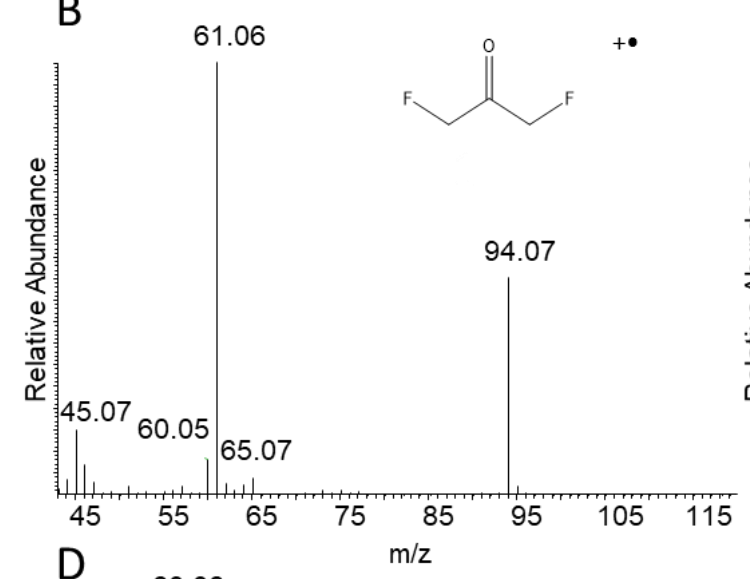

C
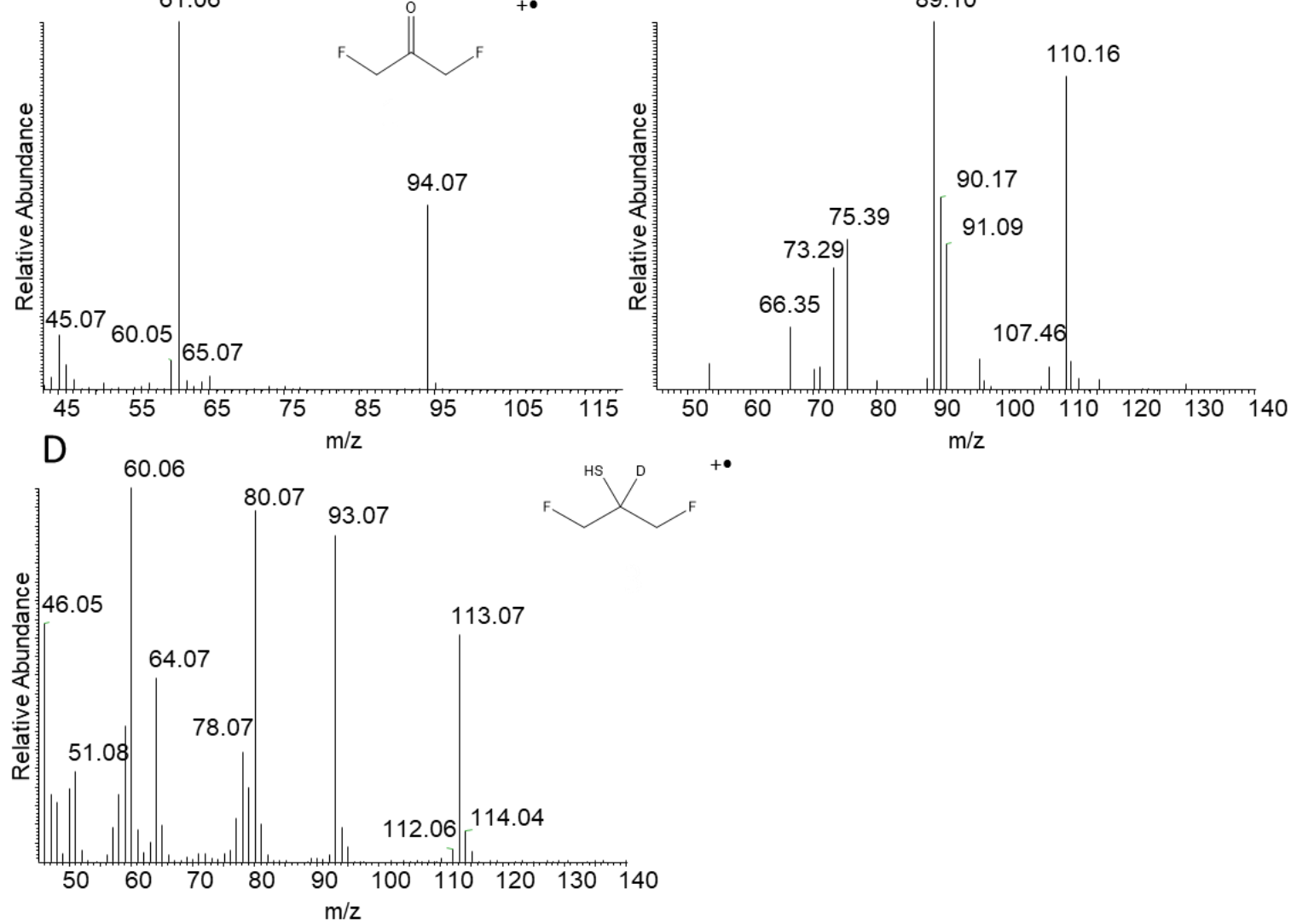

Figure S12. Chemical reductive sulfidation of 1,3-difluoropronane-2-one. A-HS-GC-MS-2 extracted ion chromatograms at the initial reaction time (TO), after the sulfidation step using $\mathrm{P}_{4} \mathrm{~S}_{10}(\mathrm{~T} 1=12 \mathrm{~h})$, and after the reduction step using $\mathrm{NaBD}_{4}(\mathrm{~T} 2=12 \mathrm{~h})$. B-Mass spectrum of 1,3-difluoropronane-2-one. C-Mass spectrum of 1,3difluoropronane-2-thione. D-Mass spectrum of 1,3-difluoropronane-2-thiol. Each mass spectrum came from GCEI-MS analysis (positive mode). 
A

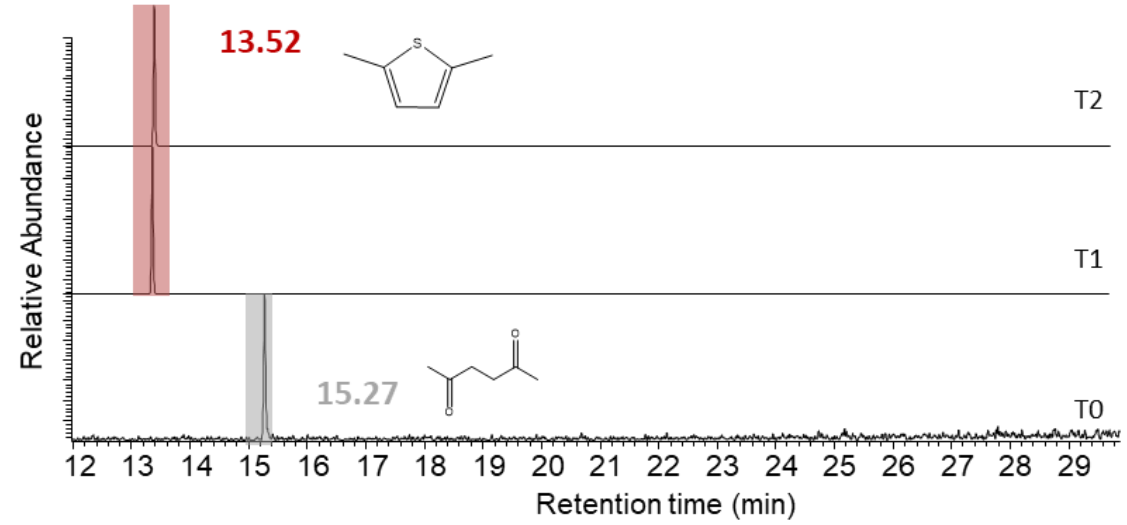

B

43.09

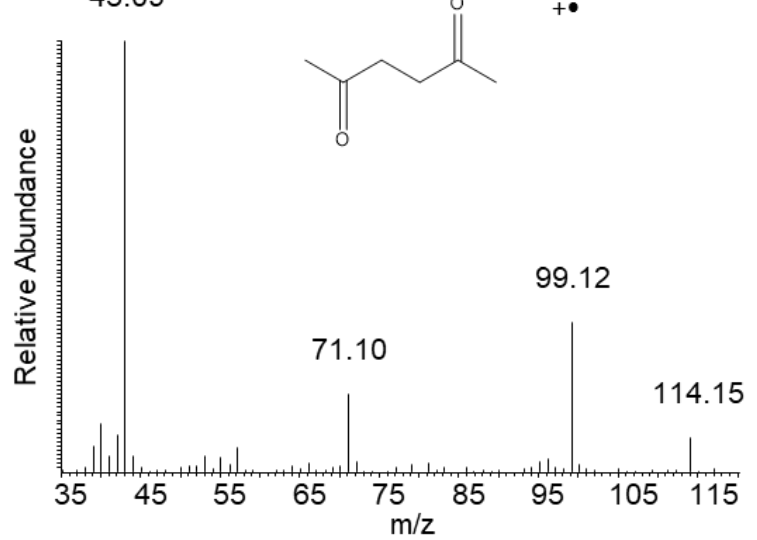

C

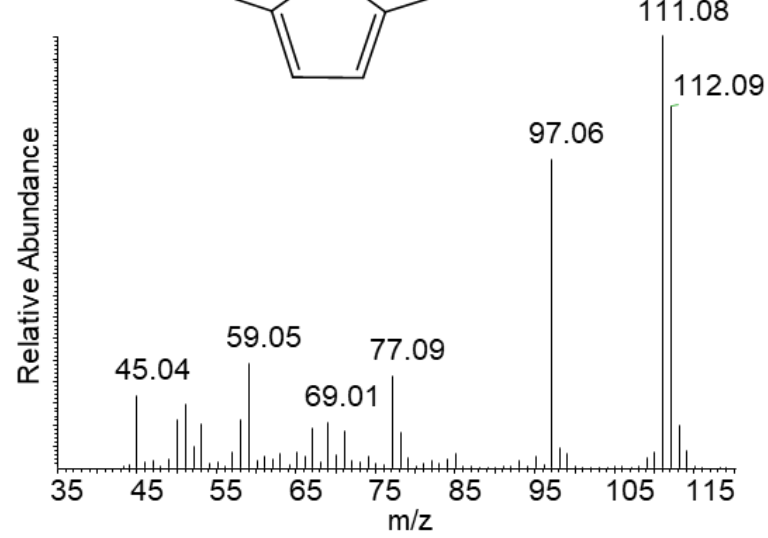

Figure S13. Chemical reductive sulfidation of hexane-2,5-dione. A-HS-GC-MS-2 extracted ion chromatograms at the initial reaction time (T0), after the sulfidation step using $\mathrm{P}_{4} \mathrm{~S}_{10}(\mathrm{~T} 1=12 \mathrm{~h})$, and after the reduction step using $\mathrm{NaBD}_{4}(\mathrm{T2}=12 \mathrm{~h}$ ). B-Mass spectrum of hexane-2,5-dione. C-Mass spectrum of dimethylthiophene. Each mass spectrum came from GC-EI-MS analysis (positive mode). 

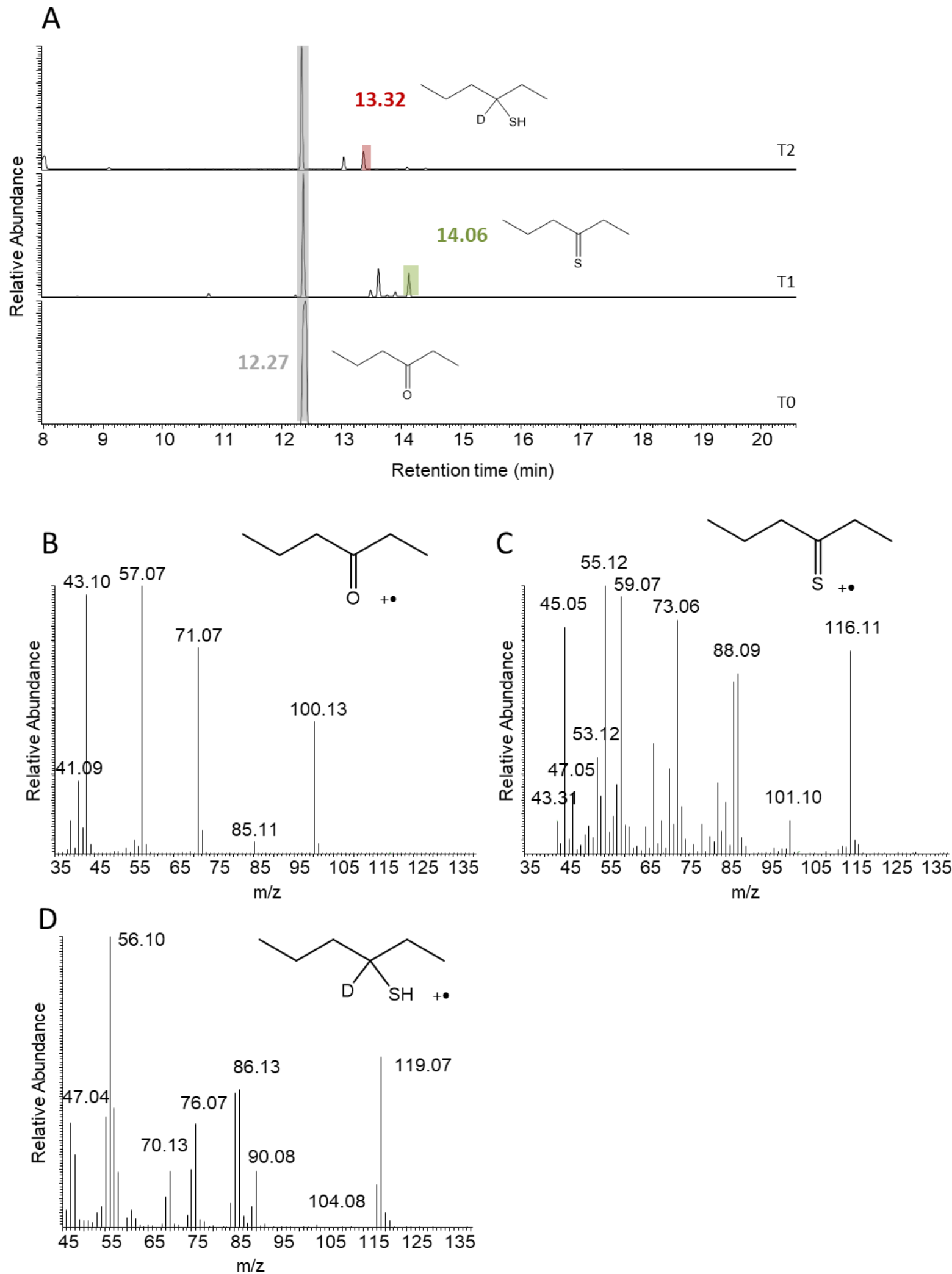

Figure S14. Chemical reductive sulfidation of hexane-3-one. A-HS-GC-MS-2 extracted ion chromatograms at the initial reaction time $(T 0)$, after the sulfidation step using $\mathrm{P}_{4} \mathrm{~S}_{10}(\mathrm{~T} 1=12 \mathrm{~h})$, and after the reduction step using $\mathrm{NaBD}_{4}$ $(\mathrm{T} 2=12 \mathrm{~h})$. B-Mass spectrum of hexane-3-one. C-Mass spectrum of hexane-3-thione. D-Mass spectrum of hexane-3-thiol. Each mass spectrum came from GC-EI-MS analysis (positive mode). 

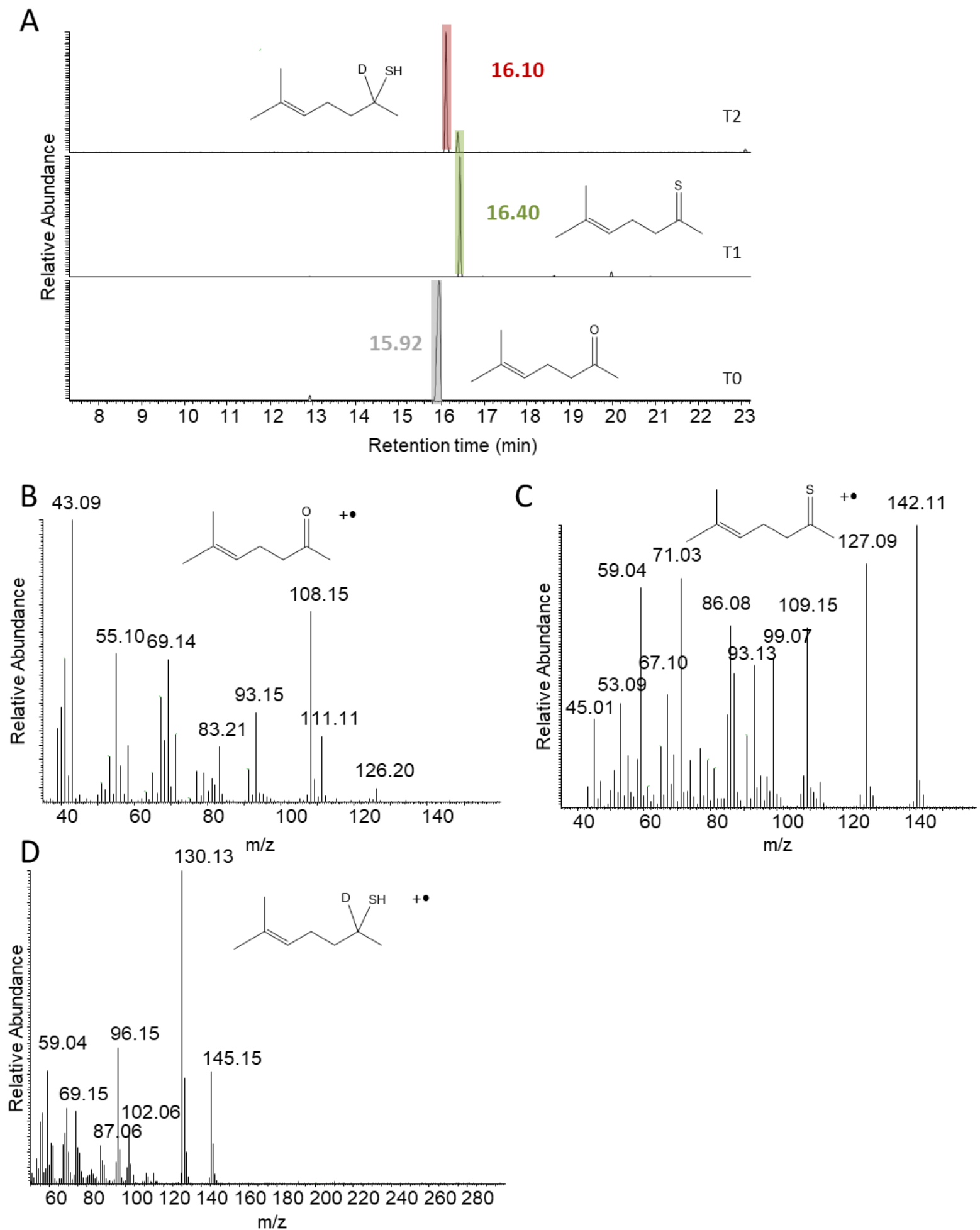

Figure S15. Chemical reductive sulfidation of 6-methylhept-5-en-2-one. A-HS-GC-MS-2 extracted ion chromatograms at the initial reaction time (T0), after the sulfidation step using $\mathrm{P}_{4} \mathrm{~S}_{10}(\mathrm{~T} 1=12 \mathrm{~h})$, and after the reduction step using $\mathrm{NaBD}_{4}(\mathrm{~T} 2=12 \mathrm{~h})$. B-Mass spectrum of 6-methylhept-5-en-2-one. C-Mass spectrum of 6methylhept-5-en-2-thione. D-Mass spectrum of 6-methylhept-5-en-2-thiol. Each mass spectrum came from GCEI-MS analysis (positive mode). 
A

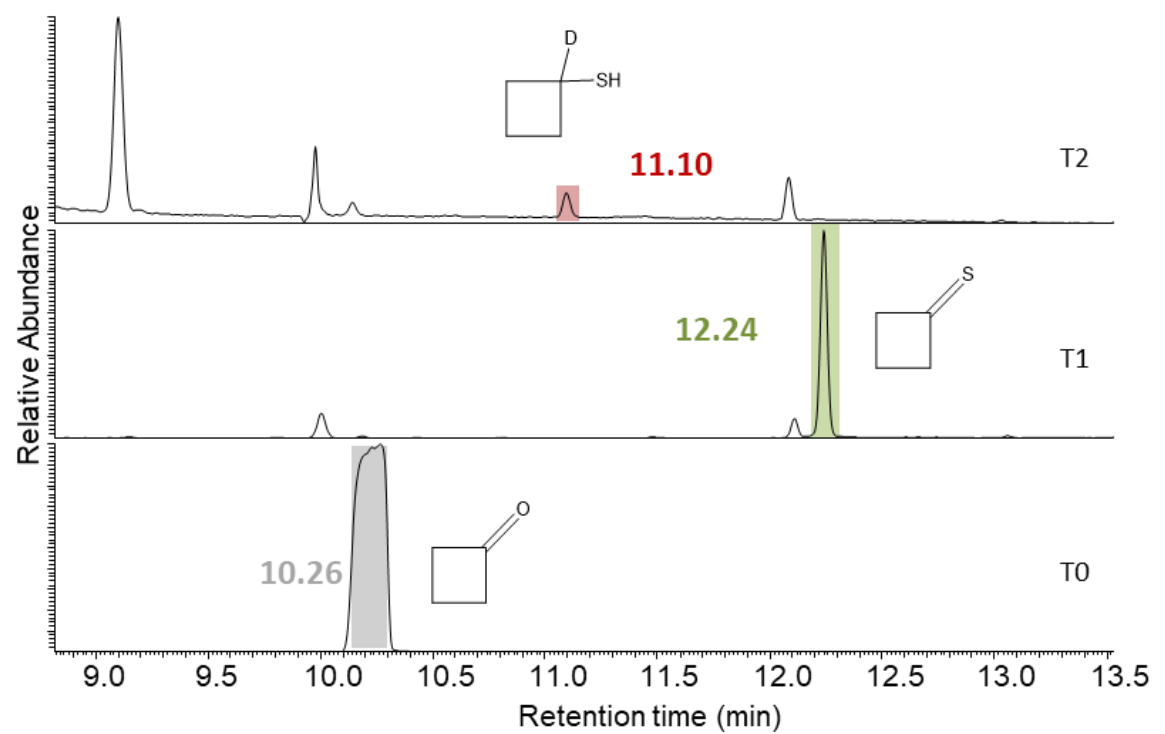

B



C


Figure S16. Chemical reductive sulfidation of cyclobutanone. A-HS-GC-MS-2 extracted ion chromatograms at the initial reaction time (T0), after the sulfidation step using $\mathrm{P}_{4} \mathrm{~S}_{10}(\mathrm{~T} 1=12 \mathrm{~h})$, and after the reduction step using $\mathrm{NaBD}_{4}$ $(\mathrm{T} 2=12 \mathrm{~h})$. B-Mass spectrum cyclobutanone. C-Mass spectrum of cyclobutanethione. D-Mass spectrum of cyclobutanethiol. Each mass spectrum came from GC-EI-MS analysis (positive mode). 




B
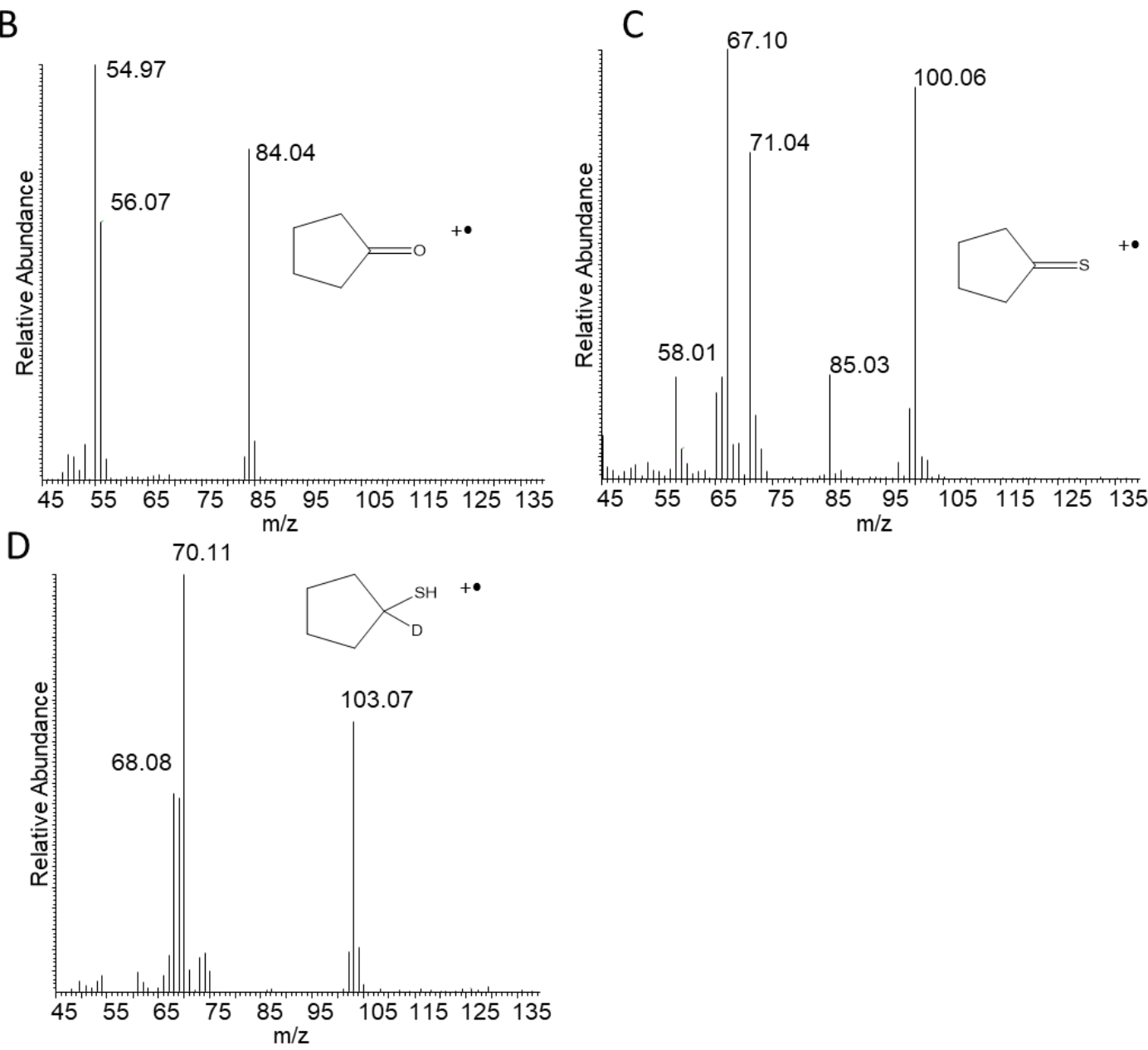

Figure S17. Chemical reductive sulfidation of cyclopentanone. A-HS-GC-MS-2 extracted ion chromatograms at the initial reaction time (TO), after the sulfidation step using $\mathrm{P}_{4} \mathrm{~S}_{10}(\mathrm{~T} 1=12 \mathrm{~h})$, and after the reduction step using $\mathrm{NaBD}_{4}(\mathrm{T2}=12 \mathrm{~h})$. B-Mass spectrum cyclopentanone. C-Mass spectrum of cyclopentanethione. D-Mass spectrum of cyclopentanethiol. Each mass spectrum came from GC-EI-MS analysis (positive mode). 


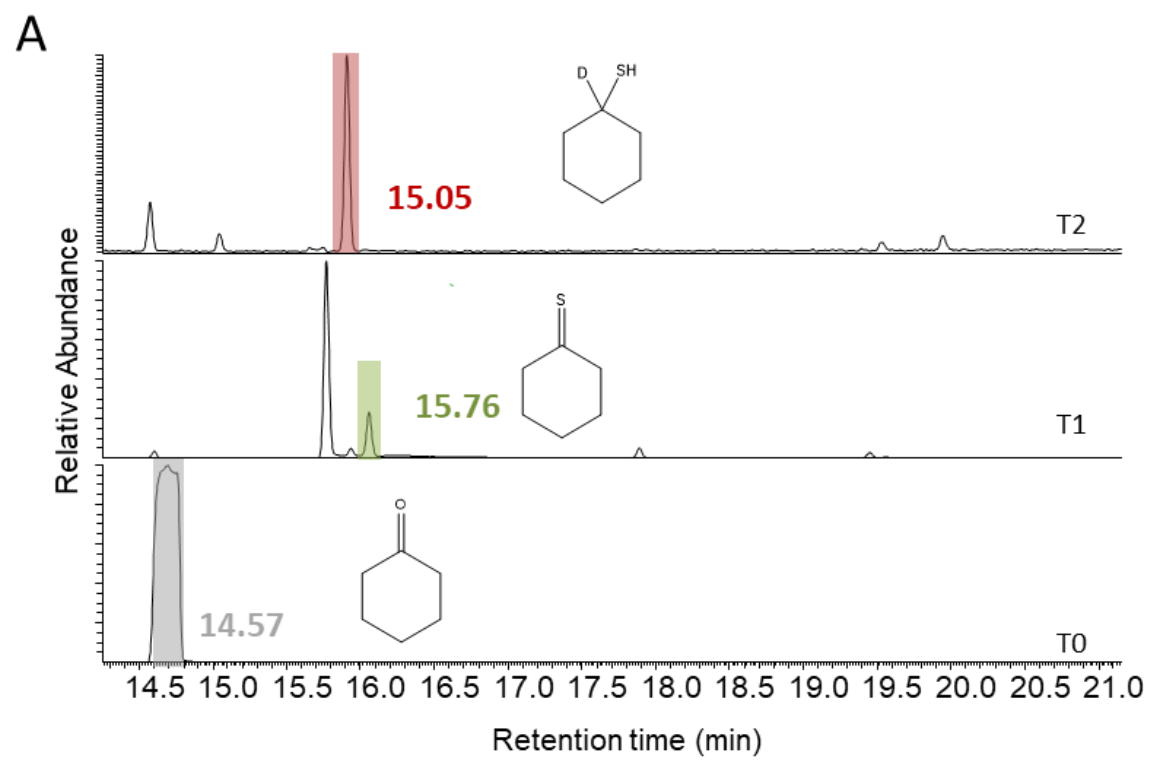

B
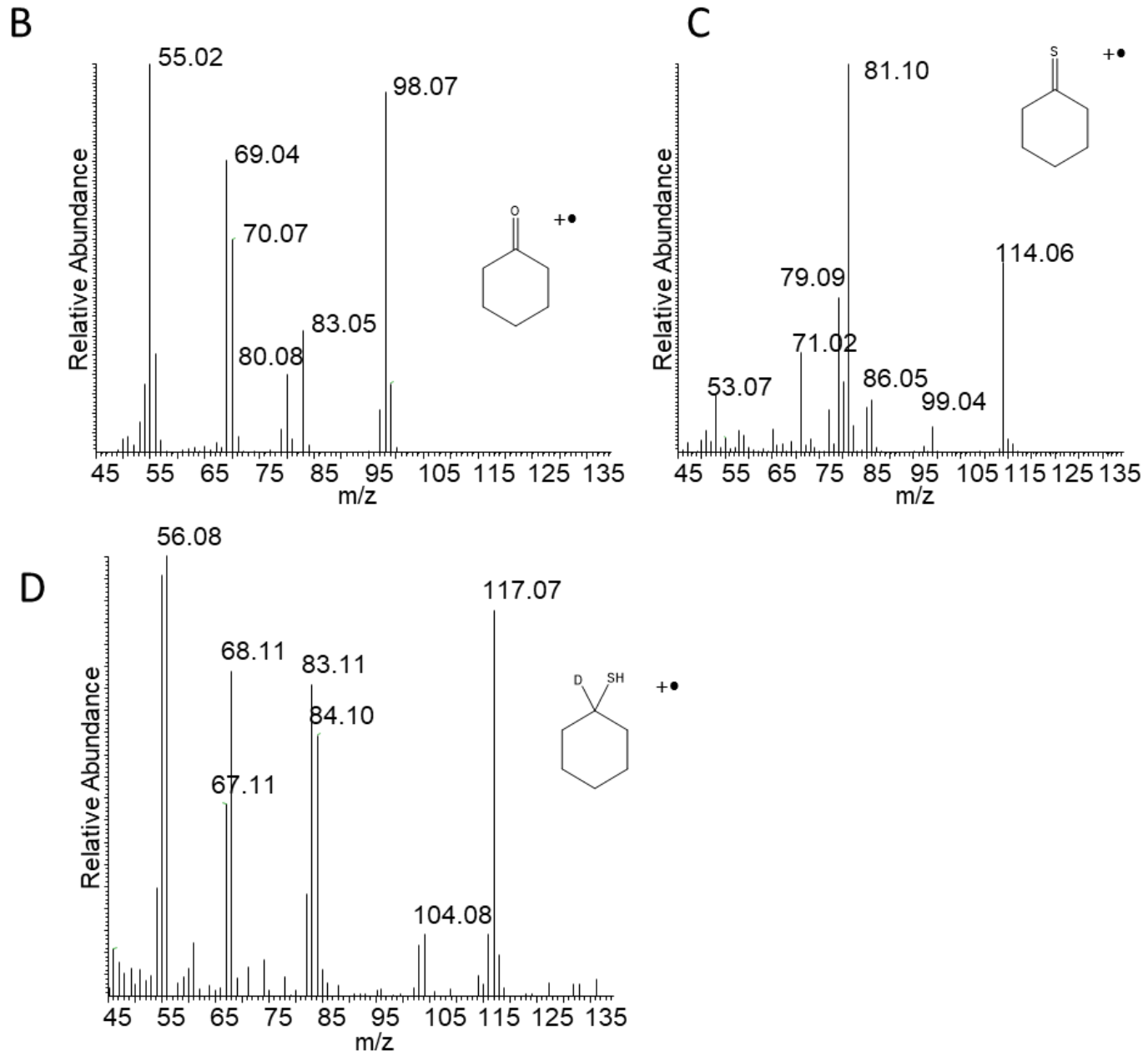

Figure S18. Chemical reductive sulfidation of cyclohexanone. A-HS-GC-MS-2 extracted ion chromatograms at the initial reaction time (TO), after the sulfidation step using $\mathrm{P}_{4} \mathrm{~S}_{10}(\mathrm{~T} 1=12 \mathrm{~h})$, and after the reduction step using $\mathrm{NaBD}_{4}$ $(\mathrm{T} 2=12 \mathrm{~h})$. B-Mass spectrum cyclohexanone. C-Mass spectrum of cyclohexanethione. D-Mass spectrum of cyclohexanethiol. Each mass spectrum came from GC-EI-MS analysis (positive mode). 
A

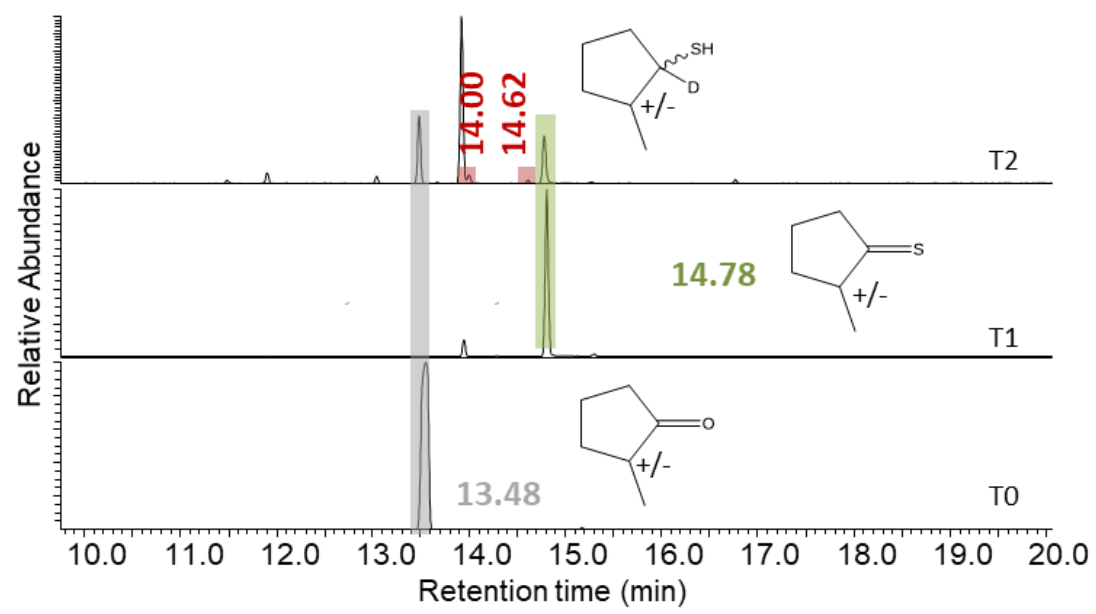

B



C

D
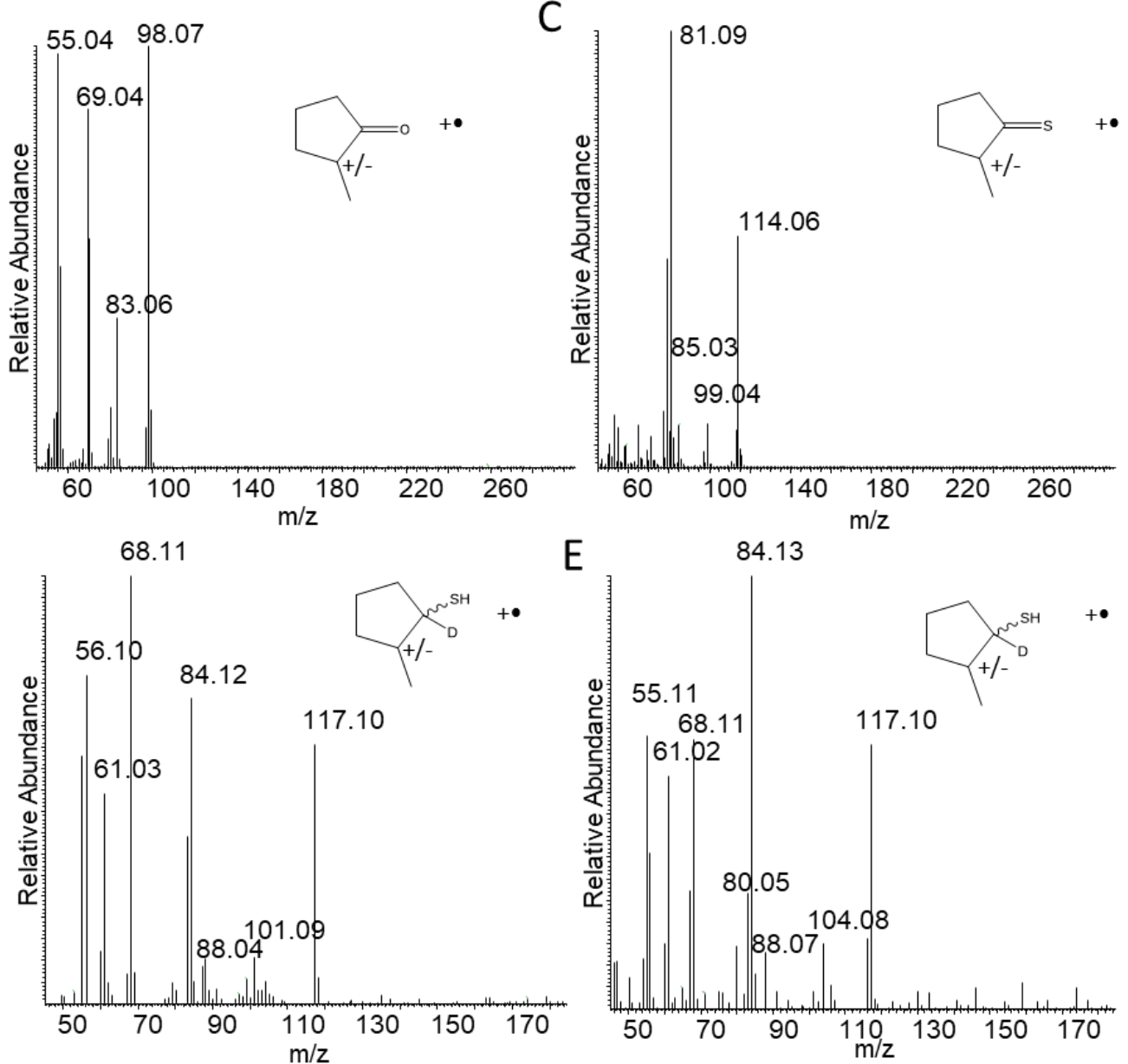

E

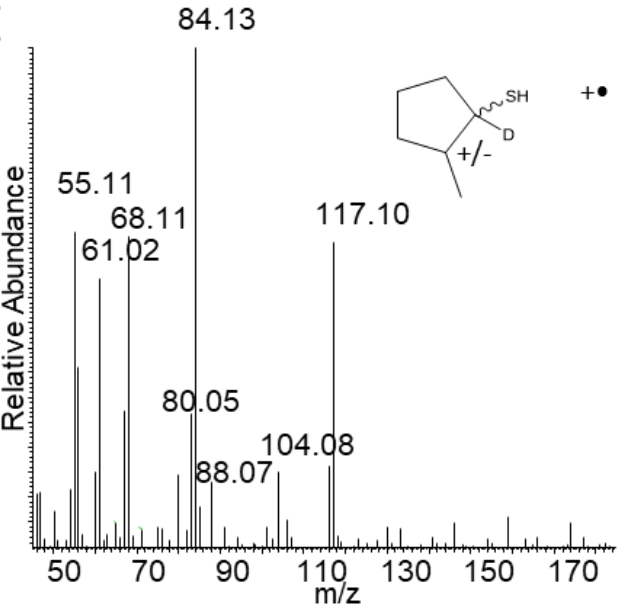

Figure S19. Chemical reductive sulfidation of 2-methylcyclopentan-1-one. A-HS-GC-MS-2 extracted ion chromatograms at the initial reaction time (TO), after the sulfidation step using $\mathrm{P}_{4} \mathrm{~S}_{10}(\mathrm{~T} 1=12 \mathrm{~h}$ ), and after the reduction step using $\mathrm{NaBD}_{4}(\mathrm{~T} 2=12 \mathrm{~h})$. B-Mass spectrum 2-methylcyclopentan-1-one. C-Mass spectrum of 2methylcyclopentan-1-thione. D-Mass spectrum of 2-methylcyclopentan-1-thiol ( $r \mathrm{t}=14.00 \mathrm{~min}$ ). E-Mass spectrum of 2-methylcyclopentan-1-thiol ( $\mathrm{rt}=14.62 \mathrm{~min}$ ). Each mass spectrum came from GC-EI-MS analysis (positive mode). 
A

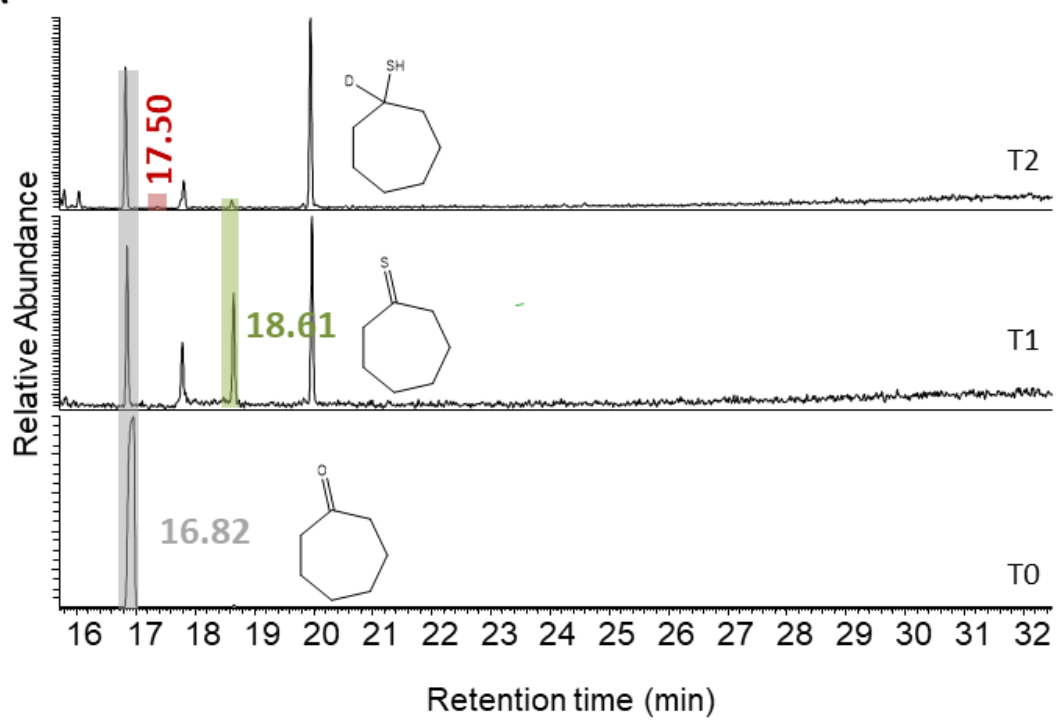

B



C $\quad 95.13$
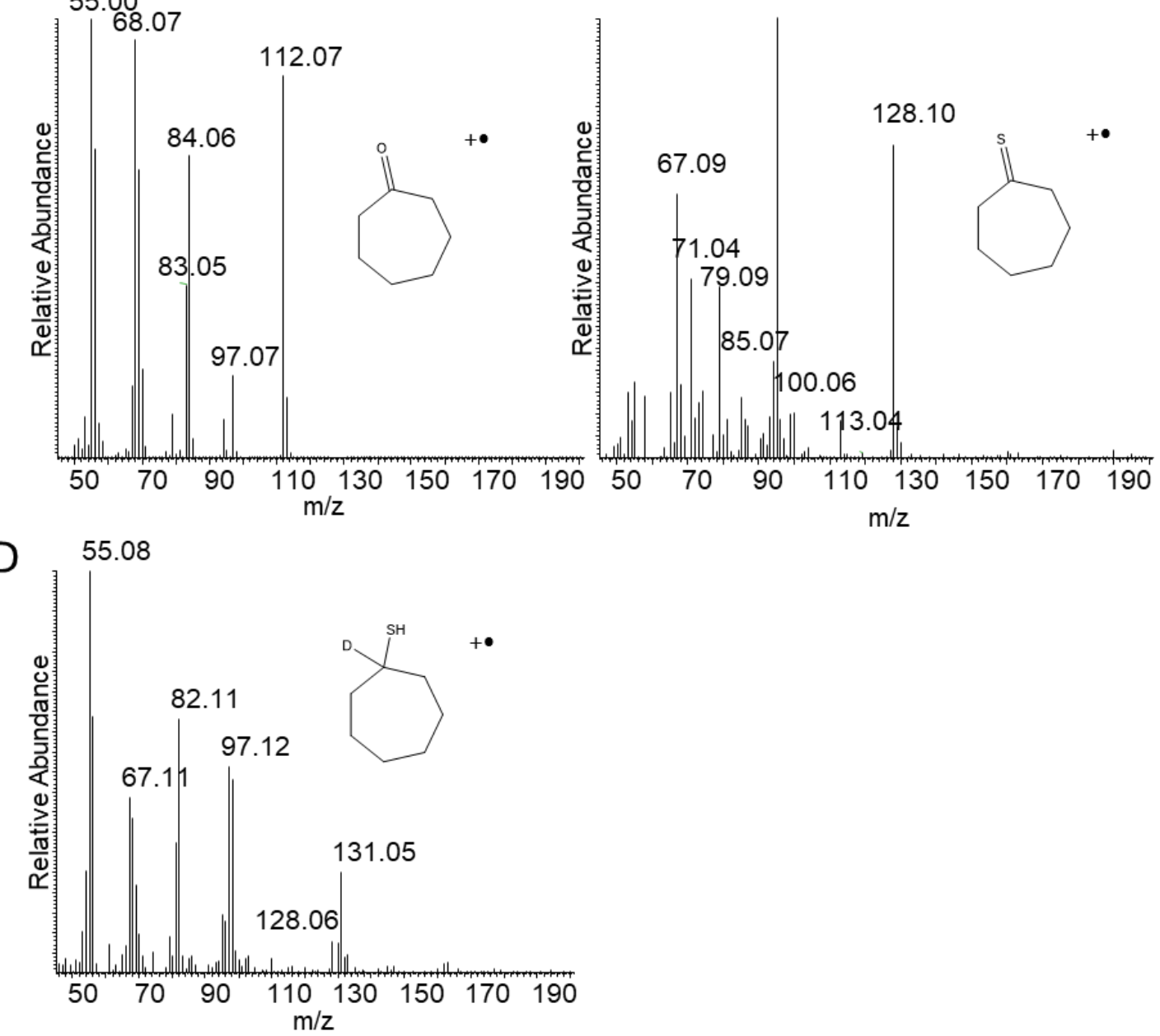

Figure

S20. Chemical reductive sulfidation of cycloheptanone. A-HS-GC-MS-2 extracted ion chromatograms at the initial reaction time (T0), after the sulfidation step using $\mathrm{P}_{4} \mathrm{~S}_{10}(\mathrm{~T} 1=12 \mathrm{~h})$, and after the reduction step using $\mathrm{NaBD}_{4}\left(\mathrm{~T}_{2}\right.$ $=12 \mathrm{~h}$ ). B-Mass spectrum cycloheptanone. C-Mass spectrum of cycloheptanethione. D-Mass spectrum of cycloheptanethiol. Each mass spectrum came from GC-EI-MS analysis (positive mode). 



Figure S21. Chemical reductive sulfidation of 2-methylcyclohexan-1-one. A-HS-GC-MS-2 extracted ion chromatograms at the initial reaction time (TO), after the sulfidation step using $\mathrm{P}_{4} \mathrm{~S}_{10}(\mathrm{~T} 1=12 \mathrm{~h})$, and after the reduction step using $\mathrm{NaBD}_{4}(\mathrm{~T} 2=12 \mathrm{~h})$. B-Mass spectrum 2-methylcyclohexan-1-one. C-Mass spectrum of 2methylcyclohexan-1-thione. D-Mass spectrum of 2-methylcyclohexan-1-thiol ( $\mathrm{tt}=16.20 \mathrm{~min}$ ). E-Mass spectrum of 2-methylcyclohexan-1-thiol ( $\mathrm{rt}=16.70 \mathrm{~min}$ ). Each mass spectrum came from GC-EI-MS analysis (positive mode). 
A

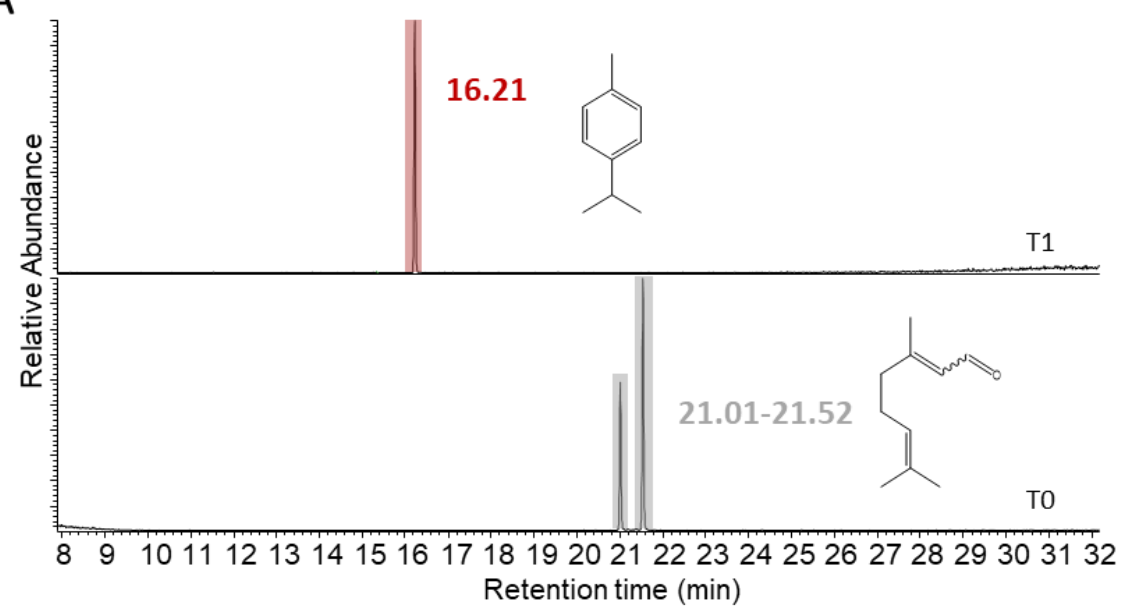

B

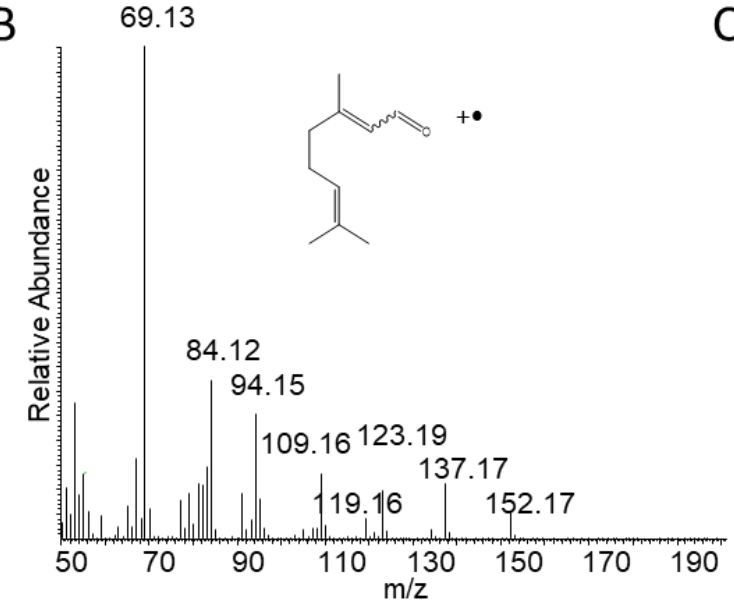

D

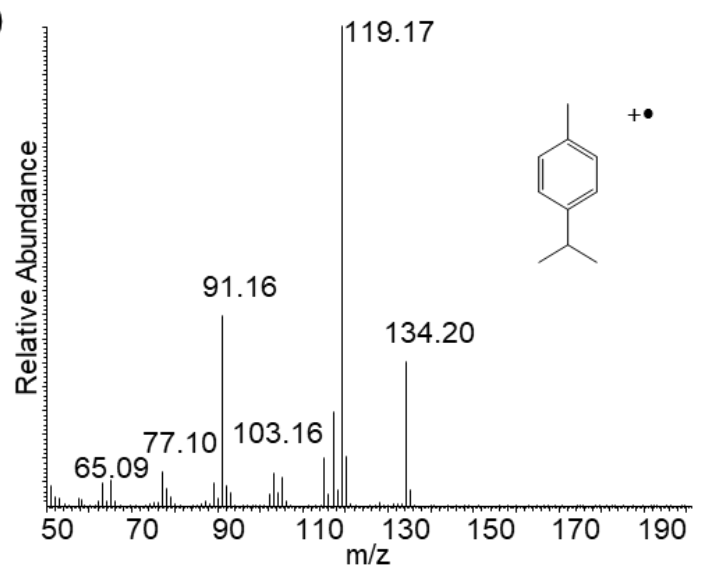

C

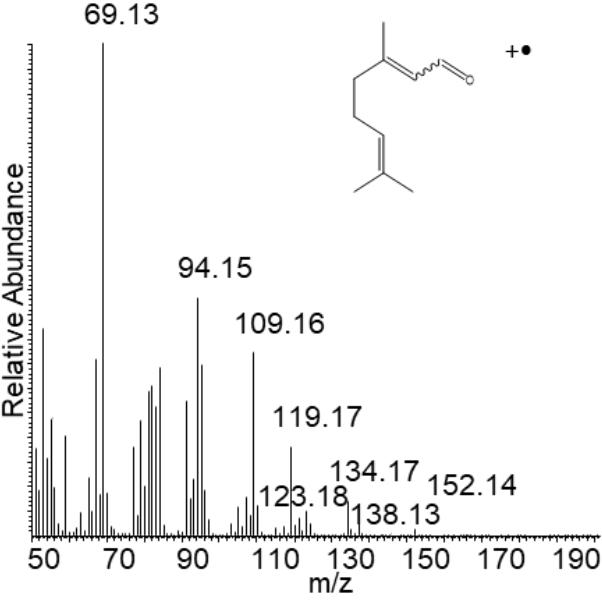

Figure S22. Chemical reductive sulfidation of citral. A-HS-GC-MS-2 extracted ion chromatograms at the initial reaction time $(\mathrm{TO})$, after the sulfidation step using $\mathrm{P}_{4} \mathrm{~S}_{10}(\mathrm{~T} 1=12 \mathrm{~h})$. B-Mass spectrum citral $(\mathrm{rt}=21.01 \mathrm{~min})$. CMass spectrum of citral $(\mathrm{rt}=21.52 \mathrm{~min})$. D-Mass spectrum of $\mathrm{p}$-cymene. Each mass spectrum came from GC-ElMS analysis (positive mode). 


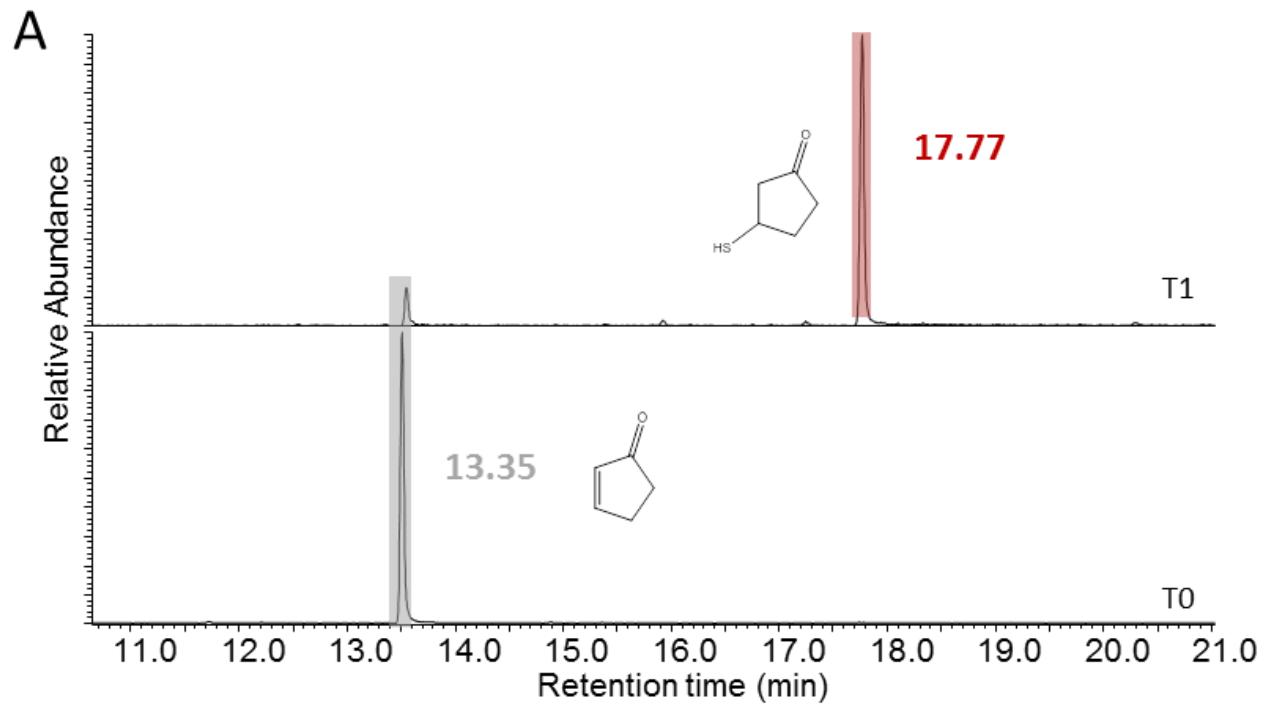

B

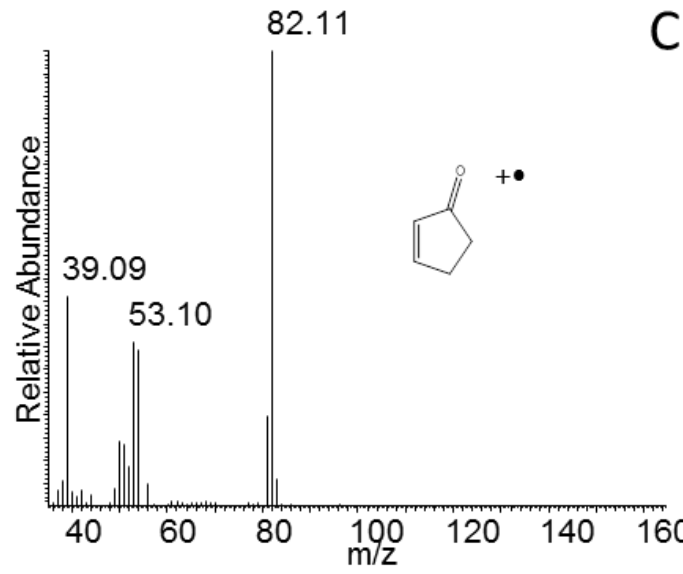

C $\quad 55.10$

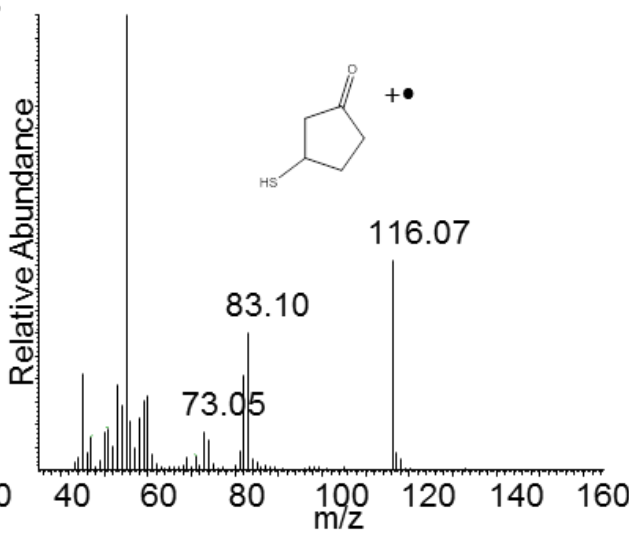

Figure S23.

Chemical reductive sulfidation of citral. A-HS-GC-MS-2 extracted ion chromatograms at the initial reaction time (T0), after the sulfidation step using $\mathrm{P}_{4} \mathrm{~S}_{10}(\mathrm{~T} 1=12 \mathrm{~h}$ ). B-Mass spectrum of cyclopent-2-en-1-one. C-Mass spectrum of 3-mercaptocyclopentan-1-one. Each mass spectrum came from GC-EI-MS analysis (positive mode). 
A

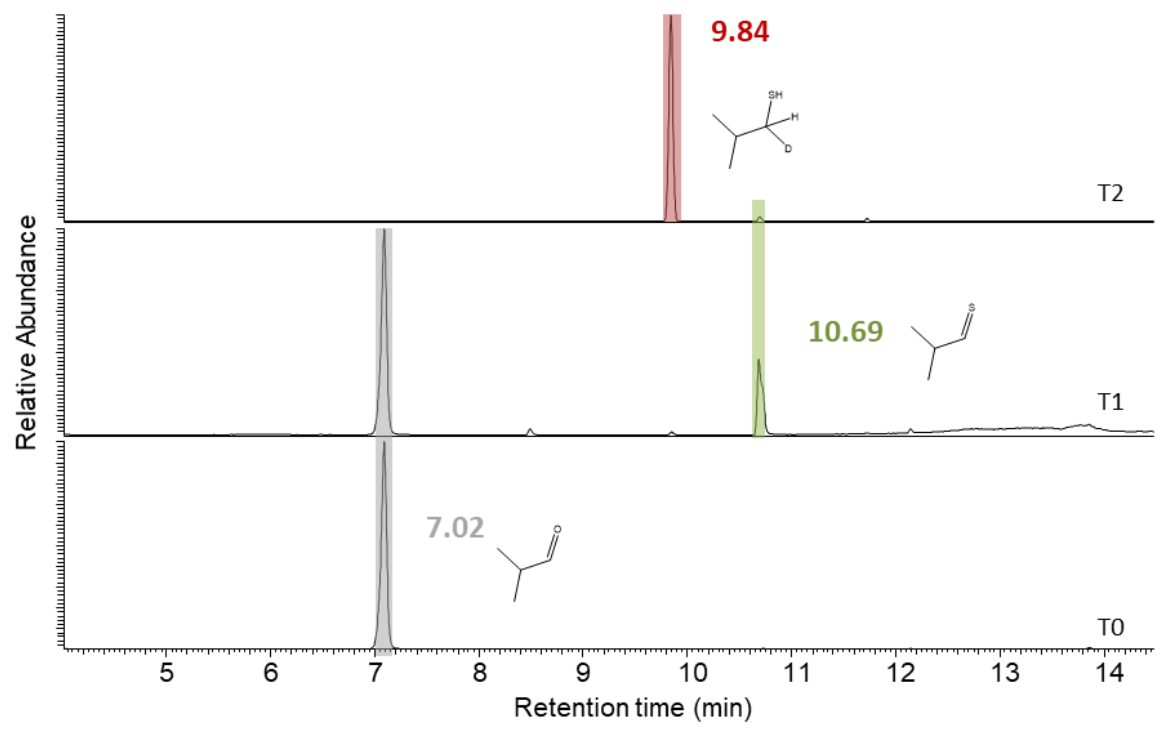

B

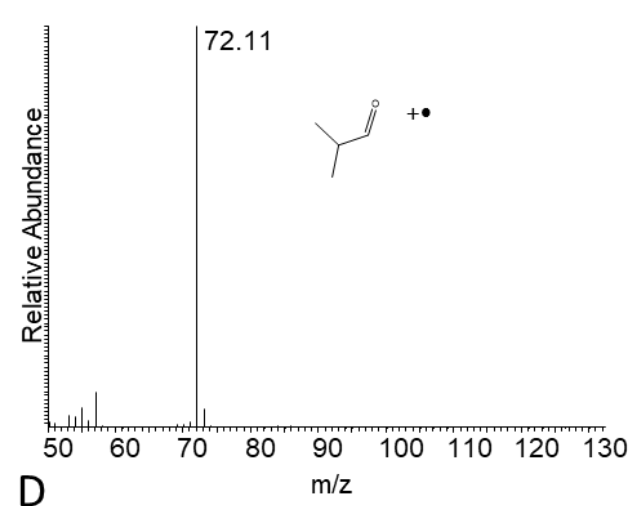

D
C

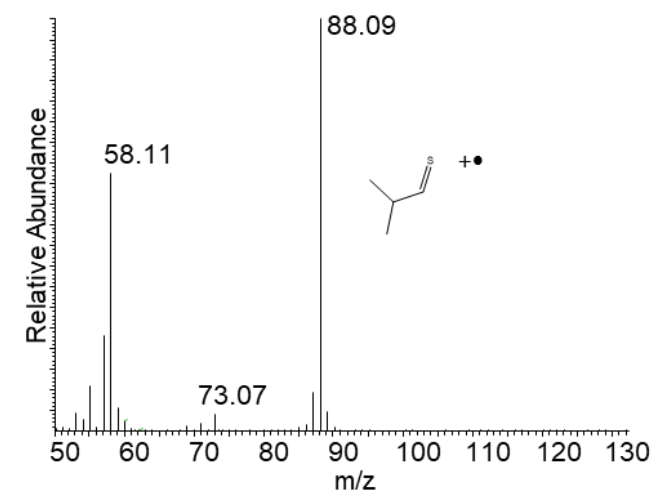

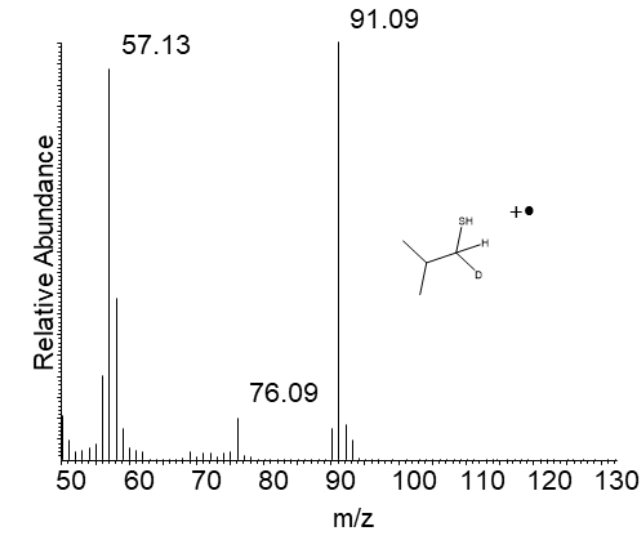

Figure S24. Chemical reductive sulfidation of isobutyraldehyde. A-HS-GC-MS-2 extracted ion chromatograms at the initial reaction time (T0), after the sulfidation step using $\mathrm{P}_{4} \mathrm{~S}_{10}(\mathrm{~T} 1=12 \mathrm{~h})$, and after the reduction step using $\mathrm{NaBD}_{4}\left(\mathrm{~T} 2_{2}=12 \mathrm{~h}\right)$. B-Mass spectrum isobutyraldehyde. C-Mass spectrum of 2-methylpropane-1-thione. D-Mass spectrum of 2-methylpropane-1-thiol. Each mass spectrum came from GC-EI-MS analysis (positive mode). 


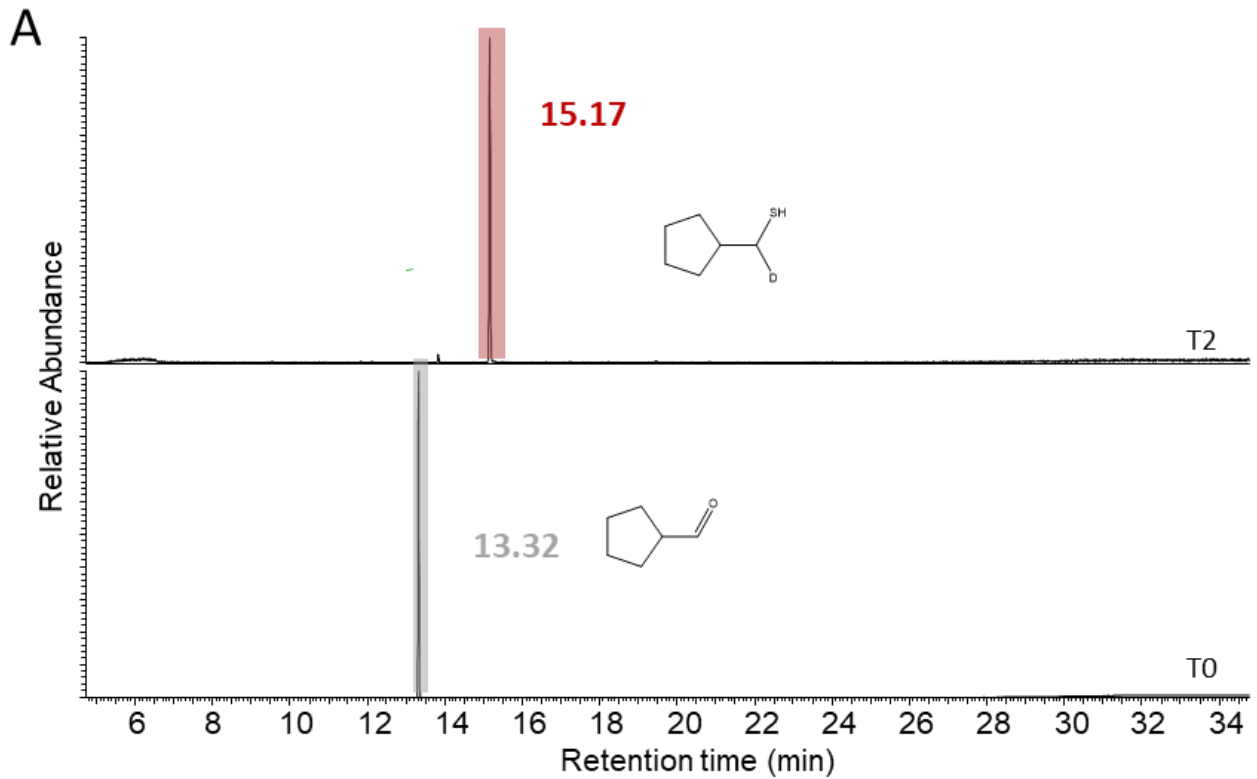

B

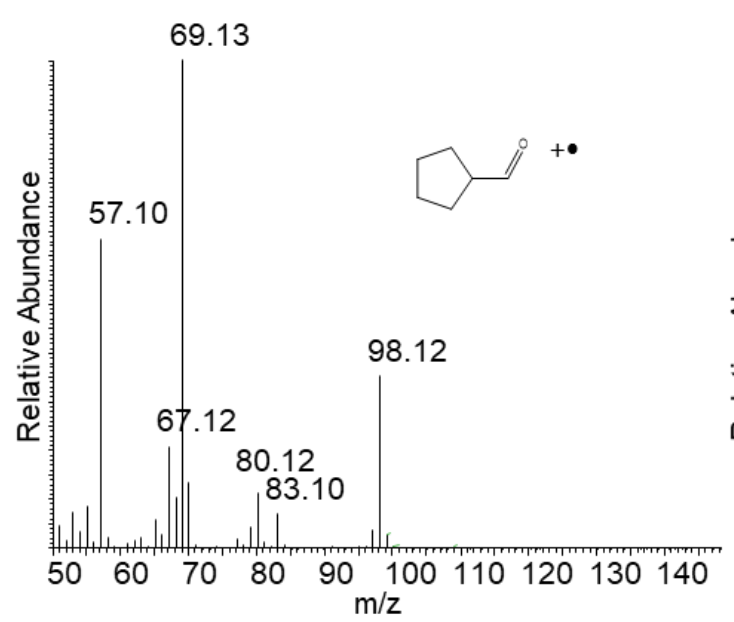

C

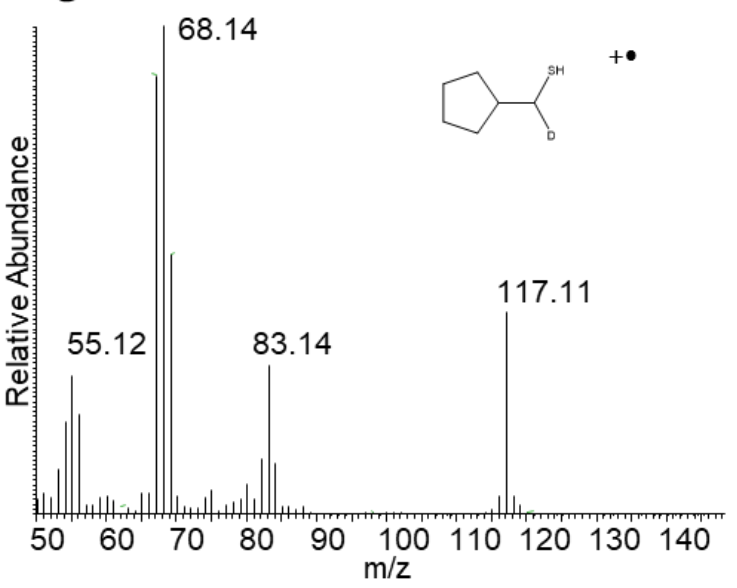

Figure S25. Chemical reductive sulfidation of cyclopentanecarbaldehyde. A HS-GC-MS-2 extracted ion chromatograms at the initial reaction time (T0), after the sulfidation step using $\mathrm{P}_{4} \mathrm{~S}_{10}(\mathrm{~T} 1=12 \mathrm{~h}$ ), and after the reduction step using $\mathrm{NaBD}_{4}(\mathrm{~T} 2=12 \mathrm{~h})$. B-Mass spectrum of cyclopentanecarbaldehyde. C-Mass spectrum of cyclopentylmethanethiol. Each mass spectrum came from GC-EI-MS analysis (positive mode). 


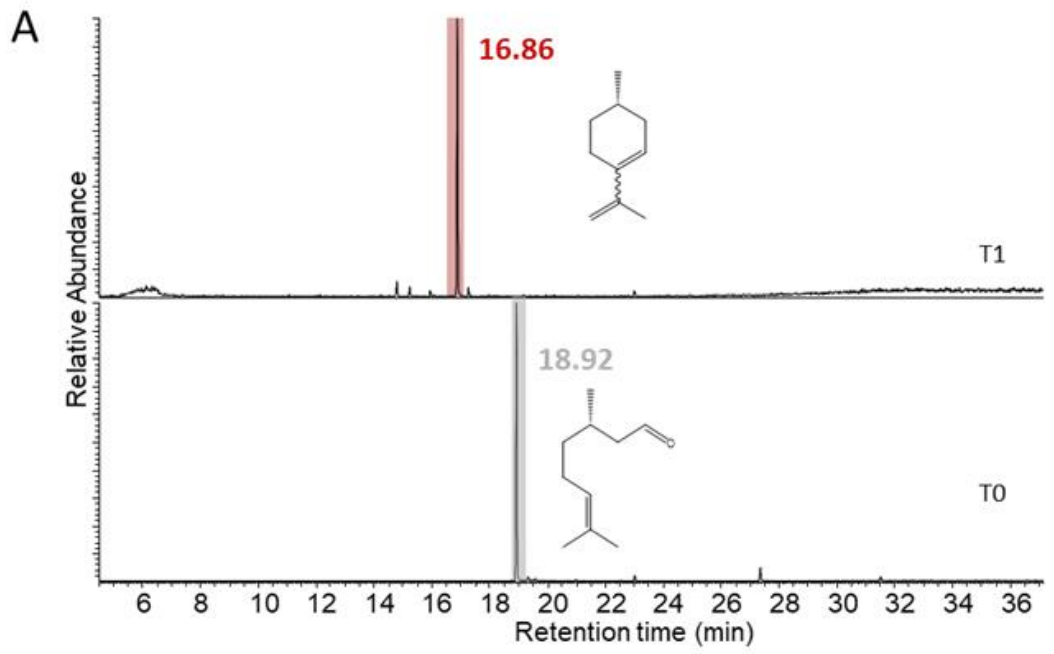

B



C

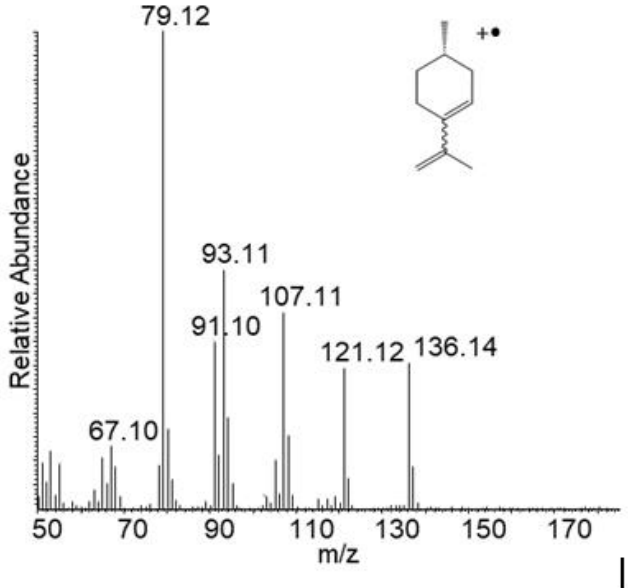

Figure S26. Chemical reductive sulfidation of (S)-citronellal. A-HS-GC-MS-2 extracted ion chromatograms at the initial reaction time (T0) and after the sulfidation step using $\mathrm{P}_{4} \mathrm{~S}_{10}(\mathrm{~T} 1=12 \mathrm{~h})$. B-Mass spectrum of $(\mathrm{S})$-citronellal. C-Mass spectrum of 3,8-p-menthadiene. Each mass spectrum came from GC-EI-MS analysis (positive mode). 
A

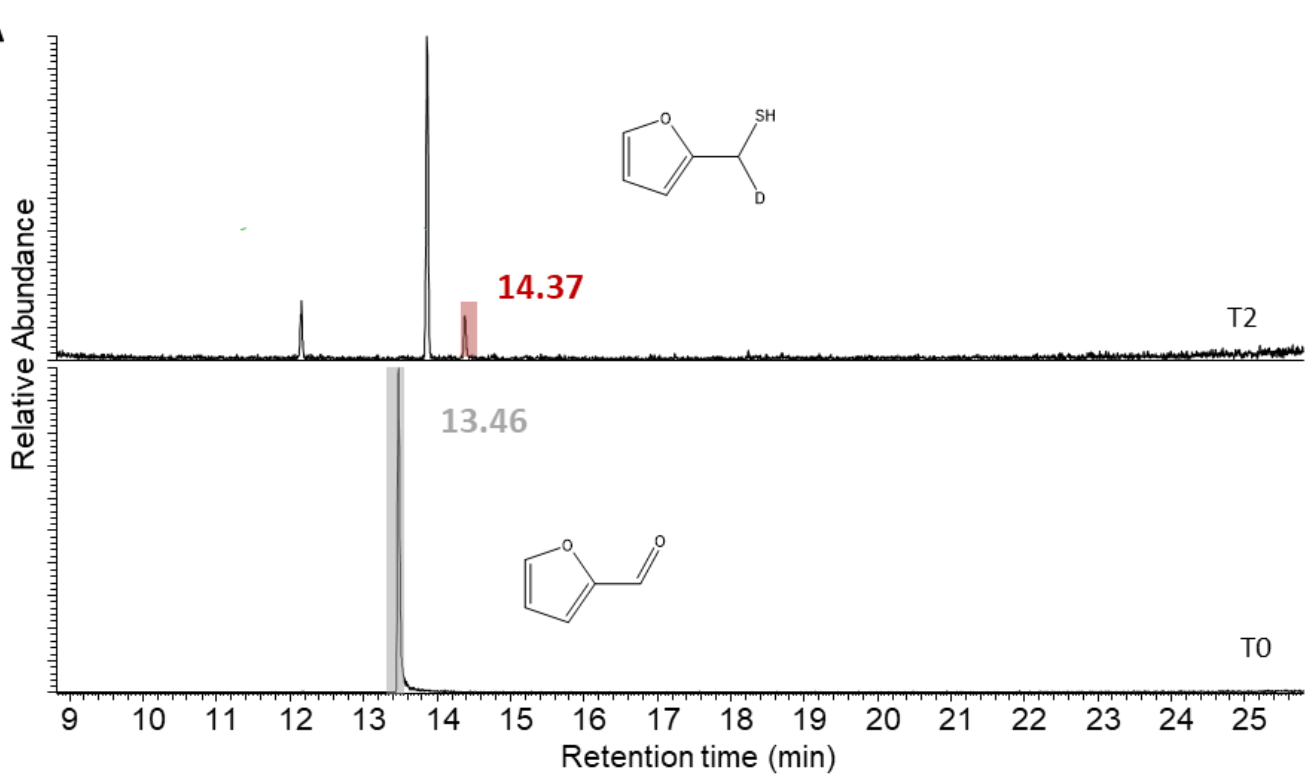

B

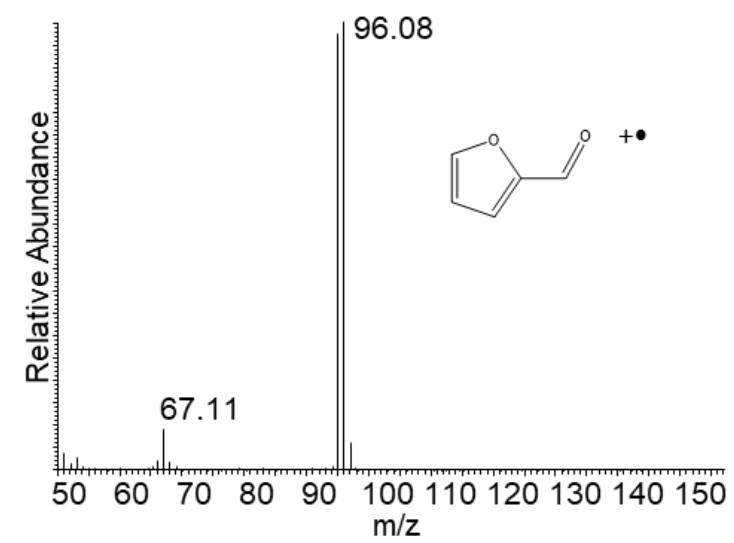

C

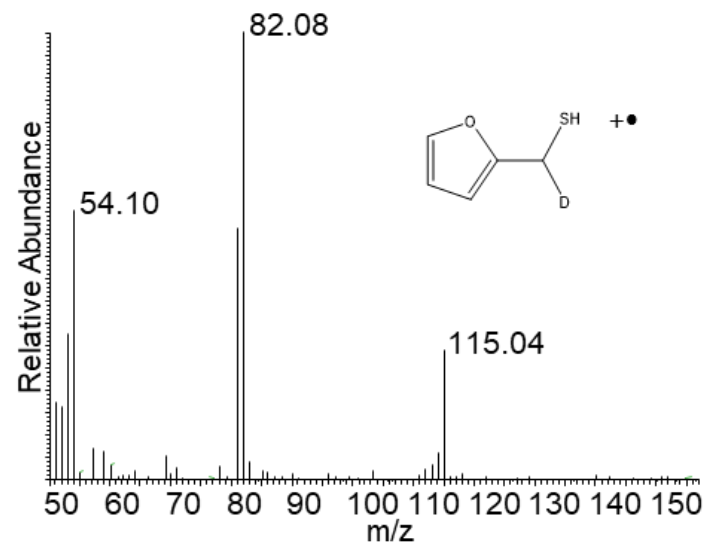

Figure S27. Chemical reductive sulfidation of furfural. A-HS-GC-MS-2 extracted ion chromatograms at the initial reaction time $(T 0)$, after the sulfidation step using $\mathrm{P}_{4} \mathrm{~S}_{10}(T 1=12 \mathrm{~h})$, and after the reduction step using $\mathrm{NaBD}_{4}\left(\mathrm{~T}_{2}\right.$ $=12 \mathrm{~h}$ ). B-Mass spectrum of furfural. C-Mass spectrum of furan-2-ylmethanethiol. Each mass spectrum came from GC-EI-MS analysis (positive mode). 


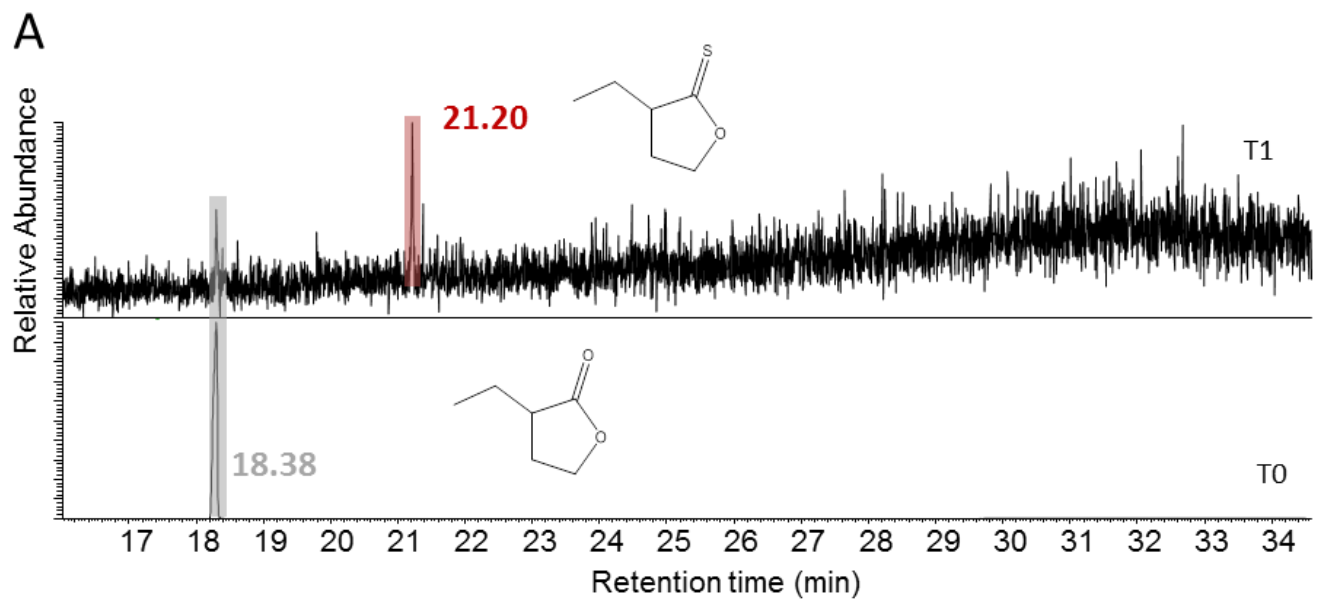

B

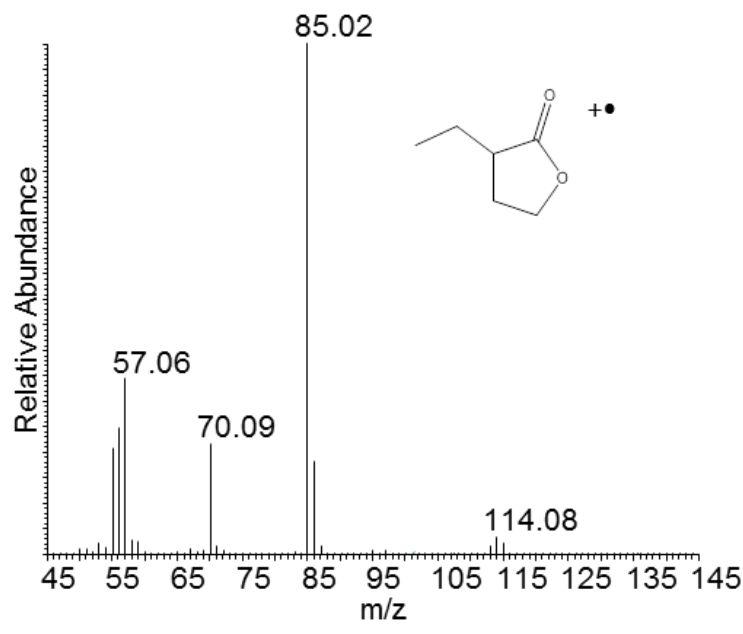

C

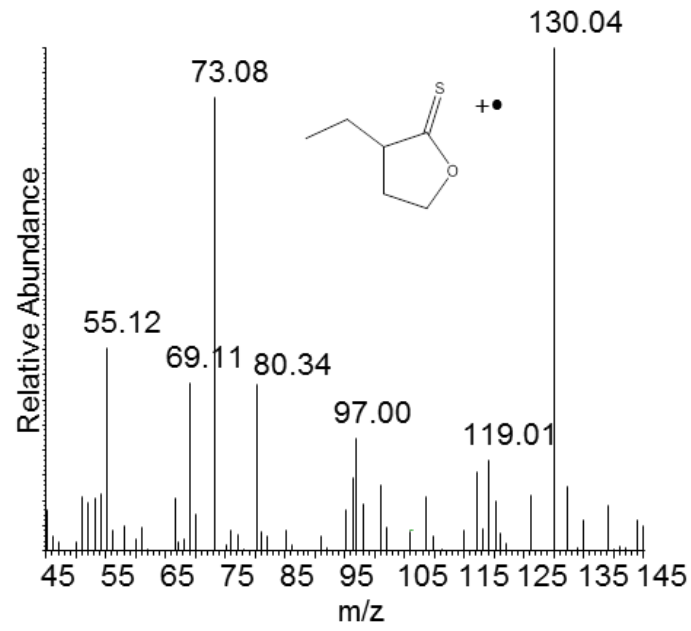

Figure S28. Chemical reductive sulfidation of 3-ethyldihydrofuran-2(3H)-one. A-HS-GC-MS-2 extracted ion chromatograms at the initial reaction time (TO), and after the sulfidation step using $\mathrm{P}_{4} \mathrm{~S}_{10}(\mathrm{~T} 1=12 \mathrm{~h})$. B-Mass spectrum of 3-ethyldihydrofuran-2(3H)-one. C-Mass spectrum of 3-ethyldihydrofuran-2(3H)-thione. Each mass spectrum came from GC-EI-MS analysis (positive mode). 
A

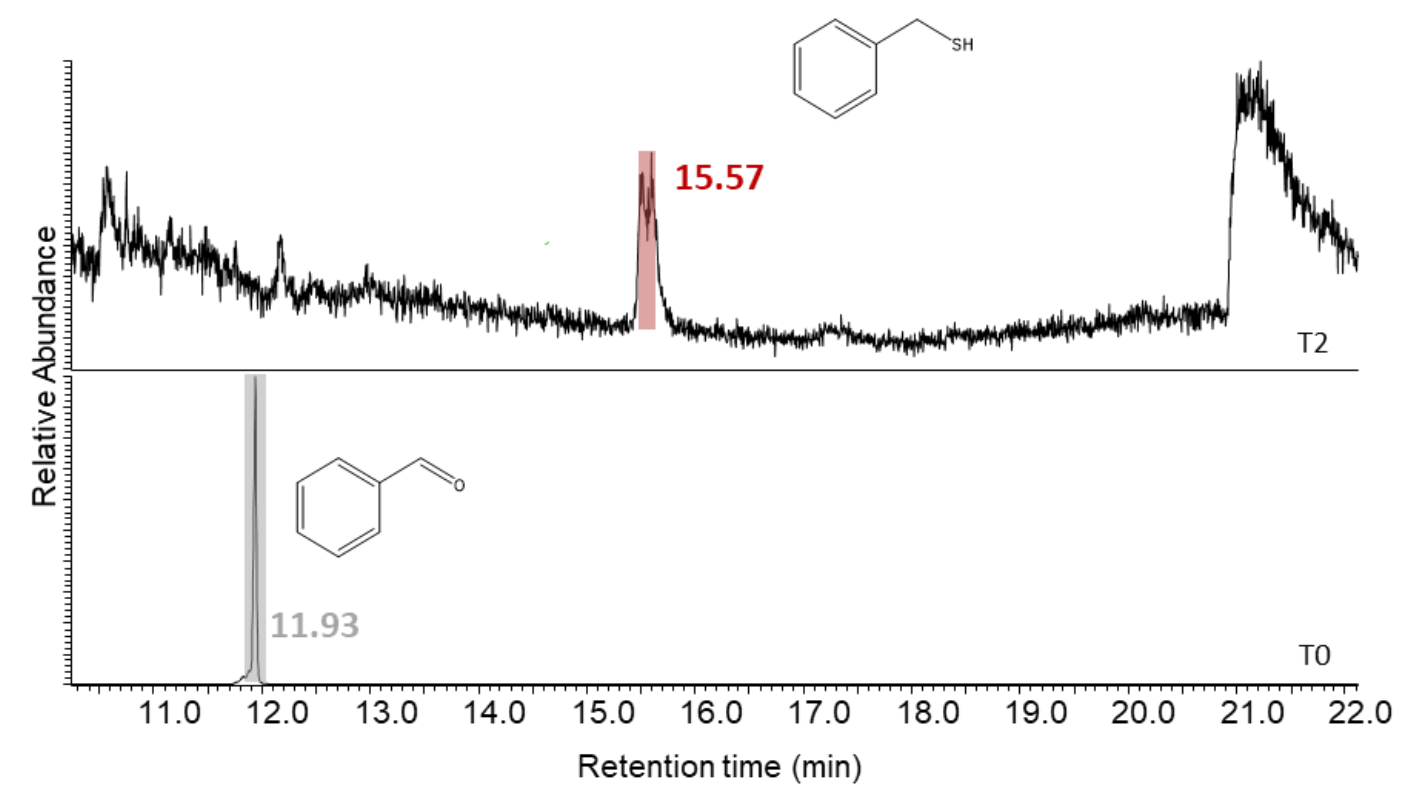

B

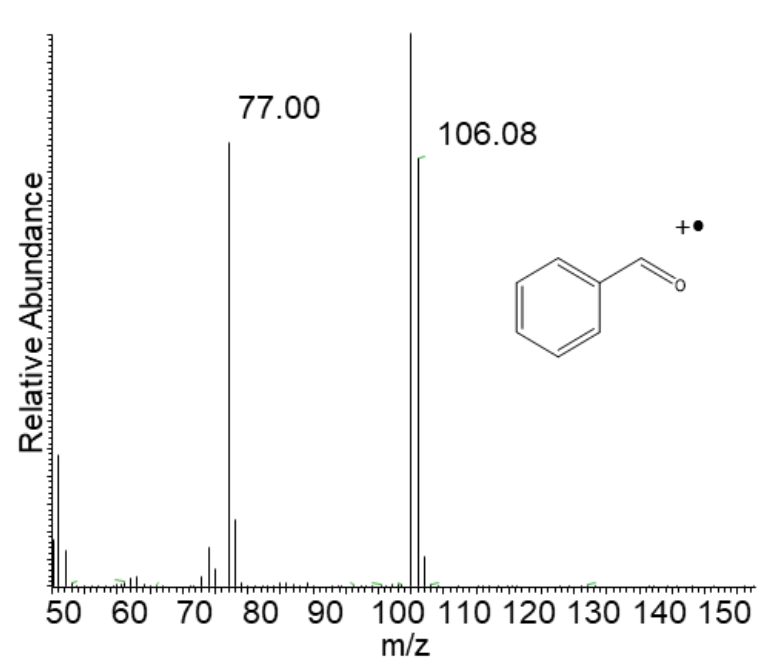

C

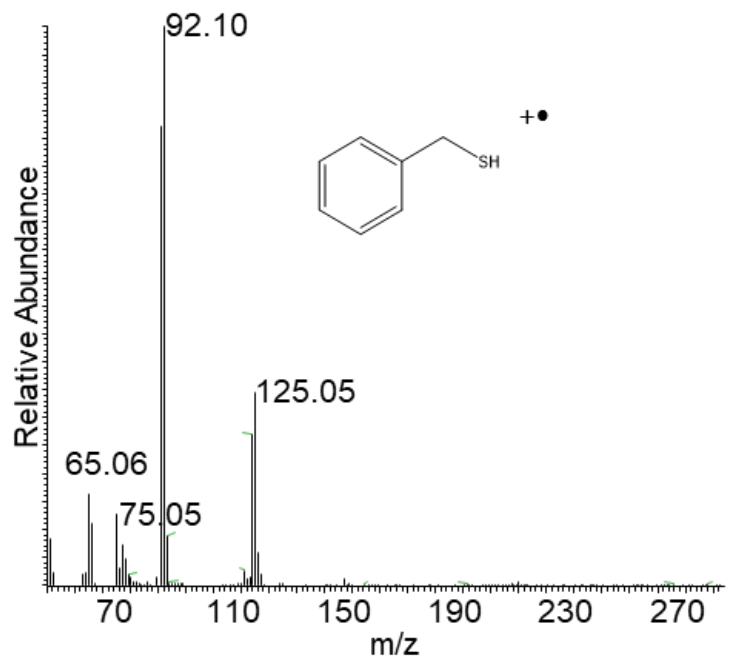

Figure S29. Chemical reductive sulfidation of benzaldehyde. A-GC-MS-2 extracted ion chromatograms at the initial reaction time (T0), after the sulfidation step using $\mathrm{P}_{4} \mathrm{~S}_{10}(\mathrm{~T} 1=12 \mathrm{~h})$, and after the reduction step using $\mathrm{NaBD}_{4}$ $(\mathrm{T} 2=12 \mathrm{~h})$. B-Mass spectrum of benzaldehyde. C-Mass spectrum of phenylmethanethiol. Each mass spectrum came from GC-EI-MS analysis (positive mode). 
A



B

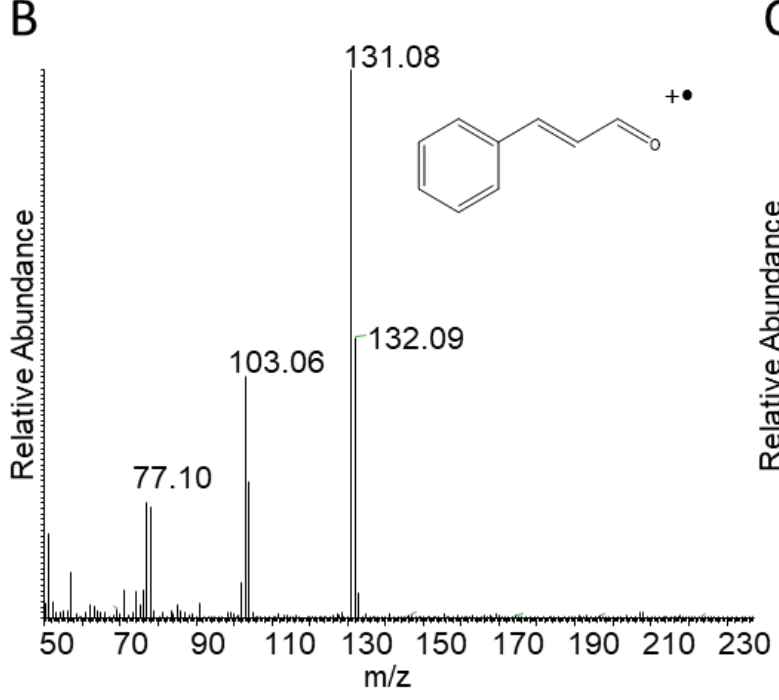

C



Figure S30. Chemical reductive sulfidation of cinnamaldehyde. A-GC-MS-2 extracted ion chromatograms at the initial reaction time (T0), after the sulfidation step using $\mathrm{P}_{4} \mathrm{~S}_{10}(\mathrm{~T} 1=12 \mathrm{~h})$, and after the reduction step using $\mathrm{NaBD}_{4}$ $(\mathrm{T} 2=12 \mathrm{~h})$. B-Mass spectrum of cinnamaldehyde. C-Mass spectrum of 3-phenylprop-2-ene-1-thiol. Each mass spectrum came from GC-EI-MS analysis (positive mode). 
A

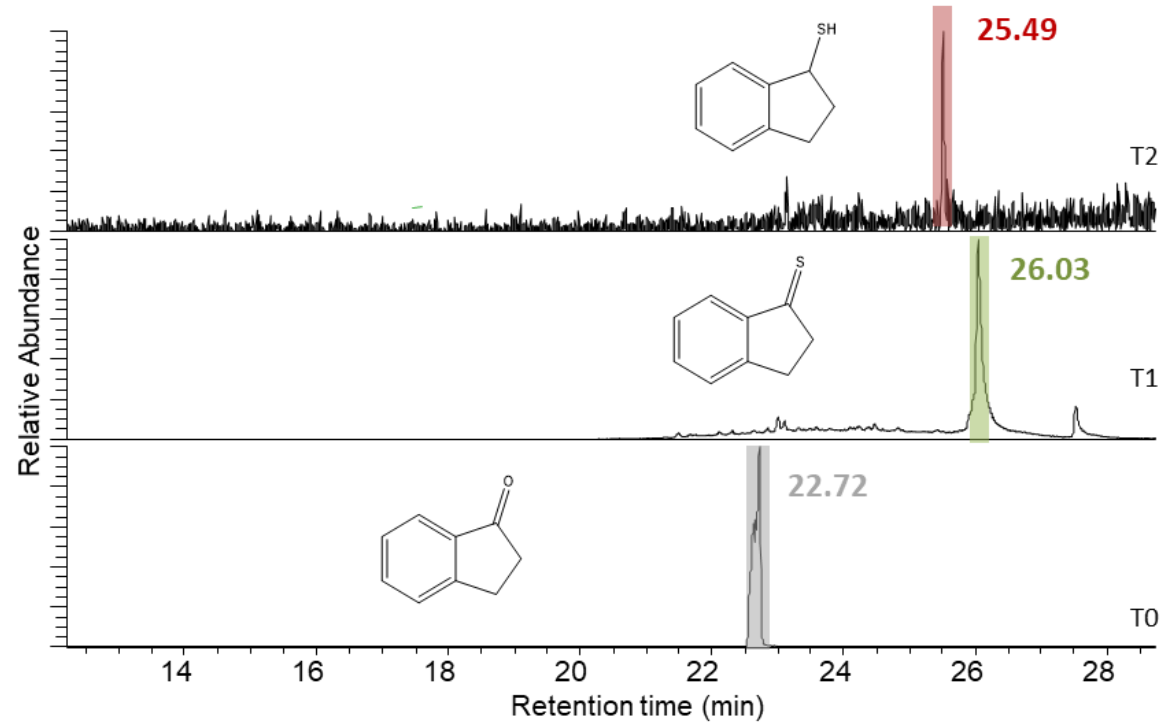

B

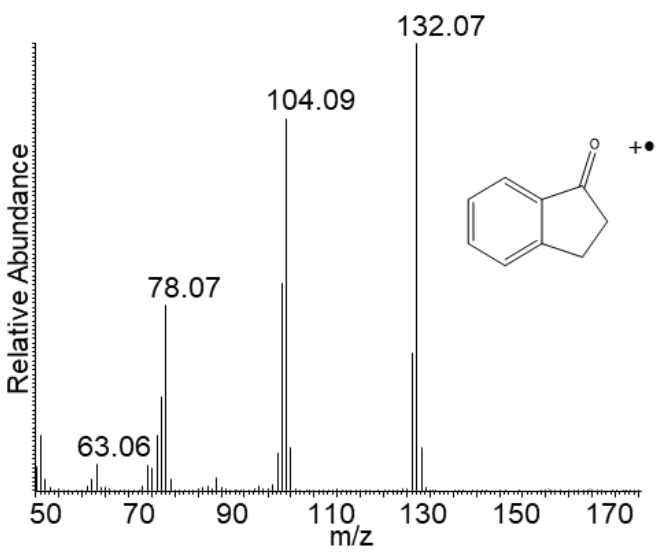

D

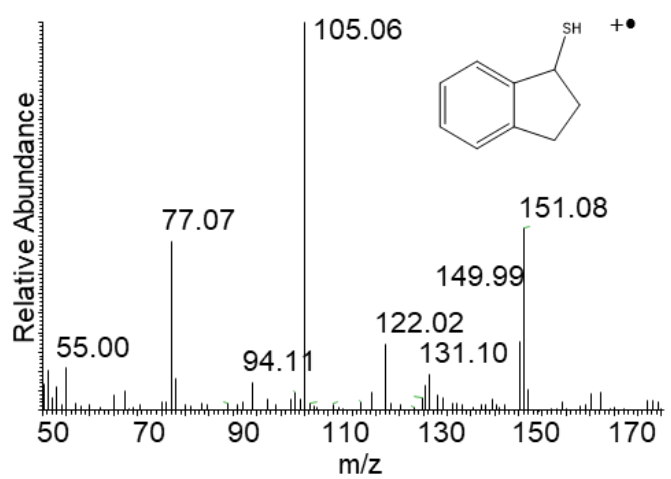

C

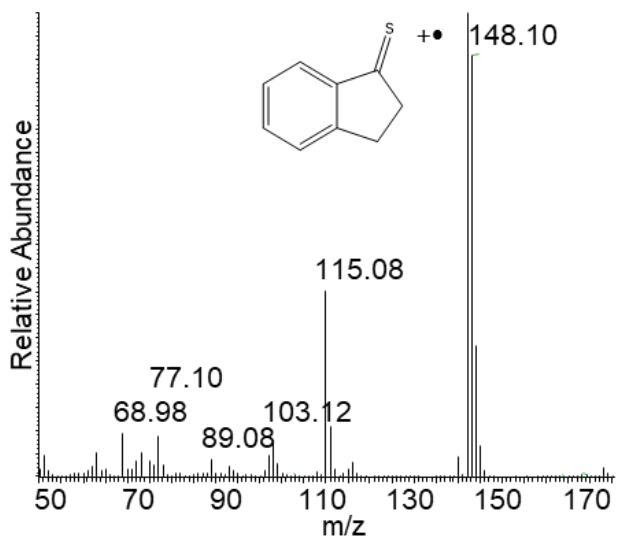

Figure S31. Chemical reductive sulfidation of indane-1-one. A-GC-MS-2 extracted ion chromatograms at the initial reaction time (T0), after the sulfidation step using $\mathrm{P}_{4} \mathrm{~S}_{10}(\mathrm{~T} 1=12 \mathrm{~h})$, and after the reduction step using $\mathrm{NaBD}_{4}$ $(\mathrm{T} 2=12 \mathrm{~h})$. B-Mass spectrum of indane-1-one. C-Mass spectrum indane-1-thione. D- Mass spectrum indane-1thiol. Each mass spectrum came from GC-EI-MS analysis (positive mode). 


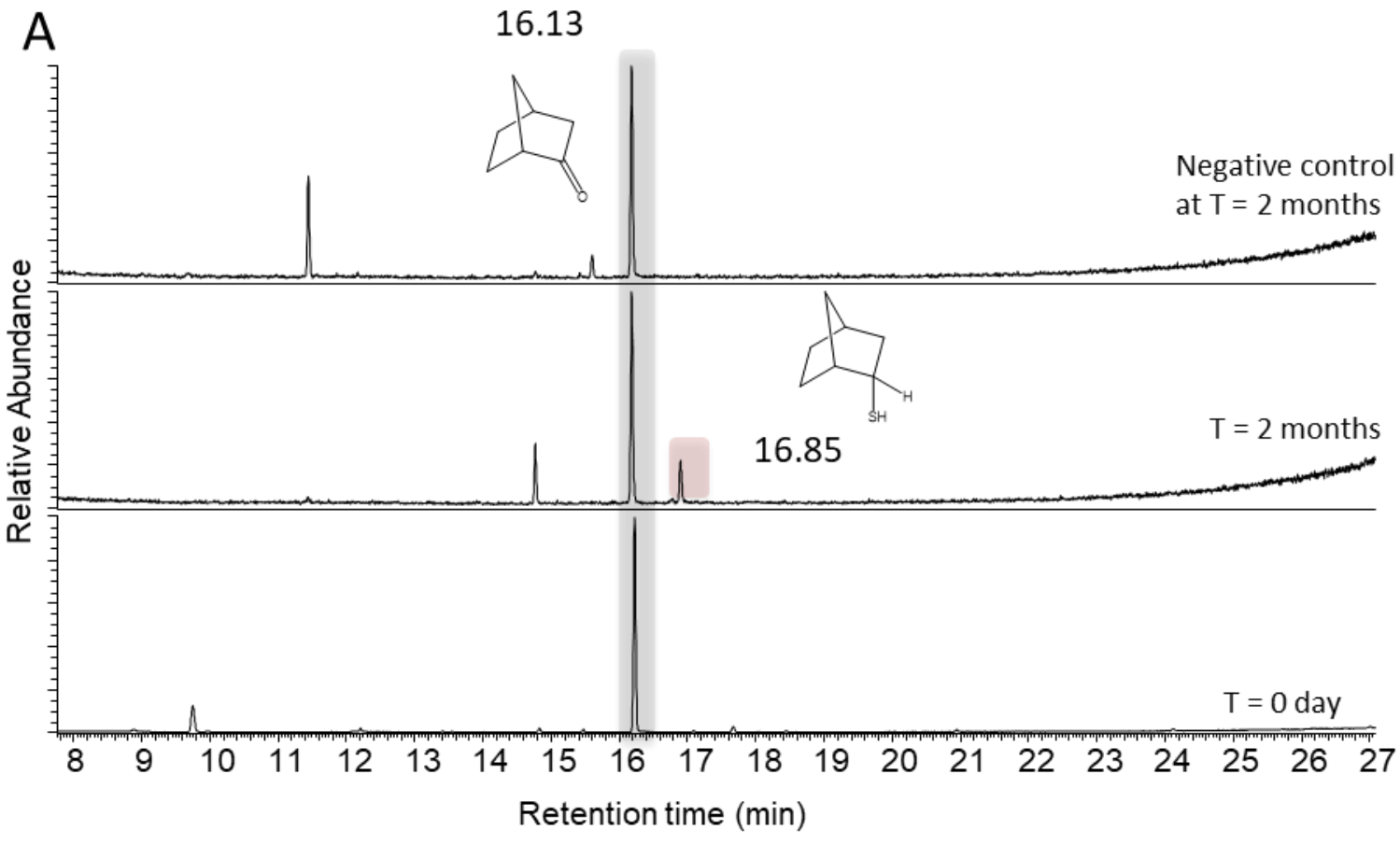

B

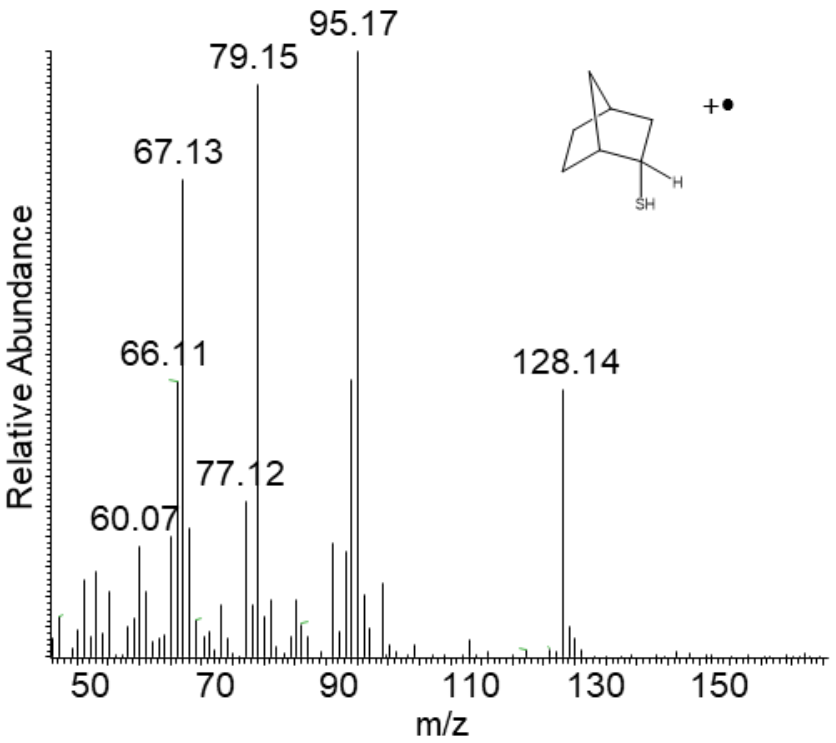

Figure S32. Bacterial reductive sulfidation of norcamphor. A-HS-GC-MS-2 chromatograms at the initial incubation time $(T=0)$, after 2-month incubation and the negative control (without bacteria) after 2-month incubation. B-Mass spectrum of norcamphorthiol ( $\mathrm{rt}=16.85 \mathrm{~min}$ ). Each mass spectrum came from GC-EI-MS analysis (positive mode). 
A



B

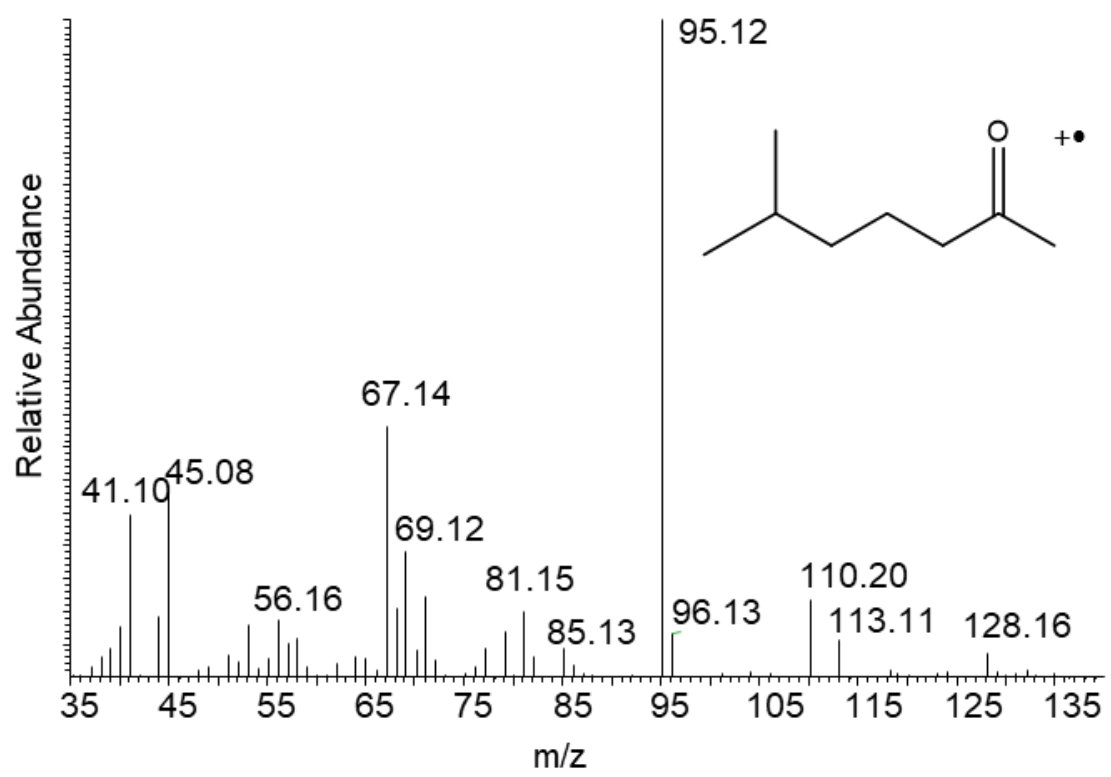

Figure S33. Bacterial reductive sulfidation of 6-methylhept-5-en-2-one. A-HS-GC-MS-2 chromatograms at the initial incubation time ( $\mathrm{T}=0$ ), after 2-month incubation and the negative control (without bacteria) after 2-month incubation. B-Mass spectrum of 6-methylheptane-2-one. Each mass spectrum came from GC-EI-MS analysis (positive mode). 
A

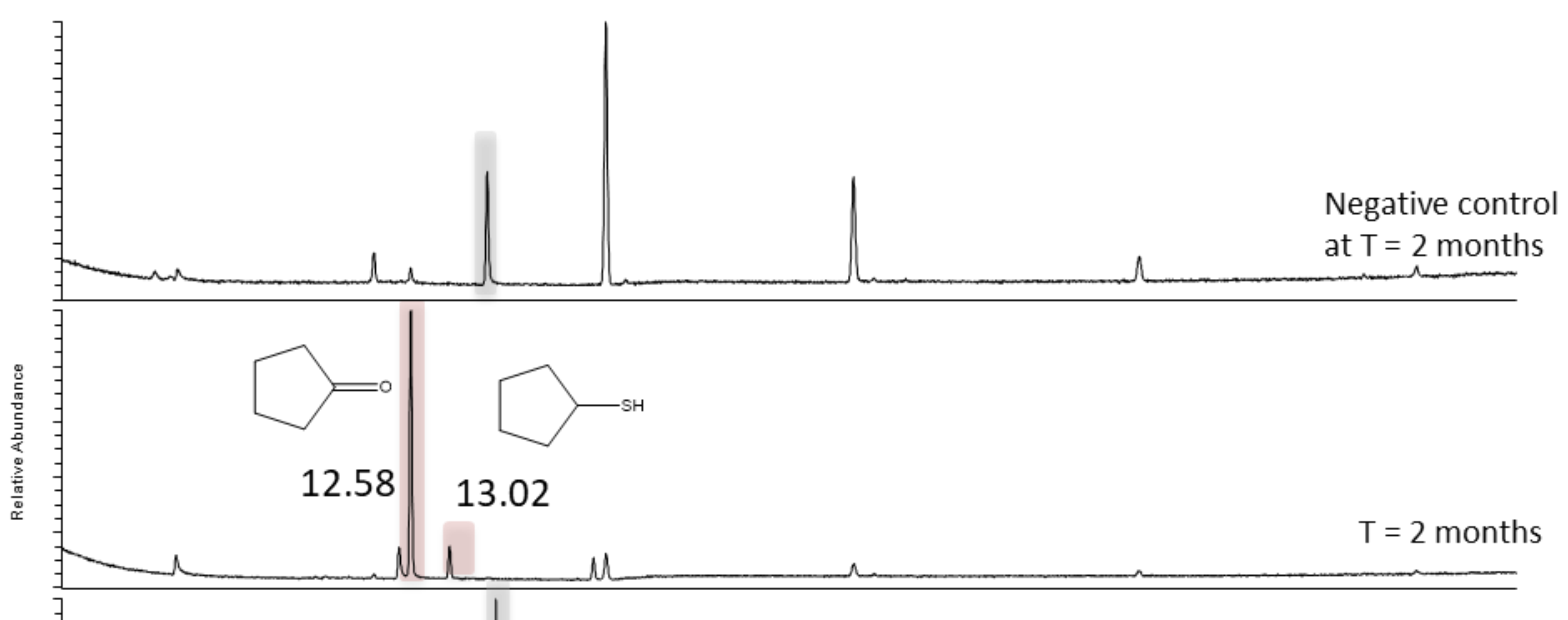

13.51

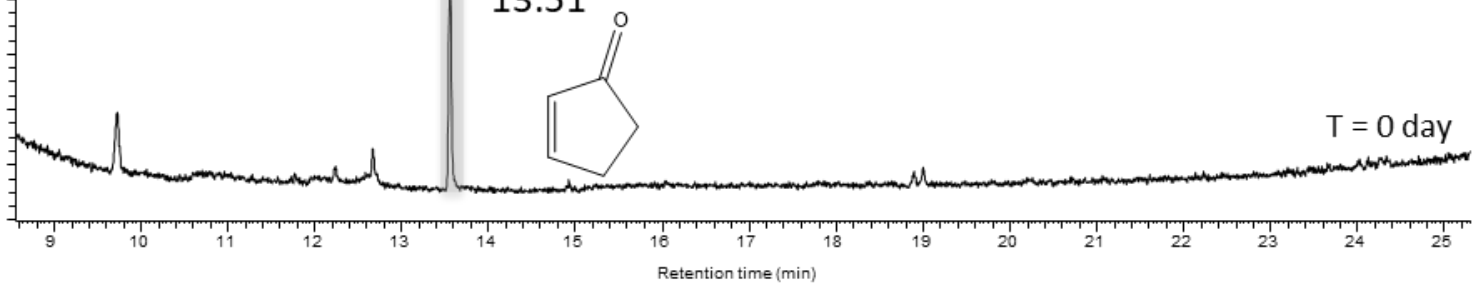

B

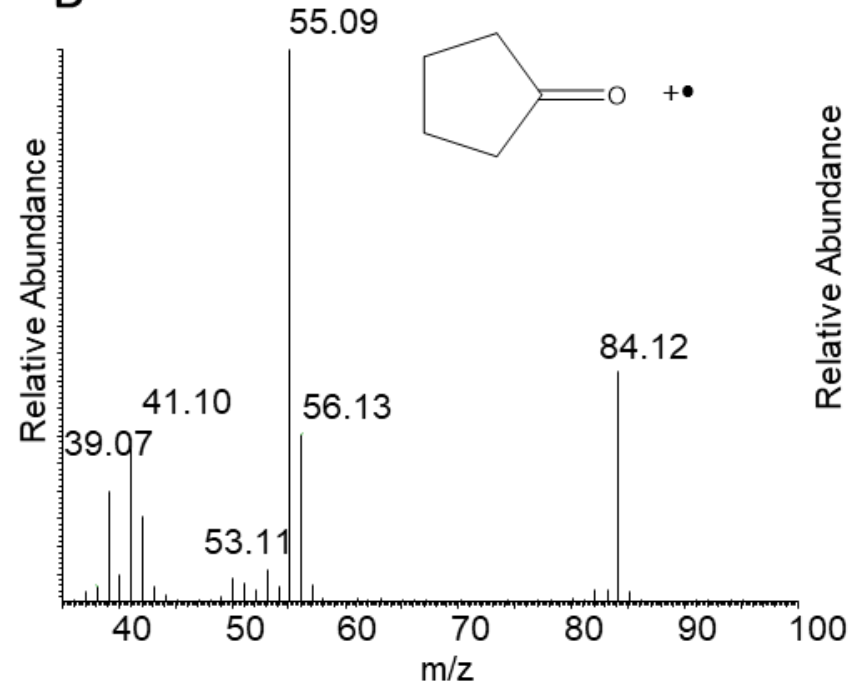

C

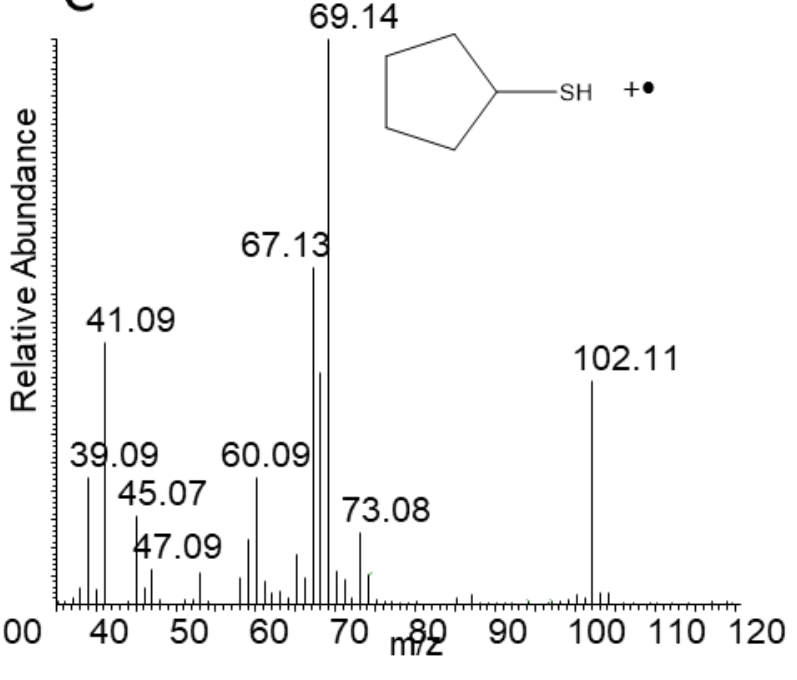

Figure S34. Bacterial reductive sulfidation of cyclopent-2-en-1-one. A-HS-GC-MS-2 chromatograms at the initial incubation time $(T=0)$, after 2-month incubation and the negative control (without bacteria) after 2-month incubation. B-Mass spectrum of cyclopentanone. C-Mass spectrum of cyclopentanethiol. Each mass spectrum came from GC-EI-MS analysis (positive mode). 




B

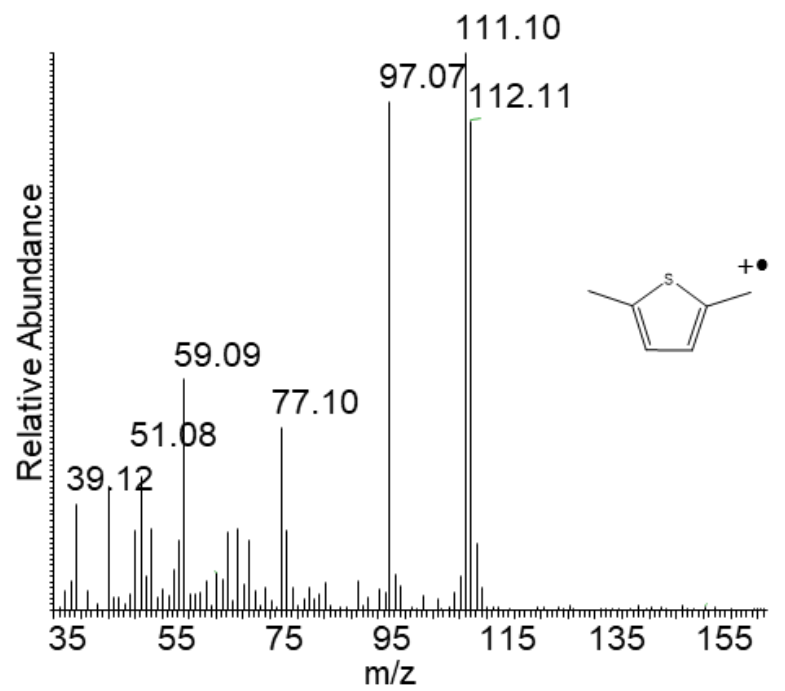

Figure S35. Bacterial reductive sulfidation of hexane-2,5-dione. A-HS-GC-MS-2 chromatograms at the initial incubation time $(T=0)$, after 2-month incubation and the negative control (without bacteria) after 2-month incubation. B-Mass spectrum of dimethylthiophene. Each mass spectrum came from GC-EI-MS analysis (positive mode). 


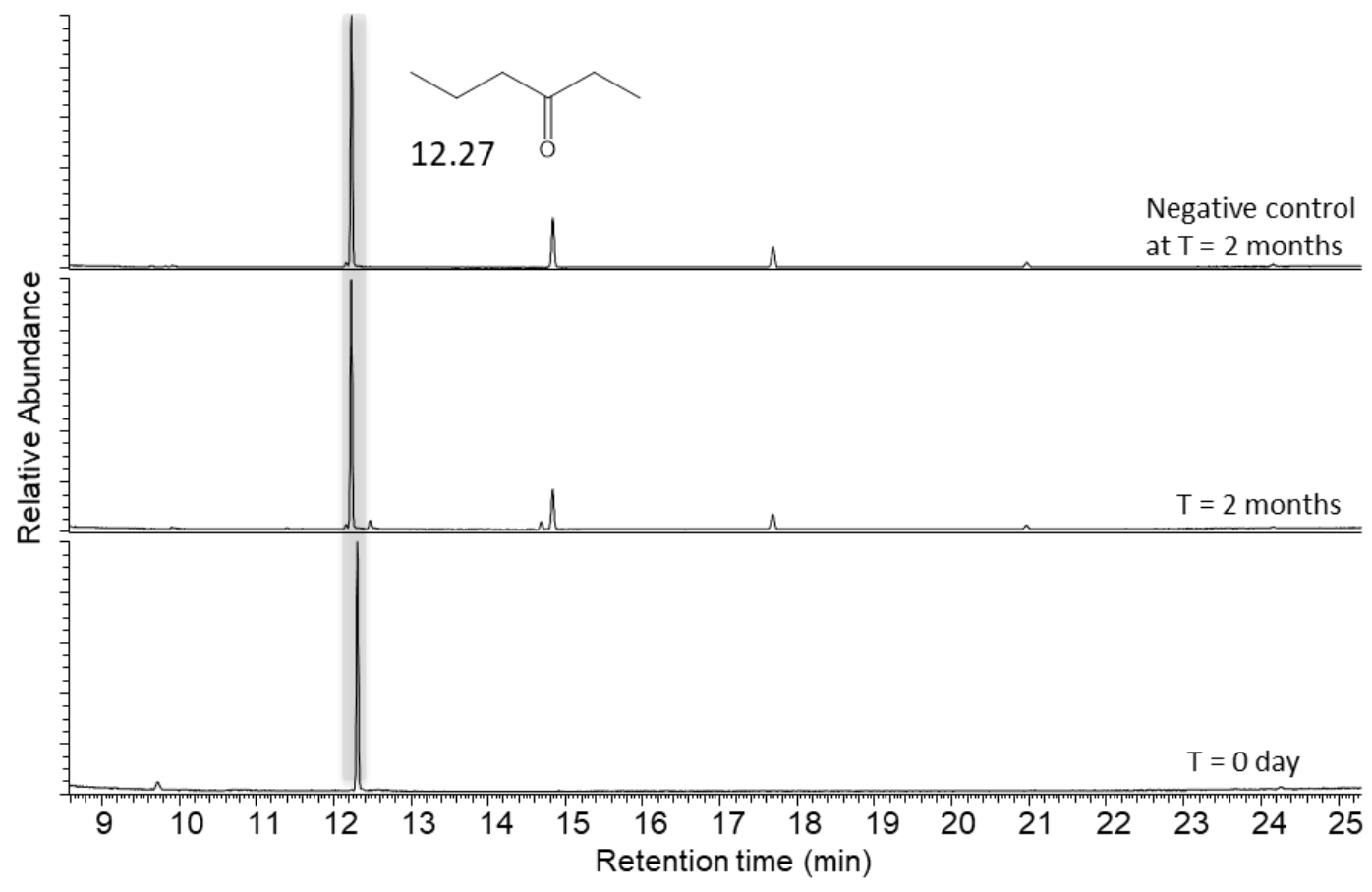

Figure S36. Bacterial reductive sulfidation of hexane-3-one. HS-GC-MS chromatograms at the initial incubation time $(T=0)$, after 2-month incubation and the negative control (without bacteria) after 2-month incubation. 


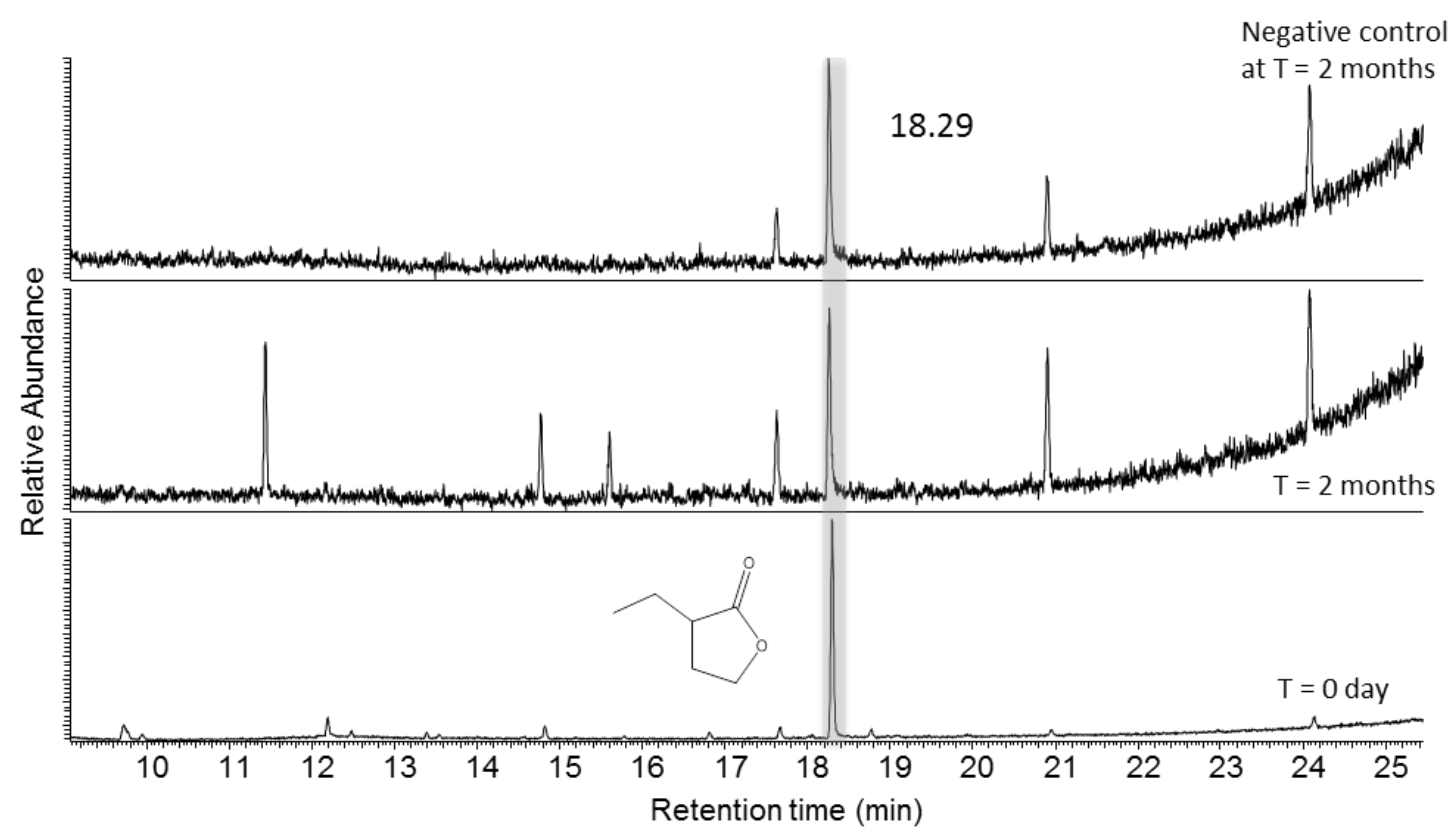

Figure S37. Bacterial reductive sulfidation of 3-ethyldihydrofuran-2(3H)-one. HS-GC-MS-2 chromatograms at the initial incubation time $(T=0)$, after 2-month incubation and the negative control (without bacteria) after 2-month incubation. 

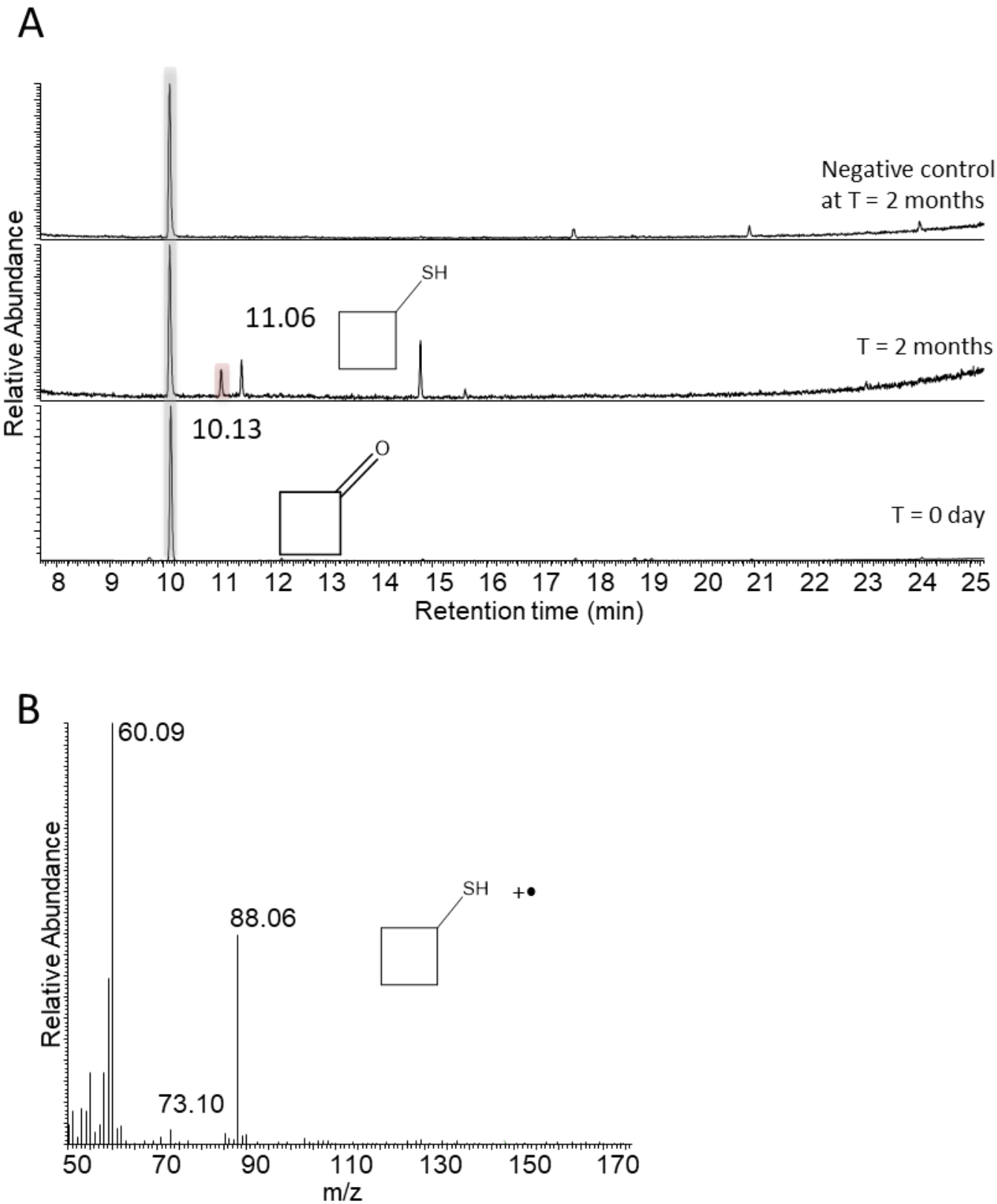

Figure S38. Bacterial reductive sulfidation of cyclobutanone. A-HS-GC-MS-2 chromatograms at the initial incubation time $(T=0)$, after 2-month incubation and the negative control (without bacteria) after 2-month incubation. B-Mass spectrum of cyclobutanethiol. Each mass spectrum came from GC-EI-MS analysis (positive mode). 



Figure S39. Bacterial reductive sulfidation of cyclopentanone. A-HS-GC-MS-2 chromatograms at the initial incubation time $(T=0)$, after 2-month incubation and the negative control (without bacteria) after 2-month incubation. B-Mass spectrum of cyclopentanethiol. Each mass spectrum came from GC-EI-MS analysis (positive mode). 

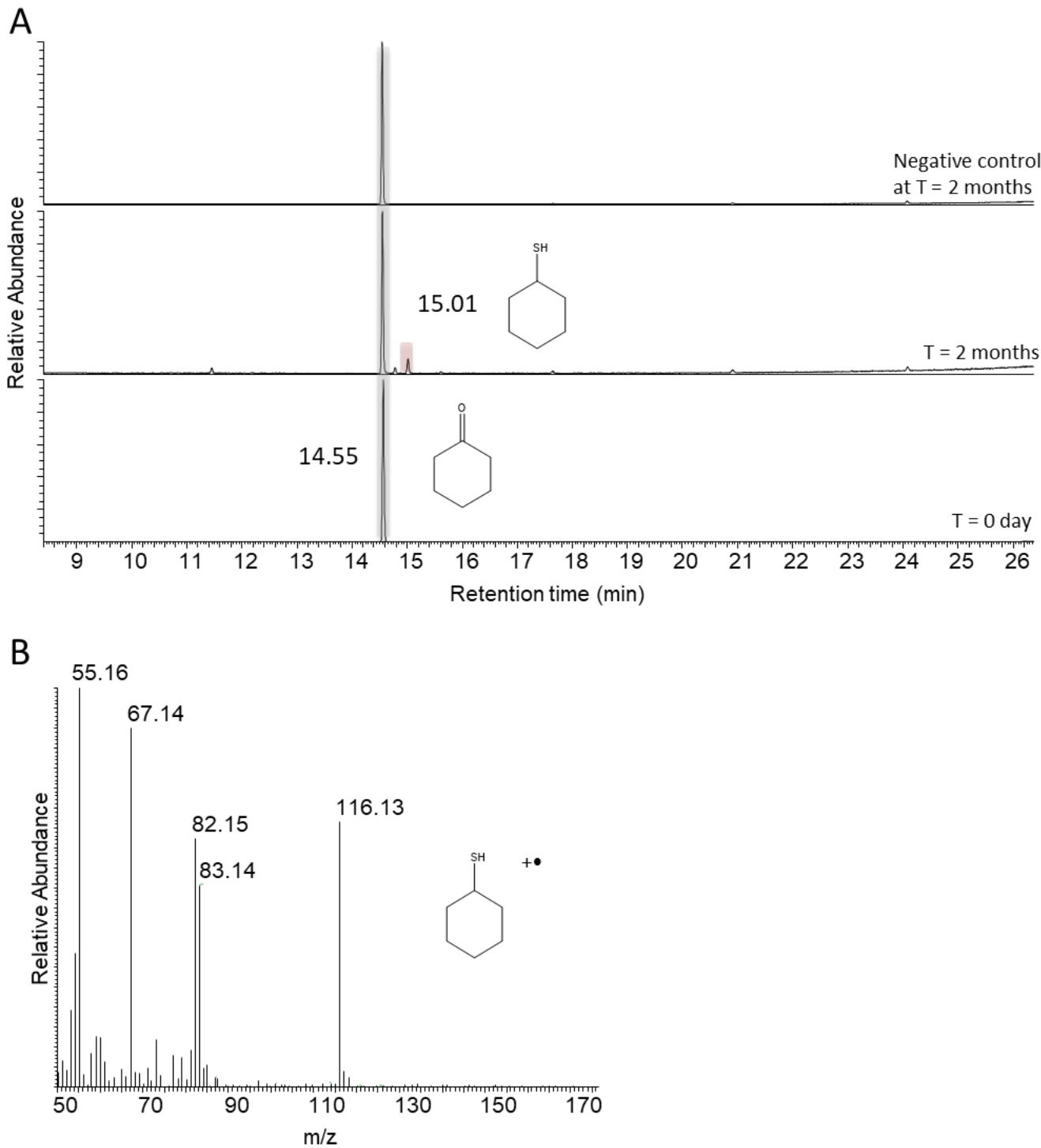

Figure S40. Bacterial reductive sulfidation of cyclohexanone. A-HS-GC-MS-2 chromatograms at the initial incubation time $(T=0)$, after 2-month incubation and the negative control (without bacteria) after 2-month incubation. B-Mass spectrum of cyclohexanethiol. Each mass spectrum came from GC-EI-MS analysis (positive mode). 


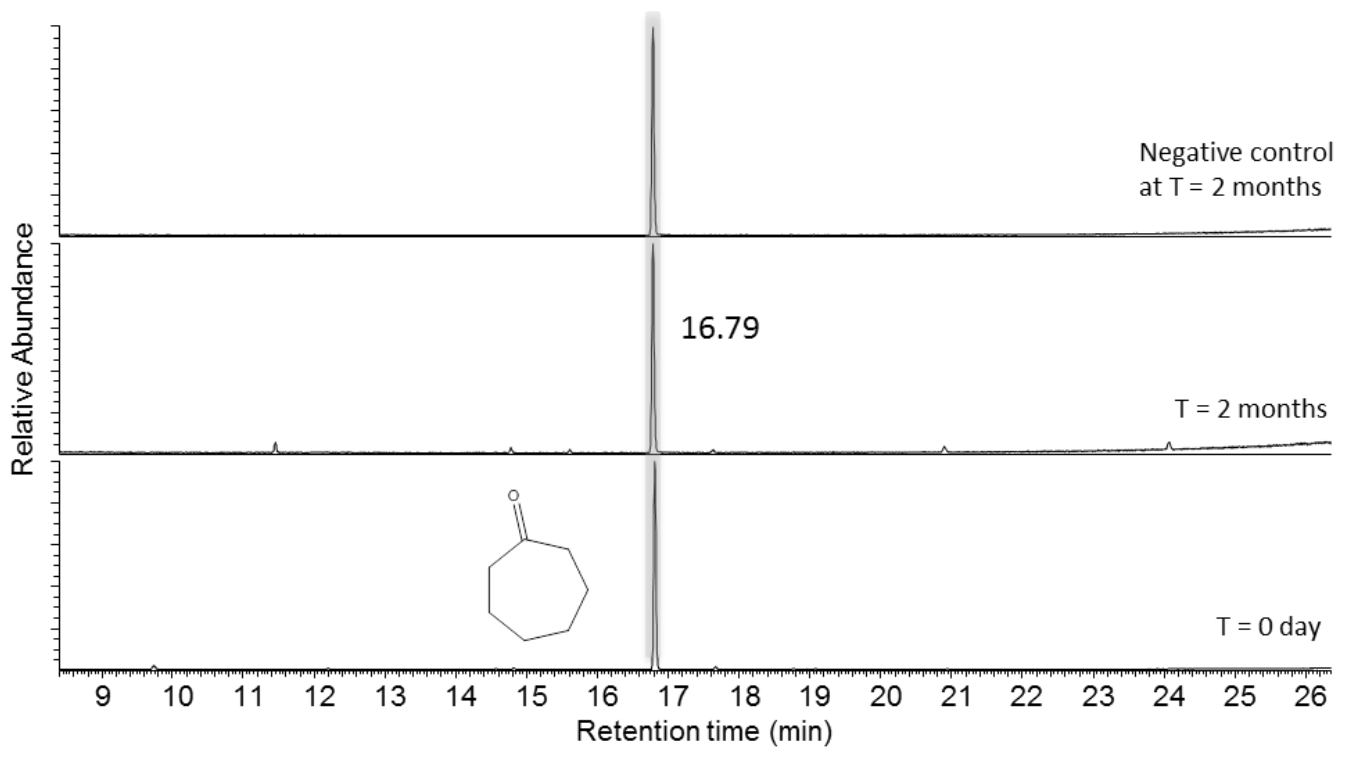

Figure S41. Bacterial reductive sulfidation of cycloheptanone. HS-GC-MS-2 chromatograms at the initial incubation time $(T=0)$, after 2-month incubation and the negative control (without bacteria) after 2-month incubation. 
A

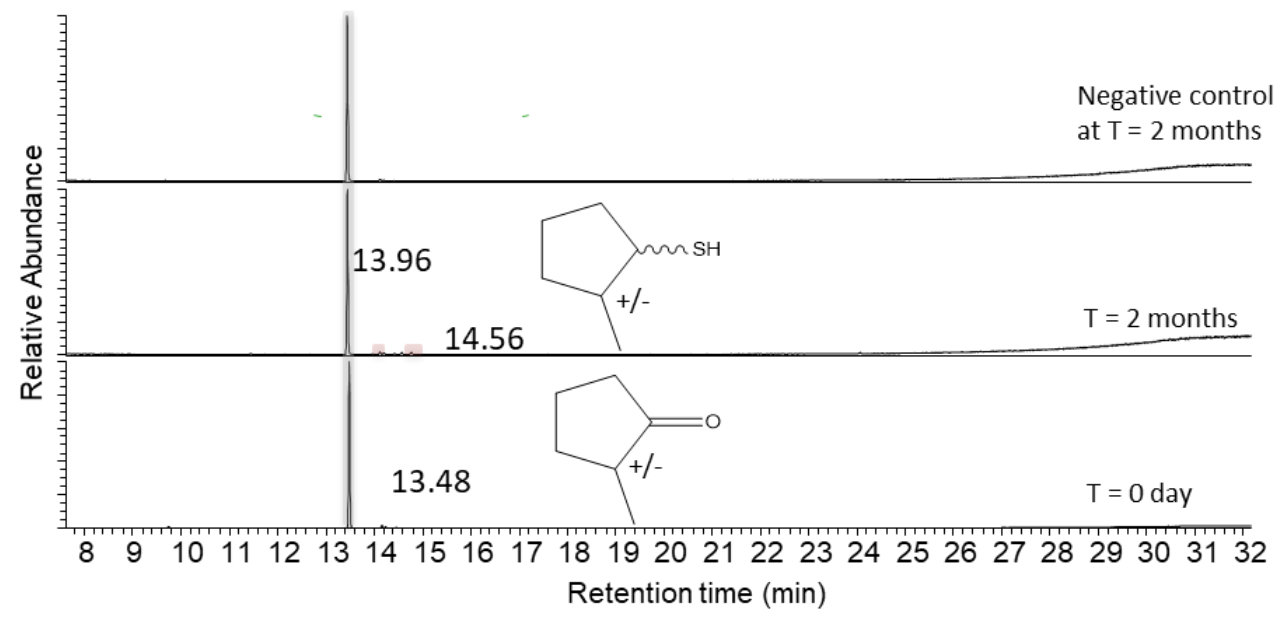

B

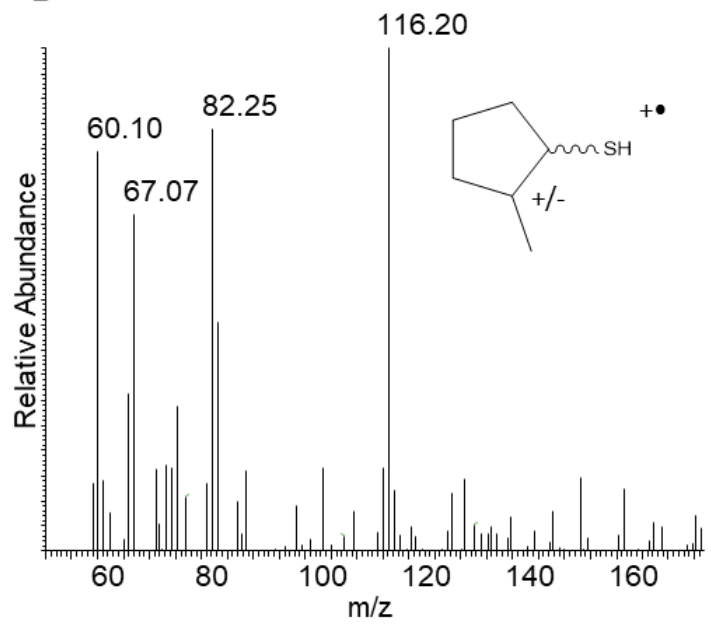

C

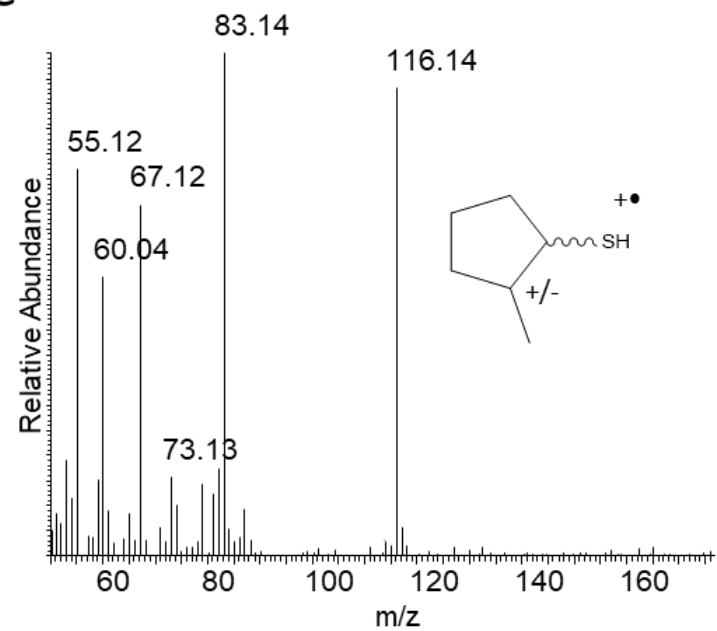

Figure S42. Bacterial reductive sulfidation of 2-methylcyclopentan-1-one. A-HS-GC-MS-2 chromatograms at the initial incubation time $(T=0)$, after 2-month incubation and the negative control (without bacteria) after 2-month incubation. B-Mass spectrum of 2-methylcyclopentan-1-thiol ( $\mathrm{rt}=13.96 \mathrm{~min}$ ). C- Mass spectrum of 2methylcyclopentan-1-thiol ( $r t=14.56 \mathrm{~min}$ ). Each mass spectrum came from GC-El-MS analysis (positive mode). 


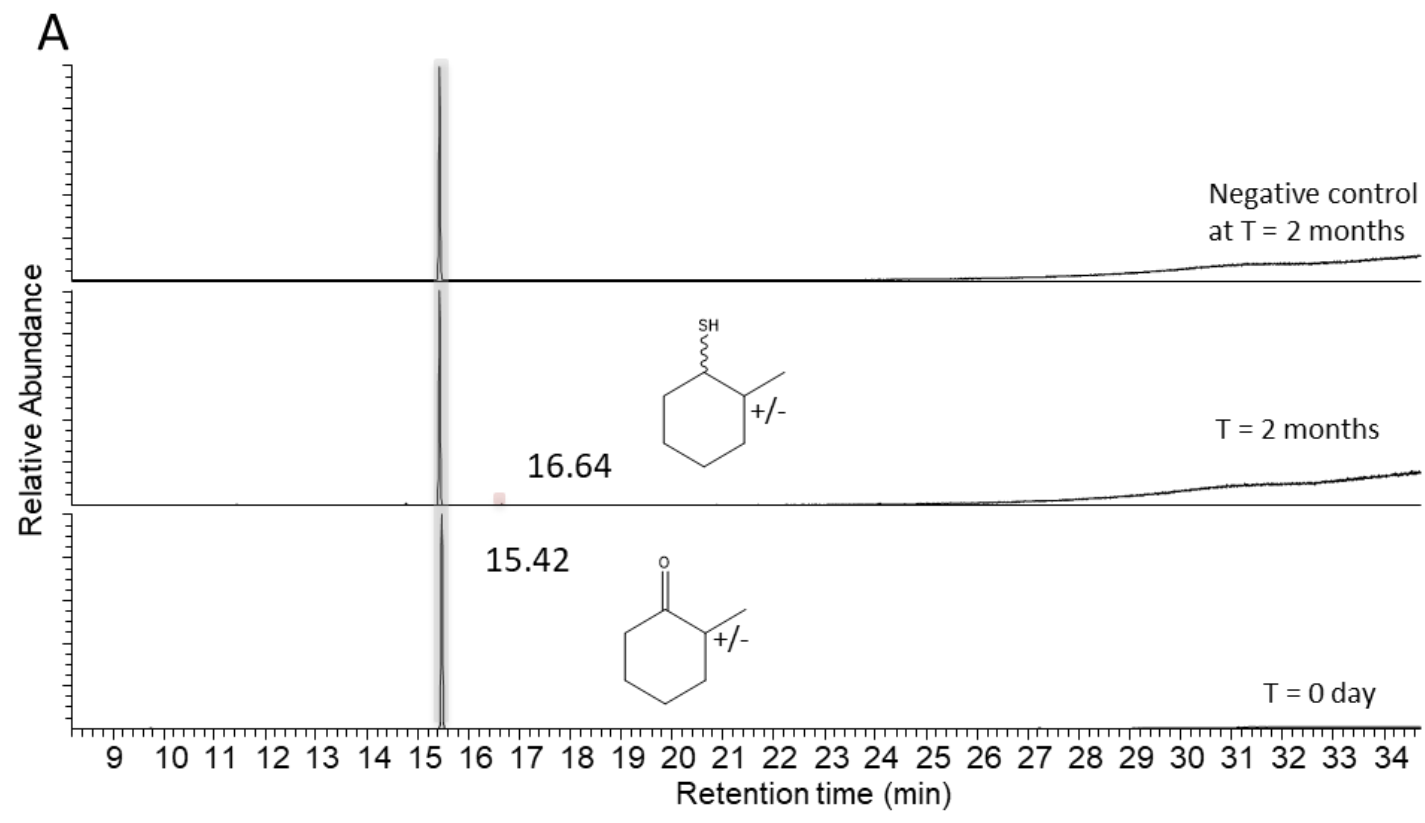

B

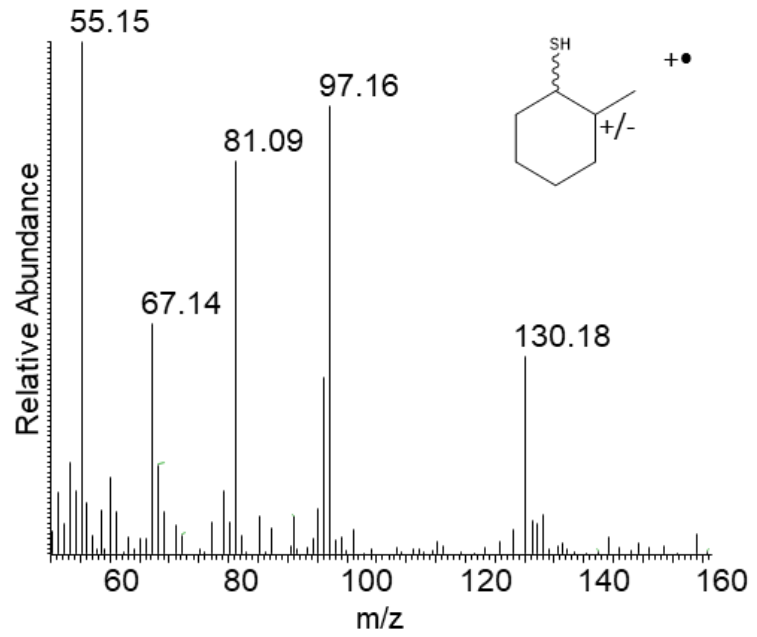

Figure S43. Bacterial reductive sulfidation of 2-methylcyclohexan-1-one. A-HS-GC-MS-2 chromatograms at the initial incubation time $(T=0)$, after 2-month incubation and the negative control (without bacteria) after 2-month incubation. B-Mass spectrum of 2-methylcyclohexan-1-thiol. Each mass spectrum came from GC-EI-MS analysis (positive mode). 


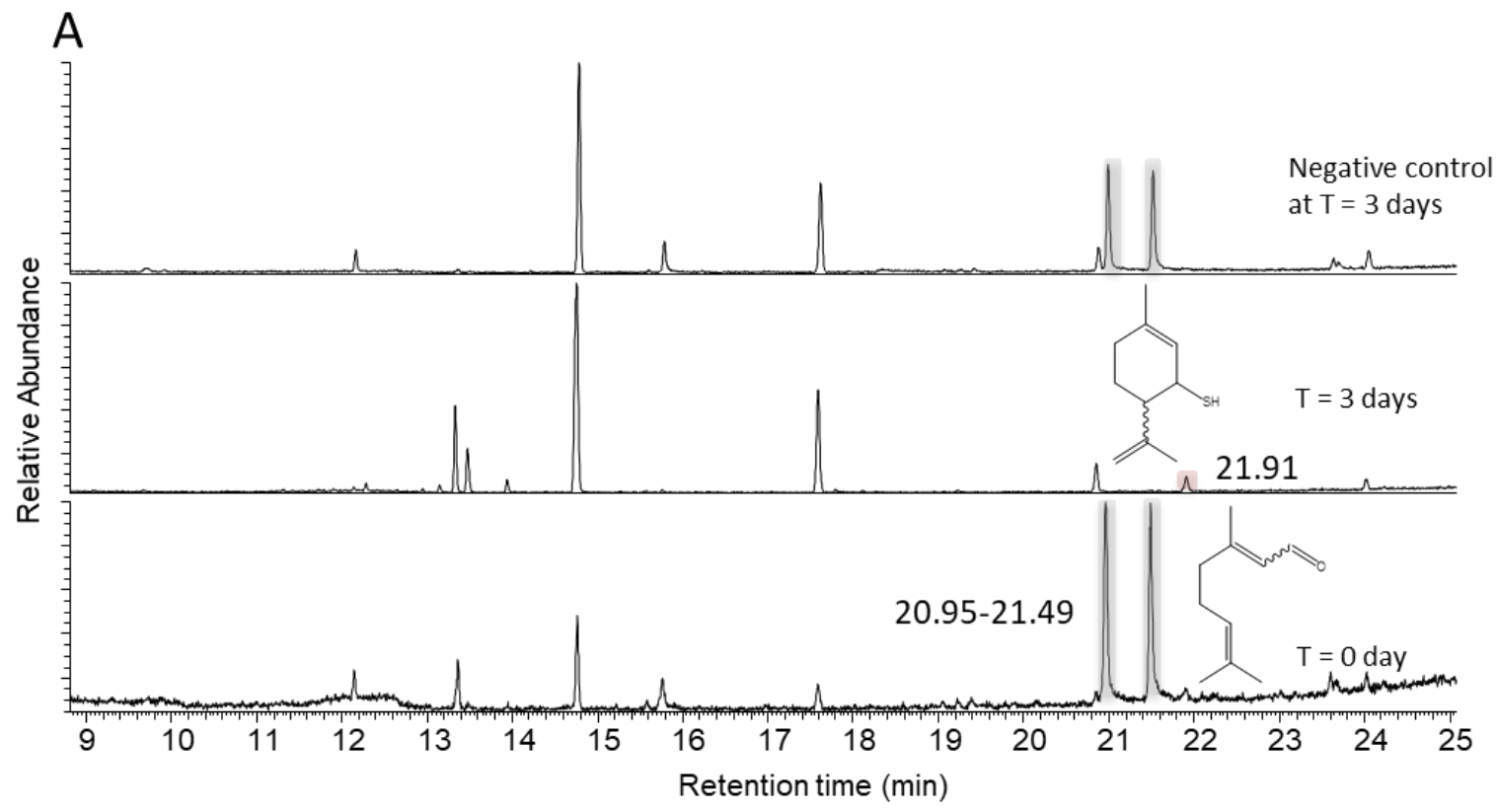

B

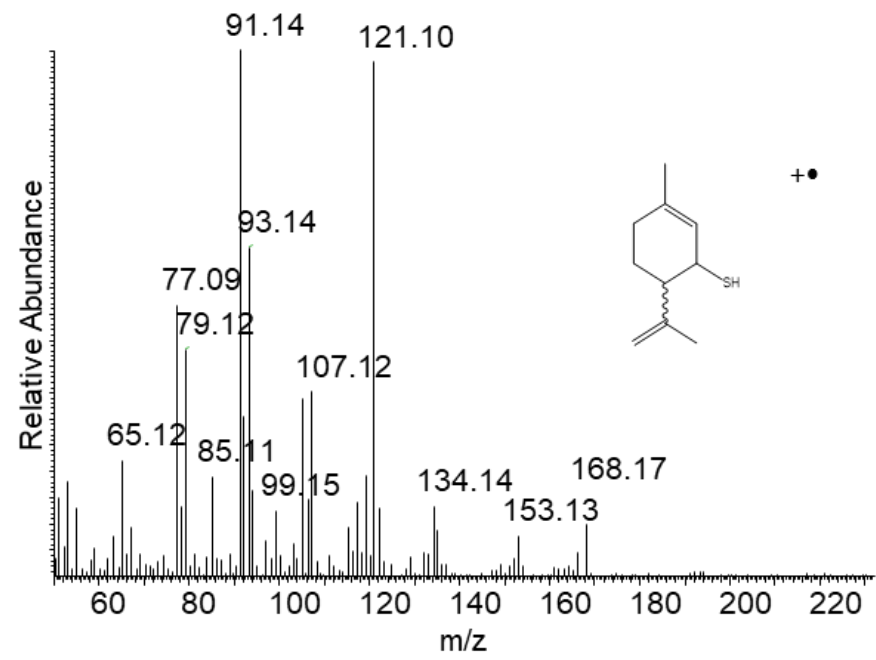

Figure S44. Bacterial reductive sulfidation of citral. A-HS-GC-MS-2 chromatograms at the initial incubation time $(T=0)$, after 3-day incubation and the negative control (without bacteria) after 3-day incubation. B-Mass spectrum of 3-methyl-6-(prop-1-en-2-yl)cyclohex-2-ene-1-thiol. Each mass spectrum came from GC-EI-MS analysis (positive mode). 
A
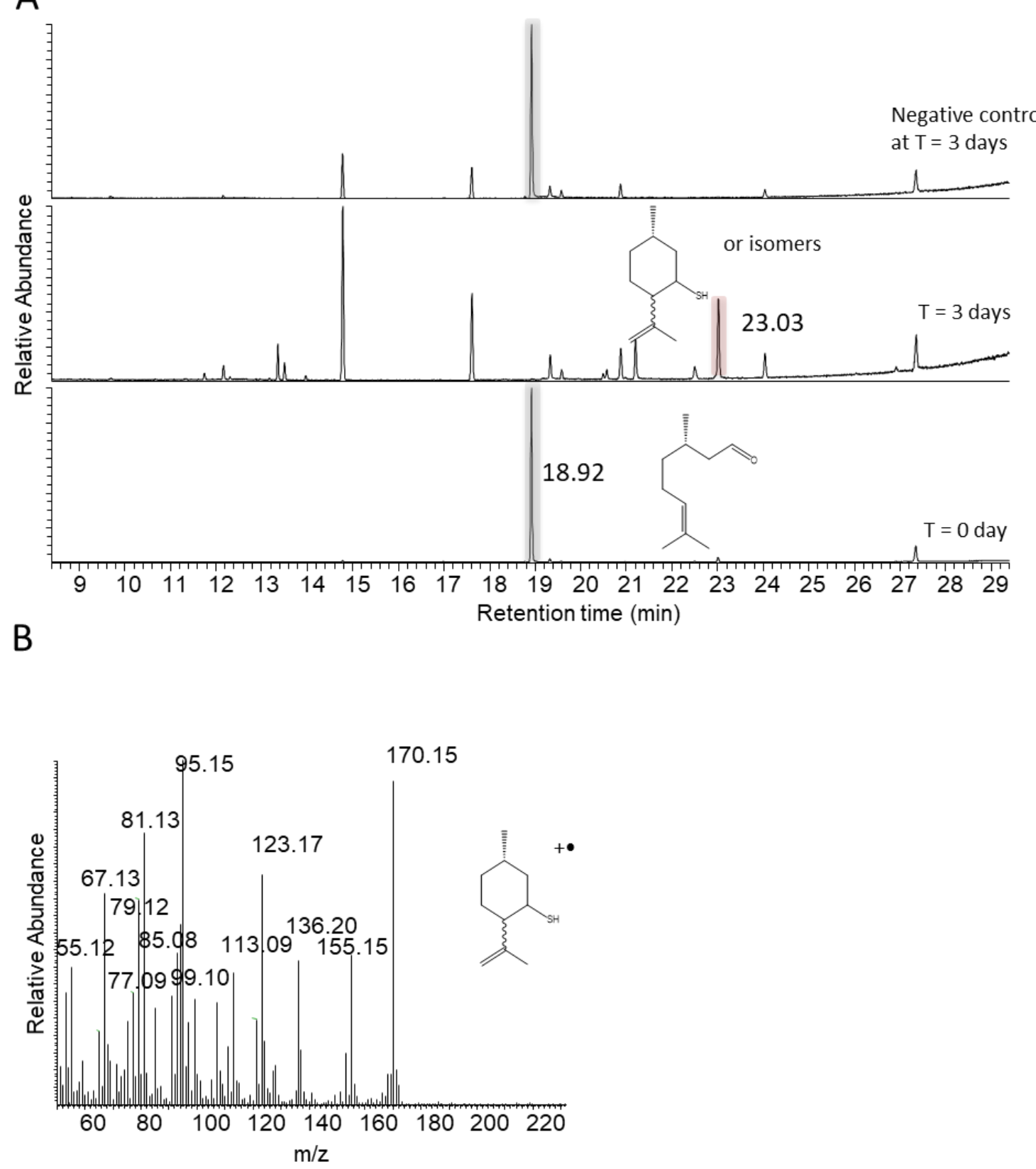

Figure S45. Bacterial reductive sulfidation of (S)-citronellal. A-HS-GC-MS-2 chromatograms at the initial incubation time $(T=0)$, after 3-day incubation and the negative control (without bacteria) after 3-day incubation. B-Mass spectrum of (5S)-5-methyl-3-(prop-1-en-2-yl)cyclohexane-1-thiol. Each mass spectrum came from GC-EIMS analysis (positive mode). 
A



B

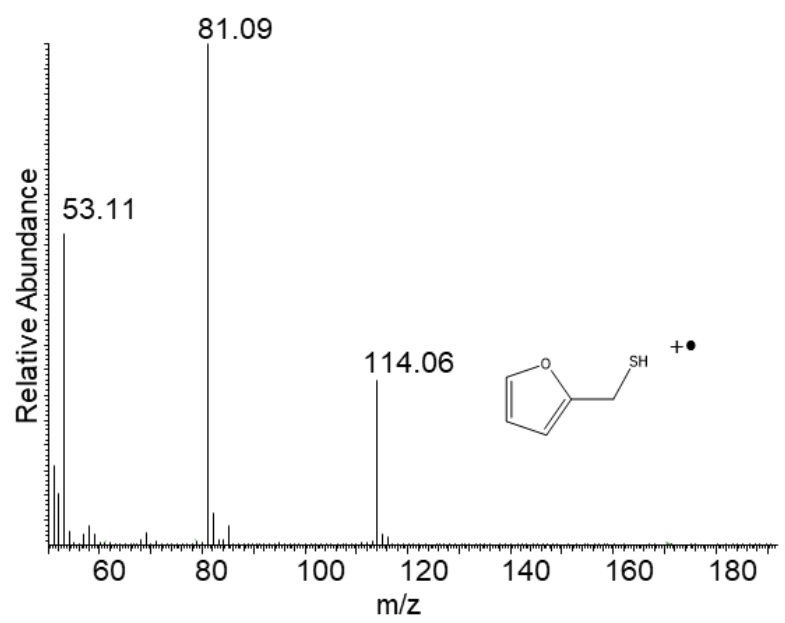

Figure S46. Bacterial reductive sulfidation of furfural. A-HS-GC-MS-2 chromatograms at the initial incubation time $(T=0)$, after 3-day incubation and the negative control (without bacteria) after 3-day incubation. B-Mass spectrum of furan-2-ylmethanethiol. Each mass spectrum came from GC-EI-MS analysis (positive mode). 
A
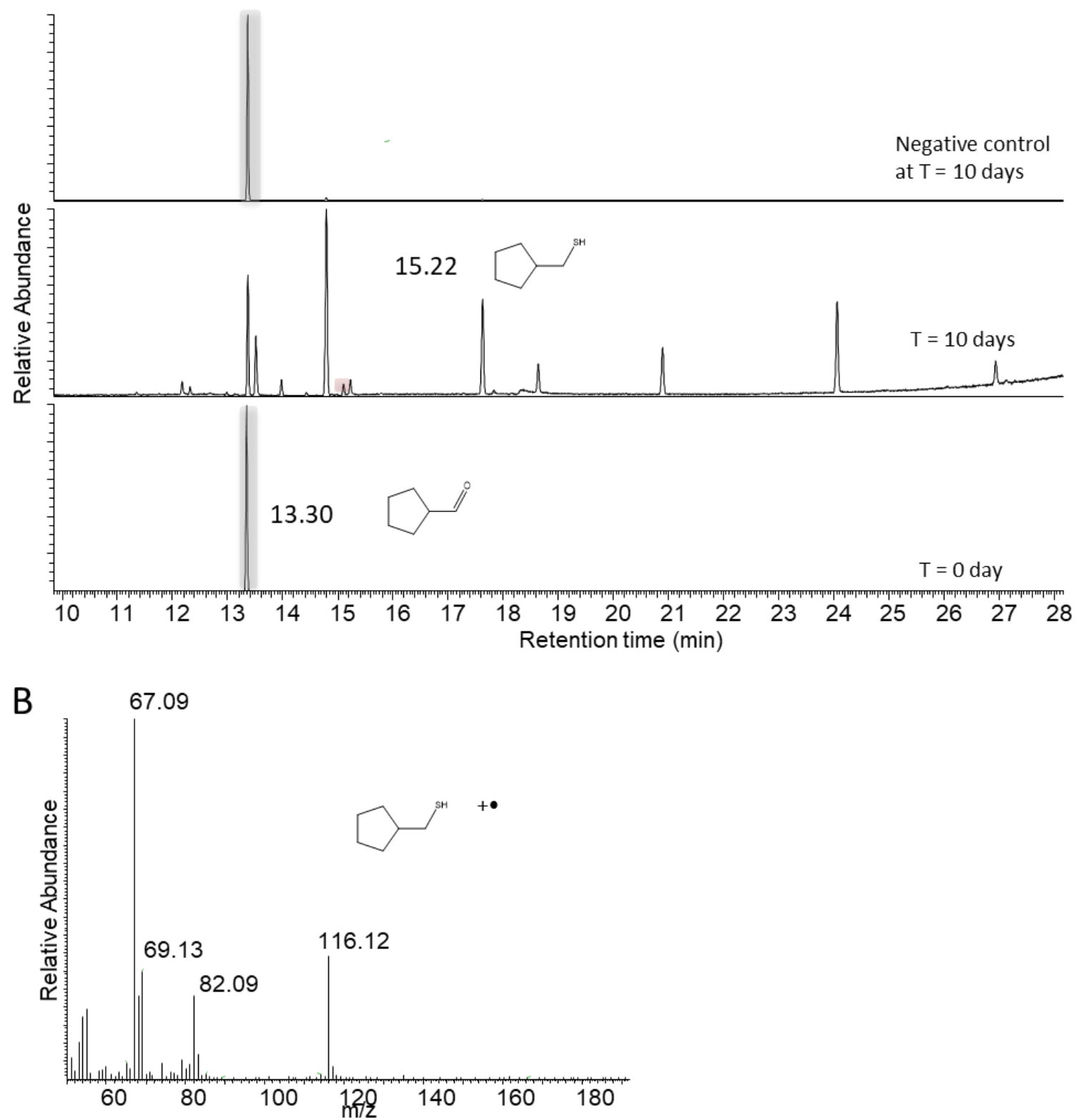

Figure S47. Bacterial reductive sulfidation of cyclopentanecarbaldehyde. A-HS-GC-MS-2 chromatograms at the initial incubation time $(T=0)$, after 10-day incubation and the negative control (without bacteria) after 10-day incubation. B-Mass spectrum of cyclopentylmethanethiol. Each mass spectrum came from GC-EI-MS analysis (positive mode). 


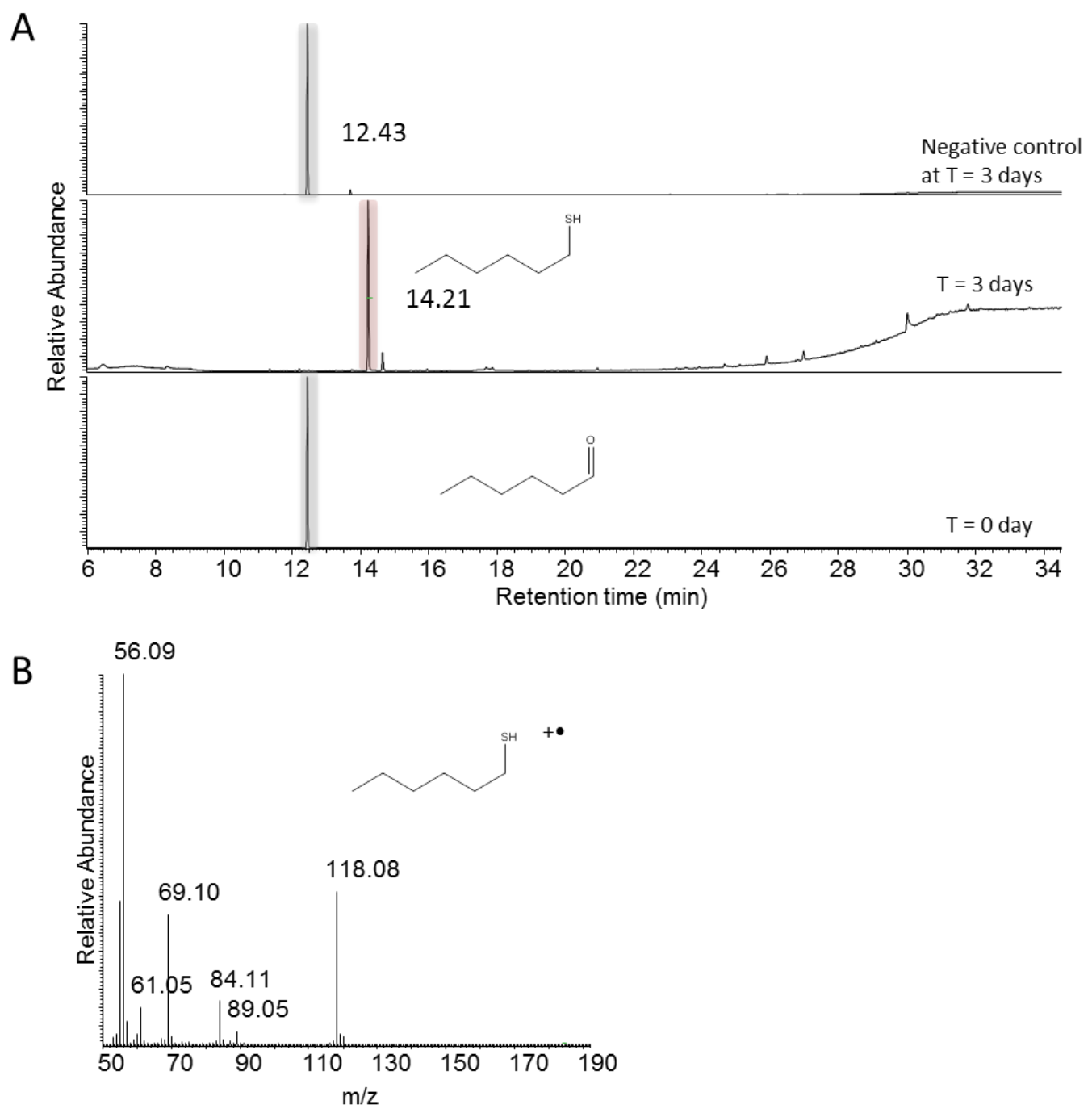

Figure S48. Bacterial reductive sulfidation of hexanal. A-HS-GC-MS-2 chromatograms at the initial incubation time $(T=0)$, after 3-day incubation and the negative control (without bacteria) after 3-day incubation. B-Mass spectrum of hexanethiol. Each mass spectrum came from GC-EI-MS analysis (positive mode). 
A

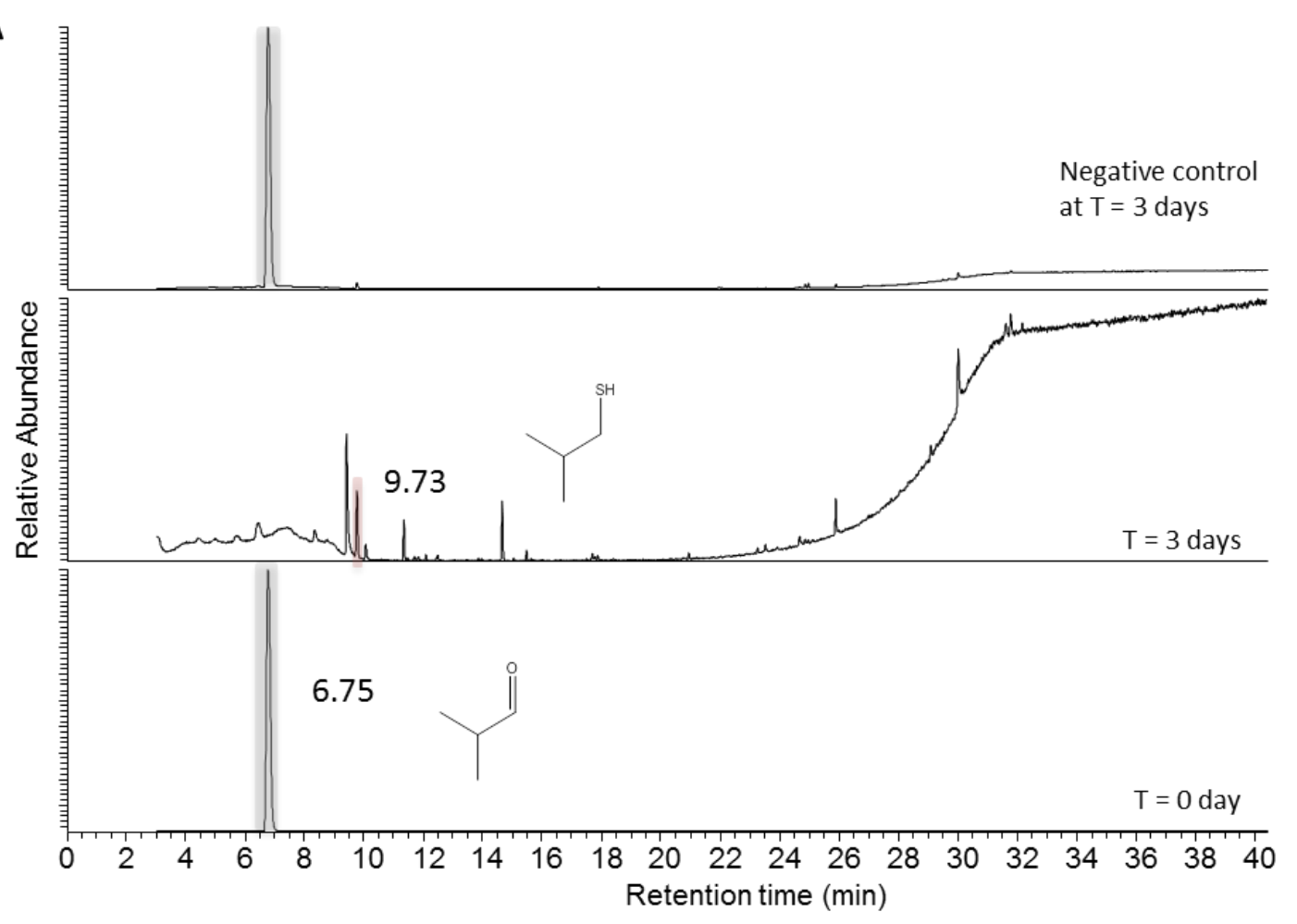

B

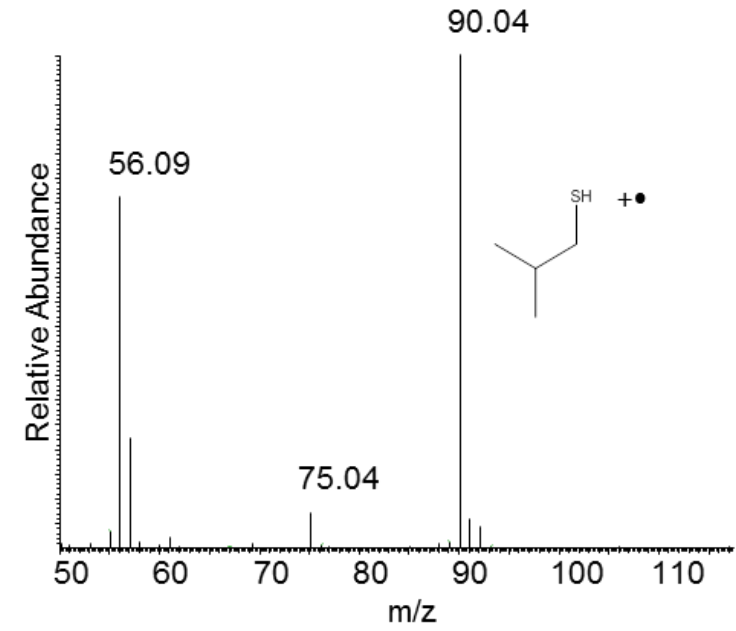

Figure S49. Bacterial reductive sulfidation of isobutyraldehyde. A-HS-GC-MS-2 chromatograms at the initial incubation time $(T=0)$, after 3-day incubation and the negative control (without bacteria) after 3-day incubation. B-Mass spectrum of 2-methylpropan-1-thiol. Each mass spectrum came from GC-EI-MS analysis (positive mode). 

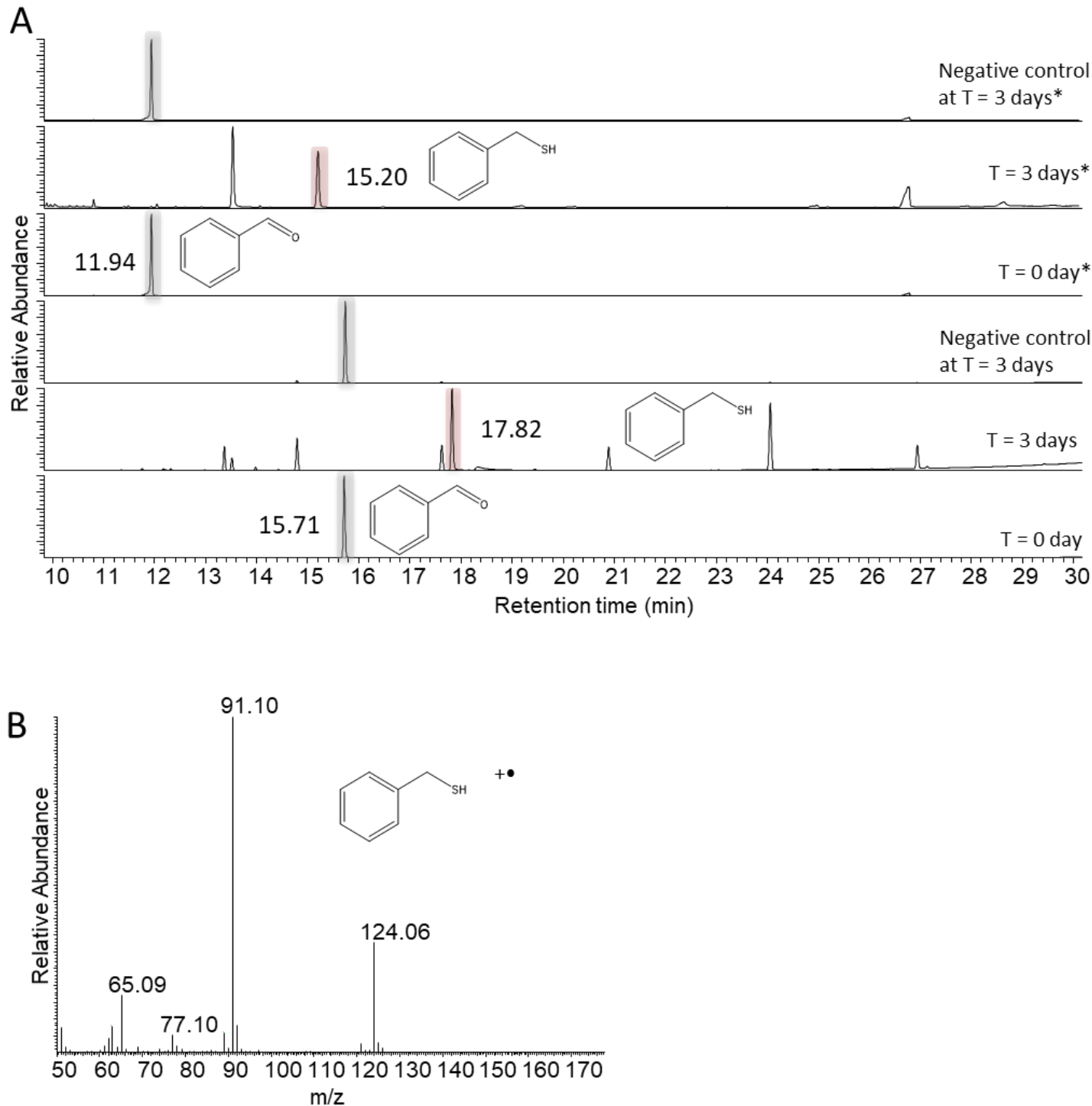

Figure S50. Bacterial reductive sulfidation of benzaldehyde. A-HS-GC-MS chromatograms (obtained with method HS-GC-MS-2) at the initial incubation time $(T=0)$, after 3-day incubation and the negative control (without bacteria) after 3-day incubation. * show the same results with method GC-MS-2. B-Mass spectrum of phenylmethanethiol. Each mass spectrum came from GC-EI-MS analysis (positive mode). 


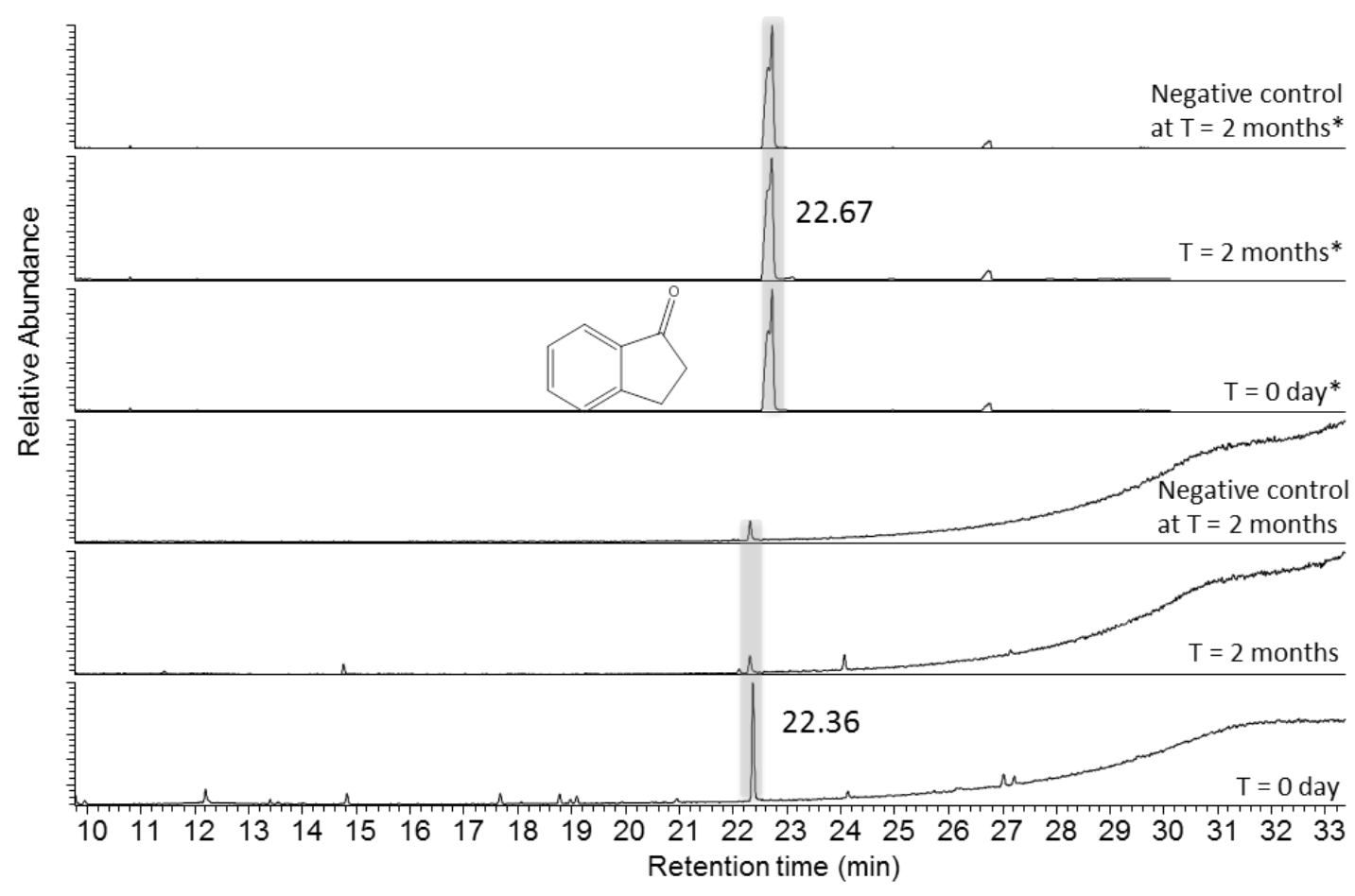

Figure S51. Bacterial reductive sulfidation of indane-1-one. A-HS-GC-MS chromatograms (obtained with method HS-GC-MS-2) at the initial incubation time $(T=0)$, after 2-month incubation and the negative control (without bacteria) after 2-month incubation. * show the same results with method GC-MS-2. 

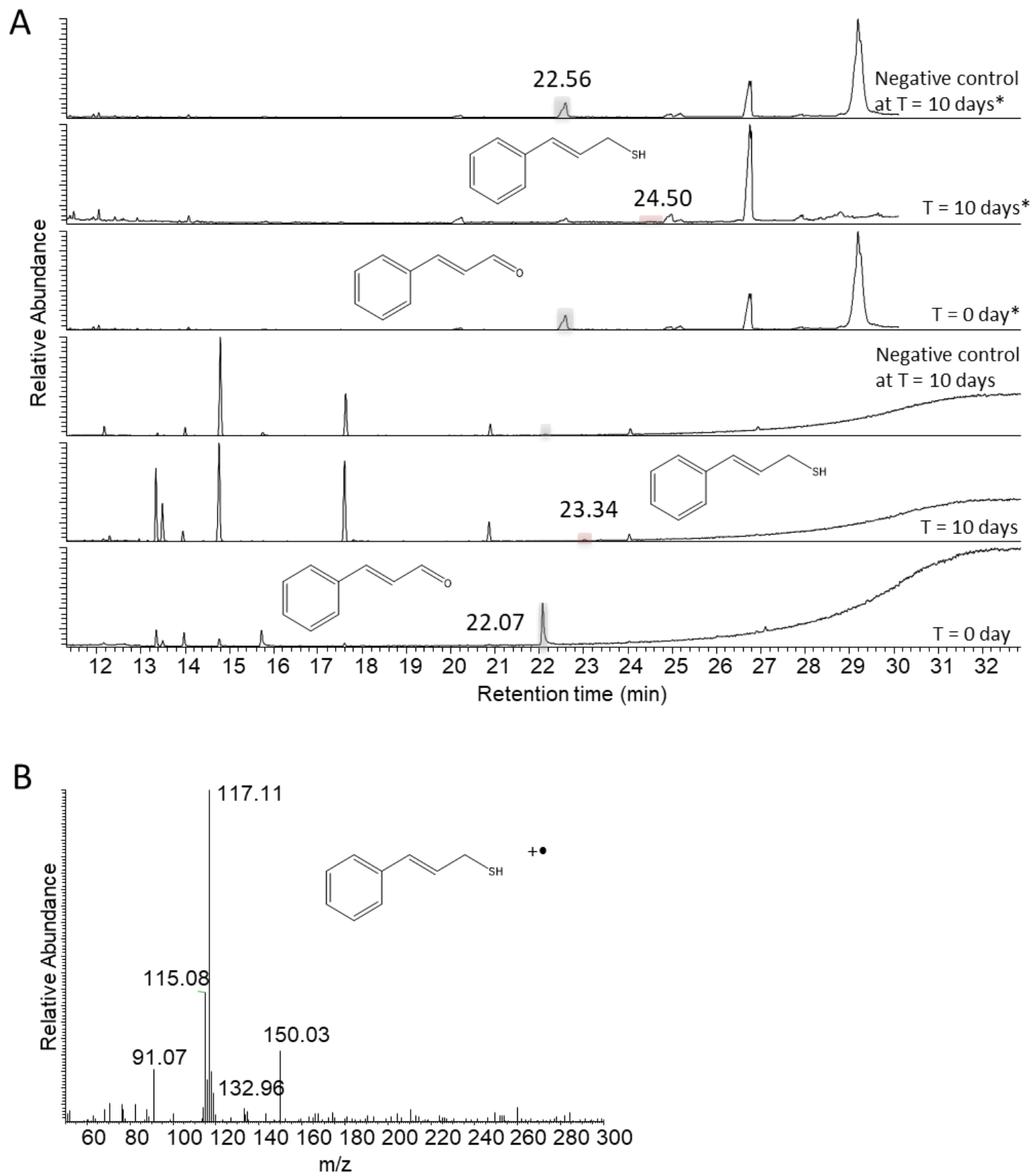

Figure S52. Bacterial reductive sulfidation of cinnamaldehyde. A-HS-GC-MS chromatograms (obtained with method HS-GC-MS-2) at the initial incubation time $(T=0)$, after 10-day incubation and the negative control (without bacteria) after 10-day incubation. * show the same results with method GC-MS-2. B-Mass spectrum of 3-phenylprop-2-en-1-thiol. Each mass spectrum came from GC-EI-MS analysis (positive mode). 


\section{Supplementary references}

1. Gilson Al, van der Rest G, Chamot-Rooke J, et al. Ground Electronic State of Peptide Cation Radicals: A Delocalized Unpaired Electron? J Phys Chem Lett. 2011;2(12):1426-1431. doi:10.1021/jz2004792

2. Riffet V, Jacquemin D, Cauët E, Frison G. Benchmarking DFT and TD-DFT Functionals for the Ground and Excited States of Hydrogen-Rich Peptide Radicals. J Chem Theory Comput. 2014;10(8):33083318. doi:10.1021/ct5004912

3. Katari M, Carmichael D, Jacquemin D, Frison G. Structure of Electronically Reduced N-Donor Bidentate Ligands and Their Heteroleptic Four-Coordinate Zinc Complexes: A Survey of Density Functional Theory Results. Inorg Chem. 2019;58(11):7169-7179. doi:10.1021/acs.inorgchem.8b03549

4. Stoliaroff A, Latouche C. Accurate Ab Initio Calculations on Various PV-Based Materials: Which Functional to Be Used? J Phys Chem C. 2020;124(16):8467-8478. doi:10.1021/acs.jpcc.9b10821

5. Savarese M, Brémond É, Ciofini I, Adamo C. Electron Spin Densities and Density Functional Approximations: Open-Shell Polycyclic Aromatic Hydrocarbons as Case Study. J Chem Theory Comput. 2020;16(6):3567-3577. doi:10.1021/acs.jctc.0c00059

6. Schoenauer S, Schieberle P. Structure-Odor Activity Studies on Monoterpenoid Mercaptans Synthesized by Changing the Structural Motifs of the Key Food Odorant 1-p-Menthene-8-thiol. J Agric Food Chem. 2016;64(19):3849-3861. doi:10.1021/acs.jafc.6b01645

7. Fabbri D, Delogu G, De Lucchi O. Thiophosphonates of 1,1-binaphthol as chiral equivalents of H2S. Preparation of 2-mercaptonorbornanes and 2-mercaptonorbornenes. Tetrahedron Asymmetry. 1993;4(7):1591-1596. doi:10.1016/S0957-4166(00)80364-X

8. Dia R-M, Belaqziz R, Romane A, Antoniotti S, Duñach E. Flavouring and odorant thiols from renewable natural resources by Inlll-catalysed hydrothioacetylation and lipase-catalysed solvolysis. Tetrahedron Lett. 2010;51(16):2164-2167. doi:10.1016/j.tetlet.2010.02.081 